\title{
B: ABTEILUNG FÜR DICHTUNG
}

\section{r. VORBEREITUNG DER SITZUNG ÜBER „LEBENSWICHTIGE FRAGEN DER ABTEILUNG“, FEBR./MÄRZ 1933}

23 Preußische Akademie der Künste, Berlin W 8, Pariser Platz 4, den 7. März 1933 Abteilung für Dichtung

Sehr verehrter Herr Präsident, gestern und heute haben Herr Professor Amersdorffer und ich versucht, uns telefonisch mit Ihnen zu besprechen, doch war die Unterredung ja Ihrer Erkrankung und Reise wegen leider nicht möglich. Darf ich Ihnen zunächst eine recht baldige und völlige Wiederherstellung wünschen.

Auch uns ist ganz außerordentlich an einer möglichst restlosen Klärung der Verhältnisse in der Abteilung für Dichtung gelegen. Dazu scheint uns eine möglichst sichere Vorbereitung einer Sitzung, an der die auswärtigen Mitglieder teilnehmen, erforderlich. Ich habe an die stellvertretende Vorsitzende, Frau Dr. Ricarda Huch (eine sehr besonnene, selbständige Persönlichkeit in nationalem Sinne), geschrieben, da $\beta$ in dieser schweren Zeit ihre Anwesenheit in Berlin erforderlich wäre. Frau Huch hat bei ihrer Übersiedlung nach Heidelberg im vorigen Jahr in Aussicht gestellt, daß sie in diesem Frühjahr möglicherweise nach Berlin zurückkehren werde. Kann sie in der Tat jetzt wieder nach Berlin kommen, so wäre die Frage des stellvertretenden Vorsitzes geregelt. Ist ihr die Rückkehr nicht möglich, so nehme ich mit Sicherheit an, daß sie auf das Amt, das sie infolge ihrer Abwesenheit nicht ausfüllen kann, verzichten wird, und die Ersatzwahl könnte dann gleichzeitig mit der Wahl des Vorsitzenden vorgenommen werden.

Was die Gewährung der Reisekosten an die auswärtigen Mitglieder betrifft, so befürchten wir nach der Erfahrung in einer ganzen Reihe von Jahren, daß gerade ein großer Teil der Mitglieder erscheinen wird, deren Anwesenheit uns bei der Entscheidung lebenswichtiger Fragen eher hemmend als förderlich sein würde, während wir nach der gleichen Erfahrung glauben müssen, daß für die Mitglieder, auf die es uns in diesem Fall ganz besonders ankommen muß, der Ersatz der Reiseauslagen für ihren Reiseentschluß nicht ausschlaggebend ist.

Ich habe die Angelegenheit auch mit dem Referenten der Akademie im Ministerium, Herrn Oberregierungsrat Dr. Zierold, besprochen, der dringend bat, nichts zu übereilen. Er hält es unter den gegebenen Umständen nicht für unwahrscheinlich, daß die Kosten bewilligt würden, indessen sei es ihm bei der in diesen Tagen drängenden Fülle von Geschäften, die der Kommissar des Reichs zu erledigen habe, nicht möglich, sofort die Entscheidung über diese Kosten herbeizuführen. Anfang nächster Woche hält er dem Kommissar Vortrag; er versichert, daß er mir dann sehr viel mehr wird sagen können als heute.

In ausgezeichneter Hochachtung

Ihr sehr ergebener Loe[rke]

24 Rudolf G. Binding, Buchschlag (Hessen), 23. 2. 33

Sehr geehrter Herr Präsident, es fällt mir - wie eine Art einfachen Anstands ein daß ich mich Ihnen zu irgend einem Schritte den Sie unternehmen würden persönlich zur Verfügung stellen sollte. Ich tue das hiermit.

Vielleicht ist es angebracht daß die Abteilung für Dichtkunst auch - wenn auch nur 
zunächst mit einer Stimme - gehört oder vernommen wird, wo es um ihre Sache geht. Einen Vorsitzenden hat sie zurzeit nicht. Aber vielleicht wäre es nicht unnütz, wenn einer - ich oder ein andrer - als „von dem Präsidenten der Akademie darum gebetenes Mitglied" dieser Abteilung ihn begleiten würde.

Denn offenbar besteht eine ziemliche Unkenntnis über Charakter und Haltung der Abteilung, da man diese lediglich von den politisch oder zeitungsmäßig hervortretenden Mitgliedern abnimmt. Sie haben sich aber, besonders auch durch die brieflichen Stimmen, selbst überzeugen können daß es - wie in der Gesamtakademie - auch bei uns Akademiker gibt; d.h. solche die wissen was es heißt der preuß. Akademie der Künste anzugehören.

Ihr sehr ergebener Rudolf G. Binding, Dr. h.c.

Der Präsident der Akademie der Künste zu Berlin, Berlin W 8, Pariser Platz 4, 25 den 28. 2. 33

Lieber und geehrtester Herr Dr. Bincling, mit einiger Verspätung, die ich einem z.Z. besonders stark mit Arbeiten $u$. Pflichten Belasteten zu verzeihen bitte, danke ich Ihnen vielmals für Ihre Zeilen vom 23. 2.

Sie stellen sich mir, und damit der Akademie persönlich zur Verfügung „zu irgendeinem Schritte" und sprechen besonders über die Frage des Vorsitzes der Abteilung für Dichtkunst. Ich habe in Hinsicht auf diese letztere doch Bedenken, ein Provisorium zu schaffen und halte es für richtiger, baldigst die Abteilung zur Anberaumung einer Sitzung aufzufordern mit der Tagesordnung: "Wahl eines Vorsitzenden “. Nach der Satzung wählen allerdings nur die Senatsmitglieder den Vorsitzenden (sowie einen stellvertretenden). Immerhin hielte ich es für wichtig, vor dieser Wahlhandlung auch das "Plenum" zusammenzurufen. Ich darf hoffen, daß Sie zu dieser Sitzung erscheinen werden! - Wenn Sie Ihren Wohnsitz in Berlin hätten, wüßte ich, wer nach meinem Wunsch Vorsitzender werden müßte! Wie denken Sie aber über Dr. Benn?

Heute gehen Briefe von mir an die Herren Dr. Döblin u. Frank ab über deren Ergebnis ich Sie unterrichten möchte. -

Ihr sehr ergebener Max v. Schillings

PS. Der Brief an Herrn Frank unterbleibt zunächst noch.

[Dr. Rudolf G. Binding] Breslau, 11. 3. 33.

An die Preußische Akademie der Künste, Abt. für Dichtung, Berlin

Sehr geehrte Herren, es ist mir sehr schmerzlich daß ich - durch schon übernommene Verpflichtungen abgehalten - zu der Sitzung am 13. März nicht erscheinen kann. ${ }^{1}$

Es ist schwer von fernher zu den Dingen und Hintergründen etwas zu sagen die heute vieles ins Schwanken und ins Ungewisse bringen - aus keinem andern Grunde als weil sie selbst den festen Grund und Boden suchen. Diesen Elementen und Umständen gegenüber sollte die Akademie - jede Abteilung für sich oder als ganze Körperschaft - darauf verweisen daß sie als staatliche Einrichtung in jeder Zeit und in jeder Zusammensetzung der Gemeinsamkeit dient der auch der Staat dient:

\footnotetext{
1 Binding kam doch.
} 
nämlich der Nation. Sie darf kühnlich behaupten daß sie nie etwas anderem gedient hat und wird ohne Übertreibung und Überhebung hoffen dürfen da $\beta$ sie auch der künftigen Nation dienen werde. Ich halte es für völlig widersinnig, sie vom Leben dex Nation zu trennen, wie immer diese aussehen mag.

Es scheint wichtig und unerläßlich daß die Akademie dies öffentlich ausspreche und der jeweiligen Regierung - als dem Wahrer und Förderer nationalen Lebens - dieses erkläre. Es erscheint mir als abwegig und unlebendig, die Akademie als eine lediglich überpolitische oder apolitische Körperschaft in Anspruch nehmen zu wollen, die am Leben der Kunst aber nicht an dem Leben des Staates teilhaben wolle.

Die Kunst und zumal die Dichtung kann nichts anderes sein als der höchste Ausdruck der Nation. Der Staat aber wird sich einer Körperschaft nicht entäußern, die solchem Ausdruck dient.

Ich erhebe es zum Antrag in der Sitzung - oder bitte einen Kollegen es zum Antrag zu erheben - diese Sätze sowohl öffentlich wie der Regierung gegenüber zu einer Erklärung der Akademie (oder der Abteilung) zu machen.

Ich werde es ermöglichen, am 15. März früh in Berlin zur Verfügung zu sein.

In kollegialer Hochachtung und Gesinnung

Rudolf G. Binding Dr. h.c.

In Berlin: Hotel Adlon

\section{GEFORDERTE LOYALITÄTSERKLÄRUNG, 13./14. 3. 1933}

27 Verhandelt in der Preußischen Akademie der Künste, Sitzung des Senats und der Abteilung für Dichtung, Berlin, den 13. 3. 1933. Beginn der Sitzung: 6 Uhr [abends]

Anwesend unter dem Vorsitz des Herrn Binding: v. Schillings, Amersdorffer, Loerke, Benn, Binding, Stucken, Fulda, v. Molo, Haslinde

Binding wird durch Zuruf zum Verhandlungsleiter gewählt. Er übernimmt den Vorsitz. Die Mitglieder haben erfahren, daß der künstlerische Leiter des Staatstheaters, Herr Hanns Johst, zum Amtssenator der Abteilung ernannt worden ist. Es ist telefonisch bei Herrn Johst erkundet worden, ob er zur heutigen Sitzung erscheinen könnte. Herr Johst antwortete, daß er infolge einer Reise erst von Dienstag ab zur Verfügung stehen könnte. Es wird Erstaunen darüber geäußert, daß von den auswärtigen Mitgliedern bei einer so wichtigen Sitzung nur eins erschienen ist.

Aufgrund von Unterredungen mit dem Präsidenten nimmt Benn das Wort zur Erläuterung der Lage. Er befürwortet, daß wir die Regelung der Verhältnisse in der Abteilung selbst in die Hand nehmen, um Auflösung oder Zwangsmaßnahmen zu vermeiden. Wir seien alle mit der Vorkriegszeit auch verbunden; ebenso seien wir der Gegenwart verpflichtet, um die Zukunft der Nation mitzugestalten. Er schlägt vor, eine Erklärung zu formulieren, die allen Mitgliedern zur Unterzeichnung zugehen und ebenso sowohl der Reorganisation der Abteilung wie einer eindeutigen zuverlässigen Arbeit der Abteilung dienen könnte. Er hat folgenden Wortlaut zur Diskussion gestellt:

„Sind Sie bereit, unter Anerkennung der veränderten geschichtlichen Lage weiter Ihre Person der Preußischen Akademie der Künste zur Verfügung zu stellen? Eine Bejahung dieser Frage schließt die öffentliche politische Betätigung gegen die Regierung aus und verpflichtet Sie zu einer loyalen Mitarbeit an den satzungsgemä $\beta$ der Akademie zufallenden Aufgaben der Nation."

Die Abteilung erkennt durch Eintritt in die Diskussion über die Formulierung der Erklärung an, daß sie eine solche für notwendig hält.

Binding wünscht die Vorfrage geklärt, ob der Beginn der dieser Sitzung zugrunde liegenden Unterhaltung der Initiative des Präsidenten oder der der Abteilung ent- 
stamme. Benn antwortet: Gedanke und Formung des Entwurfs seien von ihm selbst. Loerke ergänzt diese Auskunft durch die Mitteilung, der Präsident wünsche nur, daß gehandelt werde.

Bindings Meinung geht dahin, daß die Anwesenden durch ihr Erscheinen dartun wollen, daß sie eine zwangsweise oder Selbstauflösung der Abteilung verhindern wollen. Benn erklärt, es sei Sache des Präsidenten, bei der zuständigen Stelle zu erkunden, ob die vorgeschlagene Erklärung ihren Zwweck erfüllen würde. Haslinde begrüßt es, daß der heute erörterte Vorschlag von der Abteilung selbst gemacht werde. Er dürfe mitteilen, daß der Kommissar des Reichs Hochachtung vor der Selbstverwaltung der Akademie habe und scharfe Maßnahmen zur Umbildung der Abteilung vermeiden möchte.

Binding schlägt vor, bei der weiteren Aussprache zunächst nicht die Redaktion der Erklärung, sondern die sachlichen Gesichtspunkte zu erörtern. Jedes anwesende ordentliche Mitglied wird durch den Vorsitzenden einzeln befragt, ob es mit dem Erklärungsentwurf einverstanden sei. Sämtliche Mitglieder bejahen die Frage einzeln. Darauf wird einstimmig beschlossen, den Entwurf dem Präsidenten zuzuleiten mit der Bitte um Weiterreichung.

Der Präsident erscheint nach einiger Zeit und wünscht folgende Abänderung des zweiten Satzes: „Eine Bejahung dieser Frage schließt die öffentliche politische Betätigung gegen die Regierung aus und verpflichtet Sie zu einer loyalen Mitarbeit an den satzungsgemäß der Akademie zufallenden nationalen kulturellen Aufgaben im Sinne der veränderten geschichtlichen Lage."

Die Aussprache über die vorgeschlagenen Änderungen des Präsidenten endet sehr bald damit, daß sich wiederum jedes einzelne Mitglied mit der hier ersichtlichen Fassung einverstanden erklärte. Der Präsident betont, daß die heutige Verhandlung selbstverständlich streng vertraulich zu behandeln sei. Die Zustimmung zu der Erklärung oder ihre Ablehnung müsse mit kurzer Befristung erfolgen.

Binding erklärt, daß die logische Folge unserer Einstimmung zu der Erklärung sei, eine Zuwahl neuer Mitglieder durch die Abteilung vorzunehmen, um dieser die genügende Basis für ihre Wirksamkeit zu schaffen. Dies wurde anerkannt und daraufhin der Präsident gebeten, vertrauliche Mitteilung darüber zu machen, wrelche Persönlichkeiten seiner Kenntnis nach bei der Regierung für die Abteilung genannt würden. Der Präsident nannte Namen. Es ergibt sich, daß diejenigen Namen, welche von der Abteilung aus genannt werden, bis auf wenige mit denen übereinstimmen, die augenblicklich bei der Regierung genannt wurden. Der Präsident wird gebeten, die Vorschlagsliste der Abteilung in Verbindung mit der geplanten Erklärung bei der Regierung zur Besprechung zu bringen, und wird zugleich ermächtigt zu erklären, daß die Abteilung die auf dieser Liste stehenden Persönlichkeiten zur Wahl zu stellen bereit sei. Benn wird von den Mitgliedern gebeten, bis zur Wahl eines neuen Vorsitzenden die Sitzungen der Abteilung zu leiten. Benn ist dazu bereit.

Schluß der Sitzung: 93/4 Uhr

Rudolf G. Binding

Oskar Loerke

Preußische Alrademie der Künste, Berlin W 8, Pariser Platz 4, den 14. März 1933 - 28 Abteilung für Dichtung - Vertraulich!

Sehr geehrter Herr Kollege,

die Sitzung vom 13. d.Mts, unter Teilnahme des unterzeichneten Präsidenten (Tagesordnung "Stellungnahme zu lebenswichtigen Fragen der Abteilung"), zu der Sie eingeladen waren, hat zu folgendem Ergebnis geführt:

In Anbetracht der Lage müssen von der Abteilung sofortige Entschlüsse gefaßt wer- 
den. Die Abteilung unternimmt den Versuch, sich aus sich selbst heraus neu zu organisieren; sie sieht sich gezwungen, allen Mitgliedern die anliegende Frage vorzulegen und bittet um sofortige Beantwortung ausschließlich mit ja oder nein und Ihre Unterschrift. Die Antwort muß spätestens am 21. März bei der Akademie eingetroffen sein.

Mit kollegialem Gruß

Max von Schillings

\section{[Als Anlage:] Vertraulich!}

Sind Sie bereit, unter Anerkennung der veränderten geschichtlichen Lage weiter Ihre Person der Preußischen Akademie der Künste zur Verfügung zu stellen? Eine Bejahung dieser Frage schließt die öffentliche politische Betätigung gegen die Regierung aus und verpflichtet Sie zu einer loyalen Mitarbeit an den satzungsgemä $\beta$ der Akademie zufallenden nationalen kulturellen Aufgaben im Sinne der veränderten geschichtlichen Lage.

$\mathrm{Ja}$

Nein

(Nicht Zutreffendes bitte zu durchstreichen).

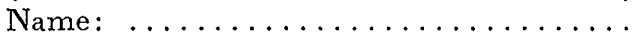

Ort und Datum: ..............

\section{AUSTRITTE (PAQUET, TH. MANN, DÖBLIN, HUCH)}

29 [Dr. Alfons Paquet] Frankfurt am Main, Wolfgangstr. 122, 15. III. 1933

Hochverehrter Herr Präsident,

ich erhielt den mir unter dem 14. III. ds. Js. zur Unterschrift vorgelegten Text einer Willenserklärung. Ich muß es ablehnen, diese Erklärung zu beantworten. Ein Ja könnte für mich zu unabsehbaren Folgerungen führen, ebenso wie ein Nein mich unter Umständen in einen Gegensatz zu der Haltung in nationalen kulturellen Dingen stellen würde, die ich in meinen Büchern und Schriften immer vertreten habe und die für jedermann offenliegen.

Um Ihnen eine genaue Kennzeichnung meines Standpunktes nicht schuldig zu bleiben, erlaube ich mir, Ihnen den beifolgenden Antrag an die Sektion für Dichtkunst vorzulegen. Einige Mitglieder, denen ich diesen Antrag zur Kenntnis bringen konnte, haben mir ihre Zustimmung ausgesprochen. Ich brauche nicht hinzuzufügen, daß ich es vor allem begrüßen würde, wenn die Akademie aus Gründen der Selbständigkeit ihrer Haltung sich entschließen könnte, den Antrag zum Beschluß zu erheben. $\mathrm{Da}$ ich es vermeiden möchte, ein anderes Mitglied der Sektion um die Vertretung meines Antrages zu bitten, so muß ich es Ihnen, Herr Präsident, anheimstellen, diesen Antrag zur Kenntnis der Sektion zu bringen.

Sollte ich bis zum 18. ds. Mts. ohne Ihre Antwort bleiben, so bitte ich Sie, von meiner Austrittserklärung Kenntnis nehmen zu wollen.

Verehrungsvoll und ergebenst

Alfons Paquet

[Als Anlage:] Antrag

Die Abteilung für Dichtung in der Preußischen Akademie wolle beschließen, die Reichsregierung auf den Zustand der Erregung und der Unsicherheit hinzuweisen,

1 Zu den Unterschriften vgl. die Anmerkung zu Dok. Nr. 49. 
der im deutschen Volke durch die Entfesselung triebhafter Strömungen entstanden ist. Unerfüllbare Versprechen nach der einen, unverdiente Beleidigungen nach der anderen Seite sind die Ursachen dieses Zustandes. Die in der Abteilung vereinigten deutschen Dichter und Schriftsteller halten es für ihre Pflicht, darauf hinzuweisen, daß ein von der Regierung gefördertes Übergewicht gewaltmäßig betonter Handlungen, die jede Besonnenheit im Volke unmöglich machen, die Gefahr von Rückschlägen in sich trägt, die noch schlimmere Leiden mit sich führen werden als sie bereits durch die Aufhebung verfassungsmäßiger Grundrechte über das Volk verhängt sind.

12. III. 33, Alfons Paquet

Der Präsident der Akademie der Künste, Berlin W 8, Pariser Platz 4, 22. März 1933

Herrn Dr. Alfons Paquet, Frankfurt a./Main, Wolfgangstr. 122

Sehr geehrter Herr Doktor,

auf Ihr Schreiben vom 15. d.Mts. erwidere ich Thnen, daß es nicht möglich war, in Anbetracht der Zeitumstände Ihren in so ultimativer Form eingereichten Antrag der Abteilung vorzulegen. Der Ihnen vorgelegte Entschluß der Abteilung war ein definitiver und keiner Revision mehr zugänglich. Es bleibt mir daher nichts übrig, als Ihren Austritt der Abteilung zur Kenntnis zu bringen. ${ }^{1}$

In vorzüglicher Hochachtung

ergebenst Max von Schillings

[Dr. Thomas Mann] Lenzerheide, 17. 3.33

Sehr verehrter Herr Präsident:

Den mir vorgelegten Revers kann ich in der gewünschten Form nicht beantworten. Ich habe nicht im Geringsten die Absicht, gegen die Regierung zu wirken und der deutschen Kultur glaube ich immer gedient zu haben, werde auch in Zukunft versuchen, es zu tun. Es ist aber mein Entschluß, von meinem Leben alles Amtliche abzustreifen, das sich im Lauf der Jahre daran gehängt hat, und fortan in vollkommener Zurückgezogenheit meinen persönlichen Aufgaben zu leben. Darum bitte ich Sie, sehr verehrter Herr Präsident, von meinem Austritt aus der Sektion für Dichtung der Preußischen Akademie der Künste Kenntnis zu nehmen.

Mit hochachtungsvoller Begrüßung

Ihr sehr ergebener Thomas Mann.

Der Präsident der Akademie der Künste, Berlin W 8, Pariser Platz 4, 22. März 1933

Sehr verehrter Herr Professor [Thomas Mann], ich bestätige Ihnen den Eingang Ihres eingeschriebenen Briefes vom 17. d.Mts. aus Lenzerheide. Ich muß aus ihm ersehen, daß Sie nicht gesinnt sind, weiter der Akademie anzugehören. Eine Stellungnahme zu Ihrem Entschluß steht mir bei der Entscheidenheit Threr Absage nicht zu. Ich möchte aber Ihren Abschied sich nicht voll-

\footnotetext{
1 Von Schillings erteilte diese Antwort auf mündliche Anweisung von Minister Rust; dies geht
} aus einem akademieinternen Verzeichnis der Austritte und Ausschlüsse (M1, Bd. 13) hervor. 
ziehen lassen, ohne Ihnen meinen Dank für Ihre Zugehörigkeit zur Akademie und Ihre Tätigkeit als Senator auszusprechen.

In vorzüglicher Hochachtung

Ihr ganz ergebener Max von Schillings

33 [Dr. Alfred Döblin] Zürich, Hochstraße 37, Pension, 17. III. 33

Sehr geehrter Herr Präsident,

ich erhalte erst heute gleichzeitig eine Einladung zu einer Sitzung und den Brief mit dem Revers hierher. Mit Recht kann von den einer staatlichen Instanz angegliederten Akademiemitgliedern eine politische Loyalitätserklärung verlangt werden, und ich kann sie ohne Weiteres abgeben, - da ich kein Politiker bin, nicht im mindesten im politischen öffentlichen Leben stehe, mein episches und philosophisches Werk liegt offen zutage und zeigt meine Weltanschauung und meine Kunstart. Ich stelle dem Herrn Kurator der Akademie anheim dies zu überprüfen. Entscheidend aber könnte unter Umständen ein anderer Punkt sein, auf den ich mir gestatte, Sie, Herr Präsident, aufmerksam zu machen. Die geschichtliche Umwälzung, von der der Revers spricht, schließt, wie Ihnen bekannt ist, ein starkes völkisches Element in sich ein. Ich bin von jüdischer Abstammung, und bisher bewirkte dieser Punkt für die Akademie keinen Unterschied im modus provocendi, weder für die Aufnahme noch für die Arbeit, die rein künstlerischer Art war. Sollte nun das erwähnte völkische Element jetzt nach der Umwälzung eine wesentliche Rolle spielen, so müßte ein Abweichen von der alten Praxis eintreten, und das müßte sich notgedrungen auf Zuwahlen wie auf das Verbleiben in der Akademie auswirken. Da ich hierüber im Unklaren bin, so bitte ich Sie, Herr Präsident, ergebenst, die Auffassung des Herrn Kurators ermitteln zu wollen und mich (und natürlich auch die Kollegen Fulda, Wassermann, Werfel, Kaiser, Mombert) gütigst zu informieren. Es versteht sich von selbst, daß wir uns der Auffassung des Herrn Kurators anschließen werden.

Ich sehe, sehr geehrter Herr Präsident, Ihrer gefl. Benachrichtigung entgegen; ich zeichne ergebenst

Dr. Alfred Döblin

P.S. Im Übrigen halte ich für rascher klärend folgenden Weg und trage meine Auffassung in Form eines Antrags für die Abt. vor:

„Die Abt. sieht die Notwendigkeit ein, den neuen staatlichen Gewalten bei der Einrichtung der Verhältnisse freie Hand zu lassen. Die Abt. bietet daher ihre Gesamtdemission an. "Darauf kann der Kurator nach Belieben nun bestätigen und Zuwahlen anordnen, oder eine Gründerkommission wie[?] im Beginn ernennen.

D.

34 [Dr. Alfred Döblin] Zürich, Hochstraße 37, Pension, 18. III. 33

Sehr geehrter Herr Präsident, ich überdenke eben noch einmal den heute an Sie expreß gesendeten Brief. Ich bejahe die geforderte Loyalitätserklärung, wie ich schon schrieb, sehe aber ein, daß ich als Mann jüdischer Abstammung unter den heutigen Verhältnissen eine zu schwere Belastung für die Akademie wäre. Ich stelle daher meinen Sitz in der Akademie zur Verfügung, - eine Sache, die mir außerordentlich schwer wird, denn die Kollegen wissen, wie sehr mich die Entwicklung unserer Abteilung interessiert hat.

In Ergebenheit Dr. Alfred Döblin 
Der Präsident der Akademie der Künste, Berlin W8, Pariser Platz 4, 22. März 1933

Herrn Dr. Alfred Döblin, Zürich, Hochstr. 37, Pension

Sehr geehrter Herr Doktor, auf Thre beiden Briefe vom 17. und 18. d.Mts. erwidere ich Ihnen, daß ich Thren Austritt aus der Abteilung für Dichtung hiermit zur Kenntnis nehme. Ihren im ersten Brief gestellten Antrag, eine neue Resolution in der von Ihnen vorgeschlagenen Form der Abteilung vorzulegen, ist in Anbetracht der Lage nicht möglich gewesen.

In vorzüglicher Hochachtung ergebenst Max von Schillings

[Dr. Ricarda Huch] Heidelberg, Friesenberg 1, 16. III. 1933

Sehr geehrter IIerr Präsident,

In Erwiderung Ihrer Zuschrift vom 14. März bestreite ich Ihre Kompetenz, mir eine Frage von so unübersehbaren Konsequenzen vorzulegen, und lehne infolgedessen ab sie zu beantworten. Die Mitglieder der Akademie werden nach Wortlaut der Satzung zur Ehrung und Anerkennung ihrer Leistungen berufen, ohne daß ein politisches Bekenntnis von ihnen gefordert würde. Ich bin, seit ich der Akademie angehöre, stets mit Nachdruck dafür eingetreten, daß bei Beurteilung oder Wahl von Mitgliedern nichts anderes maßgebend sei als ihre künstlerische Leistung und die Bedeutung ihrer Persönlichkeit. Daran werde ich auch künftig festhalten.

Mit ausgezeichneter Hochachtung

Ricarda Huch

Der Präsident der Akademie der Künste, Berlin W 8, Pariser Platz 4, 22. März 1933

Sehr verehrte gnädige Frau,

Sie haben darin vollkommen recht, daß nach dem Wortlaut der bisher gültigen Satzung der Akademie meine an die Mitglieder gestellte Frage nicht zu meinen unmittelbaren Kompetenzen gehört. Aber wir befinden uns ja in einem Zustand der allgemeinen politischen und geschichtlichen Umwälzung, in der man auf Satzungen und Statuten nicht mehr allein sich beziehen kann, wenn man zu lebensnotwendigen Beschlüssen gelangen will. In Einvernehmen mit der Abteilung für Dichtung ist der Beschluß gefaßt worden, außerhalb der Satzung allen Mitgliedern diese Frage zur Beantwortung vorzulegen.

Ich erlaube mir jedoch aus Ihrem Brief zu entnehmen, daß Sie zwar eine Beantwortung dieser Frage nicht zu geben wünschen, daß Sie aber andererseits auch nichts dagegen einzuwenden haben werden, wenn wir ein Mitglied von Ihrer hohen geistigen Bedeutung, Ihrem tiefen konservativen Lebensgefühl und Ihrer großen ins Volk reichenden schöpferischen Wirkung als Künstler weiter zu den Unseren zählen zu dürfen [sic!].

Mit dem Ausdruck ganz besonderer vorzüglicher Verehrung

Ihr sehr ergebener Max von Schillings

[Dr. Ricarda Huch] Heidelberg, Friesenberg 1, 24. März 1933

Sehr geehrter Herr Präsident!

Aus Ihrem Schreiben vom 22. März schließe ich, daß Sie meine Ablehnung, die mir vorgelegte Frage zu unterzeichnen, so aufzufassen gedenken, als hätte ich sie mit 
Ja beantwortet; dies Ja kann ich aber um so weniger aussprechen, als ich verschiedene der inzwischen von der neuen Regierung vorgenommenen Handlungen auf das schärfste mißbillige.

Sie zweifeln nicht, davon überzeugt mich Ihr Brief, daß ich an dem nationalen Aufschwung von Herzen teilnehme; aber auf das Recht der freien Meinungsäußerung will ich nicht verzichten, und das täte ich durch eine Erklärung, wie die ist, die zu unterzeichnen ich aufgefordert wurde. Ich nehme an, daß ich durch diese Feststellung automatisch aus der Akademie ausgeschieden bin.

Außerdem müßte ich darauf gefaßt sein (Erlauben Sie, daß ich den ernsten Gegenstand durch einen Scherz würze), wenn ich in dieser Form in der Akademie bliebe, mein Leben im Zuchthause zu beschließen als „in einen nationalen Verband eingeschlichen".

Ich bin, sehr geehrter Herr Präsident, mit dem Ausdruck ausgezeichneter Hochachtung Ihre ergebene Ricarda Huch

[Aktenvermerk:] A. [für Amersdorffer] Sehr bedauerlich! Ob sich noch eine Einwirkung zur „Vernunft" erreichen ließe? S[chillings].

39 Preußische Akademie der Künste, Berlin W 8, Pariser Platz 4, den 6. April 1933

Hochverehrte gnädige Frau,

die Fülle der Arbeiten der letzten Zeit und die Abhaltungen durch die Hundertjahrfeier der Musikabteilung der Akademie lassen mich erst heute dazu kommen, Ihren geschätzten Brief vom 24. v.Mts. zu erwidern.

Sie betonen mit Recht, daß ich nicht daran zweifle, daß Sie an dem nationalen Aufschwung von Herzen teilnehmen. Sie legen aber unserer, den Mitgliedern zur Stellungnahme vorgelegten Erklärung einen nicht zutreffenden Sinn unter, wenn Sie annehmen, daß sich aus einer bejahenden Stellungnahme zu ihr ein Verzicht auf das Recht der freien Meinungsäußerung ergeben würde. Dies ist selbstverständlich keineswegs der Fall. Der Inhalt der Erklärung besagt doch nur, daß die Mitglieder, die ihr beitreten, gesonnen sind, im Sinne des nationalen Aufschwungs weiter an den Aufgaben der Akademie mitzuwirken und sich nicht öffentlich in einen Gegensatz zu der Regierung, die die Trägerin dieser nationalen Bewegung ist, zu setzen.

Zur Vorlage dieser Erklärung gab uns das Verhalten des Herrn Heinrich Mann Anlaß, der in einem öffentlich plakatierten Aufruf die Sozialdemokratische und Kommunistische Partei zu einem Zusammenschluß und gemeinsamen Vorgehen gegen die nationalen Parteien bei der letzten Wahl aufforderte. Herr Heinrich Mann hat ja, wie Ihnen bekannt, aus seinem Verhalten die einzig mögliche Konsequenz gezogen und ist aus der Akademie ausgetreten. Daß Sie durch Ihre mir dargelegte Auffassung „automatisch aus der Akademie ausgeschieden“ seien, - dem vermag ich in Übereinstimmung mit meinen Herren Kollegen von der Dichterabteilung nicht beizustimmen. Ihr Austritt aus der Abteilung würde eine seltsame, unlogische Parallele zum Fall Heinrich Mann ergeben, die ganz sicher nicht in Ihrem Sinn liegen würde. Daß Sie in Thren Anschauungen mit diesem Herrn und mit Herrn Dr. Döblin (der inzwischen ebenfalls aus der Akademie ausgetreten ist) im entschiedensten Gegensatz stehen, das ist, wie mir von Herren der Dichterabteilung versichert wird, früher in Sitzungen, deren Beratungen auf politische und weltanschauliche Gebiete führten, deutlich genug hervorgetreten. Es würde daher in der Öffentlichkeit nur mißverstanden werden, wenn auch Sie, ebenso wie Heinrich Mann und Dr. Döblin, aus der Akademie ausscheiden wollte. Daß ein solcher Schritt von Ihrer Seite undenkbar ist, das ist uns allen klar, denen Ihre deutsche Gesinnung und nationale Einstellung aus 
Ihrer von uns verehrten Persönlichkeit und aus Ihrem künstlerischen Schaffen bekannt ist. Wir können Ihnen nur versichern, daß es zia dieser Überzeugung für uns der formalen Unterzeichnung der Erklärung nicht bedarf. Wir erhoffen aber von Ihnen ein bestimmtes Wort darüber, daß Sie uns treu bleiben werden, denn wie sollten wir die Möglichkeit gewinnen, die Abteilung für Dichtung im Sinne deutscher, nationaler Kunst zu stärken und auszubauen, wenn wir auf die Zugehörigkeit und Mitarbeit von Persönlichkeiten verzichten müßten, die schon längst auf die Gesinnung eingestellt sind, der die jetzige große nationale Bewegung zum Siege verholfen hat? Das Recht der freien Meinung verbleibt jedem nach wie vor; die Abteilung wünschte durch die Versendung der Erklärung nur eine Sicherung gegen unangebrachte, mit der nationalen Bewegung unvereinbare öffentliche politische Betätigung und zugleich ein Bekenntnis der Bereitschaft zur Mitarbeit an den Aufgaben der Akademie im nationalen Sinne. Dies möchte ich nochmals besonders betonen.

Mit der Versicherung größter Verehrung

Ihr ganz ergebener Max von Schillings

Präsident

[Dr. Ricarda Huch] Heidelberg, Friesenberg 1, 9. April 1933

Sehr geehrter Herr Präsir!ent!

Lassen Sie mich zuerst Ihnen danken für das warme Interesse, das Sie an meinem Verbleiben in der Akademie nehmen. Es liegt mir daran, Ihnen verständlich zu machen, warum ich Ihrem Wunsche nicht entsprechen kann.

Daß ein Deutscher deutsch empfindet, möchte ich fast für selbstverständlich halten; aber was deutsch ist und wie Deutschtum sich betätigen soll, darüber gibt es verschiedene Meinungen. Was die jetzige Regierung als nationale Gesinnung vorschreibt, ist nicht mein Deutschtum. Die Zentralisierung, den Zwang, die brutalen Methoden, die Diffamicrung Andersdenkender, das prahlerische Selbstlob halte ich für undeutsch und unheilvoll. Bei einer so sehr von der staatlich vorgeschriebenen abweichenden Auffassung halte ich es für unmöglich, in einer staatlichen Akademie zu bleiben. Sie sagen, die mir von der Akademie rorgelegte Erklärung werde mich nicht an der freien Meinungsäußerung hindern. Abgesehen daron, daß „eine loyale Mitarbeit an den satzungsgemäß der Akademie zufallenden nationalen kulturellen Aufgaben im Sinne der veränderten geschichtlichen Lage" eine Übereinstimmung mit dem Programm der Regierung erfordert, die bei mir nicht vorhanden ist, würde ich keine Zeitung oder Zeitschrift finden, die eine oppositionelle Meinung druckte. Da bleibt das Recht der freien Meinungsäußerung in der Theorie stecken.

Sie erwähnen die Herren Heinrich Mann und Dr. Döblin. Es ist wahr, daß ich mit Herrn Heinrich Mann nicht übereinstimmte, mit Herrn Dr. Döblin tat ich es nicht immer, aber doch in manchen Dingen. Jedenfalls möchte ich wünschen, daß alle nichtjüdischen Deutschen so gewissenhaft suchten, das Richtige zu erkennen und zu tun, so offen, ehrlich und anständig wären, wie ich ihn immer gefunden habe. Meiner Ansicht nach konnte er angesichts der Judenhetze nicht anders handeln als er getan hat. Daß mein Verlassen der Akademie keine Sympathiekundgebung für die genannten Herren ist, trotz der besonderen Achtung und Sympathie, die ich für Herrn Dr. Döblin empfinde, wird jeder wissen, der mich persönlich oder aus meinen Büchern kennt. Hiermit erkläre ich meinen Austritt aus der Akademie.

Indem ich Ihnen, sehr geehrter Herr Präsident, nochmals für Ihre Teilnahme danke, bin ich

Ihre ergebene Ricarda Huch 
41 [Dr. Ricarda Huch] Heidelberg, Friesenberg 1, 9. V. 1933

Sehr geehrter Herr Loerke,

Ich lese in verschiedenen Zeitungen Notizen über die Veränderungen in der Akademie, wonach ich als darin verblieben bezeichnet werde. Da ich am 9. April dem Präsidenten förmlich meinen Austritt erklärt habe, ist mir das unbegreiflich. Jedenfalls möchte ich Sie bitten, dafür zu sorgen, daß der Irrtum berichtigt wird. An die Redaktion der Frankfurter Zeitung habe ich bereits in dem Sinne geschrieben.

Mit bestem Gruß

Ricarda Huch

42 Preußische Akademie der Künste, Berlin W 8, Pariser Platz 4, den 9. Mai 1933

Sehr geehrte gnädige Frau!

Auf Ihr gefälliges Schreiben vom 9. d.Mts. erwidere ich Ihnen ergebenst, daß die aus Anlaß der Umbildung der Abteilung für Dichtung erschienene Pressenotiz nicht von der Akademie, sondern vom Ministerium ausgegangen ist.

In vorzüglicher Hochachtung

Ihr sehr ergebener Max von Schillings

Präsident

AUSSCHLÜSSE (FRANK, FULDA, KAISER, KELLERMTANN, MOMBERT, SCHICKELE, V. UNRUH, WERFEL; PANNWITZ, WASSERMANN)

43 [Jakob Wassermann] Wiener Cottage-Sanatorium, Wien XVIII, Sternwartestraße 74, 18. 3. 1933

Verehrter Hexr Präsident,

Ihre Zuschrift vom 14. ds. läßt sich in meiner Situation ohne die Beantwortung einer Vorfrage nicht schlechthin mit Ja oder Nein beantworten.

Ich bin zu jeder loyalen Mitarbeit, zu jeder Aufbau-Arbeit an der Akademie grundsätzlich bereit, da mein ganzes Werk und Sein auf nichts anderes abzielt als auf Aufbau und Erneuerung. Doch müßte ich, bevor ich eine offizielle Erklärung abgebe, erst wissen, ob mich die der Akademie vorgesetzte Behörde als Juden überhaupt annehmen wird. Sonst habe ich ja zu gewärtigen, daß man mir nach Abgabe der Erklärung trotzdem den Stuhl vor die Türe setzen wird.

Ich bin Ihr ergebener Jakob Wassermann

44 Der Präsident der Akademie der Künste, Berlin W 8, Pariser Platz 4, 23. März 1933

Sehr geehrter Herr Wassermann,

in Ihrem Schreiben vom 18. d.Mts. nehmen Sie zu der an die Mitglieder der Abteilung für Dichtung gerichteten Anfrage Stellung und machen Ihren endgültigen Entschluß von der Klärung der Frage abhängig, inwieweit für Thre Annahme oder Ablehnung dieser Erklärung bei der vorgesetzten Behörde die Tatsache mitbestimmend ist, ob der Unterzeichner jüdischer Abstammung ist. Diese Frage kann in der jetzigen Situation noch nicht endgültig beantwortet werden; ich bitte Sie daher, einer weiteren Mitteilung darüber entgegensehen zu wollen.

In größter Hochachtung

Ihr sehr ergebener Max von Schillings 
Sehr geehrter Herr Wassermann,

im Anschluß an mein Schreiben vom 23, v. Mts. möchte ich auf die aus dem jüngst erlassenen Beamtengesetz ${ }^{1}$ erkennbare amtliche Stellungnahme zur Judenfrage hinweisen und bemerken, daß ich auf die in Threm Schreiben vom 18. v. Mts. gestellte Frage kaum eine Sie befriedigende Antwort erteilen kann. Ich darf auch nicht verschweigen, daß Ihr im Märzheft der "Neuen Rundschau" erschienener Artikel „Selbstschau am Ende des sechsten Jahrzehnts" durch seine scharfen Ausführungen über das Schicksal der Juden in Deutschland außerordentlich großes Aufsehen erregt hat. Namentlich der präzise und eindeutige Satz „Und der Herd der Umtriebe, das Zentrum der Infektion, ist nach wie vor Deutschland", der sich doch auf das ganze Deutschland, auch der früheren Zeit bezieht, wird in künstlerischen wie in politischen Kreisen als ungemein ungerecht empfunden. Auch die Mitglieder der Abteilung für Dichtung vermögen für Thre Auffassung kein Verständnis aufzubringen und sehen deshalb keine Möglichkeit, Sie weiter zu den Mitgliedern der Abteilung zu rechnen. In größter Hochachtung

Der Präsident

Max von Schillings

Einschreiben

Rudolf Pannwitz, Kolocep, Kod Dubrovnika, Dalmacija (Jugoslawien), 18. 3. 33

Sehr geehrter Herr Kollege,

Heute erst erhielt ich den Brief vom 14., der meine kann nicht vor dem 22. in Berlin eintreffen.

Nachdem ich bis zu meinem 52. Jahre voll Verantwortung und in täglicher Treue an einem Lebenswerke für den Menschen, den Europäer und den Deutschen geschaffen habe bleibt mir nur übrig die Frage abzulehnen.

Mit kollegialem Gruß

Rudolf Pannwitz

Preußische Akademie der Künste, Berlin W 8, Pariser Platz 4, den 18. April 1933

Sehr geehrter Herr Schickele,

unterm 14. v. Mts. übersandte ich Thnen das anliegend in einer Abschrift nochmals beigefügte Schreiben mit der ebenfalls hier in einem weiteren Exemplar beigefügten Erklärung. Da wir bis heute ohne Ihre Antwort geblieben sind, wiederhole ich meine Bitte um baldgefällige Stellungnahme bis zum 18. d. Mts. spätestens. Falls Sie beabsichtigen, dieser Erklärung nicht beizutreten, so müßten wir annehmen, daß Sie selbst den Wunsch haben, sich außerhalb unserer Akademie zu stellen.

In größter Hochachtung

Der Präsident

Max von Schillings

René Schickele, Badenweiler (Schwarzwald), z. Zt. Sanary s. mer (Var), Villa Ben qui 48 hado, 18. 4. 33.

Sehr geehrter Herr Präsident, Ihr Brief ging über Badenweiler und hat mich verspätet erreicht. Leider kann ich Thre Frage nicht, wie Sie wünschen, ohne weiteres mit ja oder nein beantworten, solang ich nicht weiß, inwiefern der "Sinn der veränderten geschichtlichen Lage“

1 Vgl. Dok. Nr. 107. 
auch den Sinn der Akademie verändert. Zweifellos wurde gerade die Abteilung für Dichtung nach unpolitischen Gesichtspunkten gegründet, ohne Rücksicht auf staatliche Grenzen, für die Anerkennung und Pflege des gesamtcleutschen Schrifttums. Sollte dieser Sinn eine neue, über die bestehenden Statuten hinausgehende Bindung sein, so könnte ich, übrigens schon mit Rücksicht auf meine Staatsangehörigkeit, der Akademie nicht länger angehören. Es wird Ihnen, sehr geehrter Herr Präsident, ein leichtes sein, dies zu entscheiden, und ich wäre Ihnen dankbar, wenn Sie mich Ihre Entscheidung wissen ließen.

Hochachtungsvoll

Ihr sehr ergebener René Schickele

49 Preußische Akademie der Künste, Berlin W 8, Pariser Platz 4, den 5. Mai 1933

Sehr geehrter Herr Schickele,

unter Bezugnahme auf Ihr gefälliges Schreiben vom 18. v.Mts. und nach an maßgebender amtlicher Stelle eingeholten Informationen muß ich Ihnen leider mitteilen, daß Sie nach den für die Neuordnung der kulturellen staatlichen Institute Preußens geltenden Grundsätzen künftig nicht mehr zu den Mitgliedern der Abteilung für Dichtung gezählt werden können.

In größter Hochachtung

Der Präsident

Max von Schillings

Einschreiben

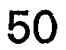

$$
\begin{aligned}
& \text { Vertraulich! } \\
& \text { Sind Sie bereit, unter Anerkennung der veränderten } \\
& \text { J. fipu'l 1933 }
\end{aligned}
$$

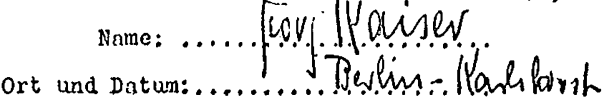

$$
\begin{aligned}
& \text { Tresterwallee } 942
\end{aligned}
$$

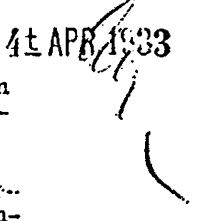

Sehr geehrter Herr Kaiser, ${ }^{1}$

nach an maßgebender amtlicher Stelle eingeholten Informationen muß ich Ihnen leider mitteilen, daß Sie nach den für die Neuordnung der kulturellen staatlichen Institute Preußens geltenden Grundsätzen künftig nicht mehr zu den Mitgliedern der Abteilung für Dichtung gezählt werden können.

In größter Hochachtung

Der Präsident

Max von Schillings

Einschreiben 
[Max Liebermann] An das Sekretariat der preuß. Akademie der Künste, Berlin

Sehr verehrter Herr Professor,

ich ersuche Sie, von nachstehender Erklärung der zuständigen Stelle Mitteilung zu machen.

„Hiermit lege ich das Ehrenpräsidium der preuß. Alsademie der Künste nieder und erkläre meinen Austritt als Senator sowie ordentliches Mitglied der Genossenschaft der Akademie."

Mit freundlichen Grüßen

Berlin, 7. Mai 1933

Ihr sehr ergebener d.O.

Dr. h.c. Max Liebermann

Erklärung Max Liebermanns in der Centralvereins-Zeitung, Berlin, 11. 5. 1933

Ich habe während meines langen Lebens mit allen meinen Kräften der deutschen Kunst zu dienen gesucht. Nach meiner Überzeugung hat Kunst weder mit Politik noch mit Abstammung etwas zu tun, ich kann daher der Preußischen Akademie der Künste, deren ordentliches Mitglied ich seit mehr als dreißig Jahren und deren Präsident ich durch zwölf Jahre gewesen bin, nicht länger angehören, da dieser mein Standpunkt keine Geltung mehr hat. Zugleich habe ich das mir verliehene Ehrenpräsidium der Akademie niedergelegt.

\section{GRÜNDUNG EINER „DEUTSCHEN AKADEMIIE DER} DICHTUNG “, MAI 1933

Telegramm - buchschlag bei sprendlingen - F 8372284/50913 - 4. 5.1933 preussische akademie pariser platz berlin

gestrige ausfuehrungen ministers ueber akademieabt seine auffassung ihrer stellung und aufgaben exachte sehr schoen beruhigend fruchtbar hoffe daher vorgeschlagener weg werde beiderseits ganghar - bincling

An die Preußische Akarlemie der Künste, Berlin W 8, Pariser Platz 4, 6. 5. 33, Herrn Prof. Dr. Amersdorffer

[...] Bei der Besprechung mit dem Minister am Mittwoch [3. 5.] schien der Wunsch schnellen Handelns eine gewisse Übereilung nicht auszuschließen, die hoffentlich

1 Derselbe Bescheid ging am 8. Mai 1933 an Pannwitz und Wassermann, die wie Schickele die Loyalitätserklärung nicht unterschrieben hatten. Am 5. 5. 1933 ging er auch an Frank, Fulda, Kaiser, Kellermann, Mombert, von Unruh und Worfel, obwohl sie die Erklärung zustimmend unterschrieben hatten. Die Ausschlußbescheide erfolgten nach mündlicher Anweisung des Ministers an Akademiepräsident von Schillings; sie stützten sich, ohne daß bereits ein entsprechender Erlaß ergangen war (vgl. den Erlaß v. 9. 12. 1933, Dok. Nr. 120), auf die sinngemäße Anwendung des $\oint 3$ des Berufsbeamtengesetzes (Dok. Nr. 107). Alle übrigen nichtausgeschlossenen Mitglieder der Abteilung für Dichtung unterschrieben die Erklärung in gewünschtem Sinn. Eine Ausnahme machte Hermann Bahr, der zu diesem Zeitpunkt bereits schwer erkranlst war. 
Herr von Schillings anschließend für beide Teile vermieden hat. Wenn auch eine Einberufung der Mitglieder mit kürzerer Frist als die Satzungen vorschreiben, selbstverständlich erscheint und unbedingt nötig ist, so sollte meines Erachtens wenigstens von einer Ladung aller Mitglieder zu der notwendigen Sitzung nicht abgesehen werden. Ich halte es für völlig unnötig die Mitglieder auszuschalten. Auch erbiete ich mich - was Sie bitte dem Herrn Präsidenten mitteilen wollen - zu persönlicher oder brieflicher Behandlung einiger Fälle die uns vielleicht besonders angehen; ich denke da besonders an Mombert und Fulda.

Bei dem ganz ausgezeichneten Eindruck den ich während der langen Unterredung von der Person und den Absichten des Ministers empfangen habe glaube ich mit Bestimmtheit an eine Lösung der Situation die nicht kompromißhaft, sondern ganz klar ist - auch im Hinblick auf die Mitgliedschaft in der Akademie, Abt[eilung]. $f$. Dichtung. Ich liebäugele sogar mit dex Möglichkeit einer Art Verbannung - einer Selbstverbannung auf Zeit oder lebenslänglich - für Einzelne, wie sie das Altertum kannte.

In aller Hochachtung und Ergebenheit

Ihr Rudolph G. Binding

\section{BERUFUNGEN NEUER MITGLIEDER}

56 [Aktennotiz] Herrn Dr. Benn ganz ergebenst

Der Minister empfielt die Zuwahl folgender Herren:

Hans Grimm, Paul Ernst, Wilhelm Schäfer, Agnes Miegel, Börries von Münchhausen, Blunck, Emil Strauß, Carossa, Werner Beumelburg, Peter Dörfler, Kolbenheyer, Griese, Hanns Johst, Will Vesper, eventuell Otto Erler.

[Handschriftlich:] Im übrigen beziehe ich mich auf das Telefongespräch. Zie[rold] 5.5. [abgezeichnet:] Benn 5./5., 6h

57 Verhandelt in der Abteilung für Dichtung am 5. Mai 1933, nachmittags 6 Uhr Beginn der Sitzung: 6 Uhr

Anwesend: Dr. Benn als Vors., Loerke, Stucken, von Molo - zugezogen: Amersdorffer (ohne Stimmberechtigung).

Der Vorsitzende berichtet über die mündlichen Vorverhandlungen wegen der Ergänzung der Mitglieder der Dichterabteilung, besonders über eine in seinem und Herrn Dr. Bindings Beisein vor zwei Tagen stattgehabten Besprechung bei dem Herrn Kultusminister. Der Vorsitzende teilt ferner mit, daß der Herr Minister die Abteilung für die heute vorzunehmende Wahl neuer Mitglieder von der Einhaltung aller Einzelbestimmungen des $\S 5$ der Satzung der Akademie ${ }^{1}$ entbunden hat. Er verliest die nach Vereinbarung mit allen Instanzen aufgestellte Liste, die zu einem großen Teil mit der früher von der Abteilung selbst aufgestellten Liste übereinstimmt. Es erfolgt eine Aussprache, nach der folgende Dichter einstimmig in die Abteilung gewählt werden:

Hans Grimm, Paul Exnst, Wilhelm Schäfer, Agnes Miegel, Börries von Münchhausen, Hans Friedrich Blunck, Emil Strauß, Hans Carossa, Werner Beumelburg, Peter Dörfler, Erwin Guido Kolbenheyer, Friedrich Griese, Hanns Johst, Will Vesper.

1 In $\S 5$ dex Satzung war die Wahl neuer Mitglieder durch die Wahlversammlung der Akademiemitglieder (geheime Zettelabstimmung) genau geregelt. 
Der Schriftsteller Otto Erler, auf den von bestimmter kulturpolitischer Seite aus hingewiesen wurde [ursprüngl.: auf dessen Wahl die bisher gehörten Instanzen ein geringeres Gewicht legen], wird vorläufig nicht gewählt, weil sein Schaffen den anwesenden Mitgliedern nicht bekannt und die zur Verfügung stehende Zeit zu kurz ist, um Informationen über sein Werk einzuholen.

[Folgender Abschnitt ist mit der Bemerkung Bitte fortlassen! versehen :] Herr Loerke spricht im Namen der Anwesenden dem kommissarischen Vorsitzenden den Dank der Abteilung für die Führung der schwierigen Verhandlung in der gegenwärtigen Zeit aus.

Schluß der Sitzung 7 1/4 Uhr

Dr. Benn

Dr. Amersdorffer

Münchener Zeitung, 8. 5. 1933: Die neue Dichter-Akademie

Nunmehr ist es, wie der preußische Kultusminister Rust heute vor einem Kreis von Pressevertretern im Rahmen grundsätzlicher Ausführungen über die Kulturpolitik der neuen Regierung mitteilte, zu einer völligen Neuordnung der Dichterakademie, der Abteilung 3 der preußischen Akademie der Künste gekommen. Aus der Dichterakademie sind ausgeschieden: Döblin, Bruno Frank, Fulda, Georg Kaiser, Kellermann, Thomas Mann, Alfred Mombert, Alfons Paquet, Rudolf Pannwitz, René Schickele, von Unruh, Wassermann, Werfel.

Der Kultusminister hat die folgenden Dichter in die Dichterakademie berufen: Werner Beumelburg, Hans Friedrich Blunck, Hans Carossa, Peter Dörfler, Paul Ernst, Friedrich Griese, Hans Grimm, Hanns Johst, Kolbenheyer, Agnes Miegel, Börries von Münchhausen, Wilhelm Schäfer, Emil Strauß und Will Vesper. Über die Auswahl weiterer Persönlichkeiten des deutschen Schrifttums wird die neugeformte Abteilung 3 der Akademie nunmehr selbst entscheiden können. Es ist also schon in allernächster Zeit, wenn die erste konstituierende Sitzung stattgefunden hat, mit weiteren Berufungen zu rechnen. Kultusminister Rust wies auf die große Aufgabe hin, die der Dichtung gerade in diesen Tagen, da der patriotische Kitsch sich in den Vordergrund zu drängen scheint, gestellt ist.

Stefan George ist nicht aufgefordert worden, weil er es bisher stets abgelehnt hat, sich zur Verfügung zu stellen. Man hofft aber, eine Form zu finden, in der die Verbundenheit des neuen Deutschland mit Stefan George klar zum Ausdruck gebracht werden kann. $[\ldots]$

Walter von Molo, Berlin-Zehlendorf, Schweitzerstr. 7, den 11. Mai 1933

Hochverehrter Herr Minister!

Mit wirklich innigem Dank für die in der heutigen vormittäglichen Audienz gesagten Worte beehre ich mich, beiliegend einiges entscheidende Material noch vorzulegen. Zur Sache selbst ${ }^{1}$ bemerke ich:

Ich war mit Herm Kolbenheyer herzlich befreundet vor dem Kriege, und ich war einer der allerersten, der über seine Werke schrieb in der Öffentlichleeit, auf seine Bitte hin. Lange Jahre nach dem Krieg verbreitete noch der Georg Müller-Verlag

1 Der neu in die Abteilung berufene Erwin Guido Kolbenheyer hatte den Ausschluß Walter von Molos aus der Sektion gefordert; unter von Molos Vorsitz hatten die Sektionsmitglieder im Oktober 1930 die von Kolbenheyer und Schäfer vorgelegte Geschäftsordnung abgelehnt. Daraufhin waren Kolbenheyer, Schäfer und Strauß im Jan. 1931 demonstrativ aus der Akademie ausgetreten. Akademiesekretär Amersdorffer hatte von Molo auf seinen bevorstehenden Ausschluß vorbereitet, woraufhin dieser bei Minister Rust intervenierte. 
einen Prospekt über Kolbenheyer's Werke, auf denen mein Lob angeführt war. Ich lege den „Meister Joachim Pausewang“ bei mit einer Widmung Kolbenheyer's. Als wir uns nach dem Kriege in der Akademie wieder trafen, haben wir gemeinschaftlich ernst gearbeitet. Und noch am 13. Oktober 1930, als ich als Vorsitzender bereits zurückgetreten war, haben wir freundschaftlich miteinander gesprochen und mit Wilhelm Schäfer und anderen gemeinsam zu Mittag gegessen.

Über die Generalversammlung der Akademie vom 13. und 14. Oktober 1930 unterrichten Sie, sehr verehrter Herr Minister, die Originalprotokolle der Akademie (1, 2, 3). Dann bitte ich, Beilage 4 (Protokoll) einzusehen; hieraus ist der Beginn des Konfliktes zu ersehen. Ich mache darauf aufmerksam, an dieser Sitzung nahmen außer den ausgeschiedenen Mitgliedern Fulda und Döblin teil: Amersdorffer, Haslinde, Loerke, Stucken, Frau Huch und ich. Beilage 5 unterrichtet über den Rücktritt Hermann Hesses. Beilage 6 enthält den Bericht über die Ablehnung der KolbenheyerSchäferschen Geschäftsordnung. Der Beschluß war, wie das Protokoll erweist, einstimmig, also stimmten Stucken und Loerke ebenso wie ich und zwei inzwischen ausgeschiedene Mitglieder. Wohlgemerkt: dieser Beschluß war darin einstimmig, wie aus dem Protokoll hervorgeht, als wir baten, die Geschäftsordnung möge zurückgezogen werden. Beilage 7 enthält den formulierten Beschluß, der an die auswärtigen Mitglieder verschickt wurde.

Nunmehr setzte erst der Protest von Kolbenheyer ein, wie aus dem Sitzungsprotokoll vom 17. Dezember 1930 (Beilage 8) zu ersehen ist. Außer den zwei inzwischen ausgeschiedenen Mitgliedern nahmen an der Sitzung teil Amersdorffer, Haslinde, Petersen, Loerke, Stucken, Molo. Für den Beschluß, die Geschäftsordnung zu beseitigen, traten weiter Däubler und von Scholz ein. Wie aus dem Schluß des Protokolls hervorgeht, regte der Vertreter des Kultusministeriums, Herr Ministerialrat Haslinde, an, in einem von ihm zu verfassenden Gutachten die Frage juristisch zu klären. Beilage 9 zeigt das Gutachten unseres damaligen rechts- und verwaltungskundigen Senatsmitgliedes, Ministerialrat Dr. Haslinde. In der Sitzung vom 12. Januar 1931 (Beilage 10) überreichte Loerke die inzwischen eingegangenen Austrittserklärungen von Kolbenheyer, Schäfer und Emil Strauß. Diese Sitzung leitete Herr Döblin. Es waren anwesend, außer drei ausgeschiedenen Mitgliedern, Loerke, Stucken, Frau Huch. Ich war auf Vortragsreise und daher nicht anwesend. Man wird mir also schwerlich einen Vorwurf machen können, daß ich gegen diese Austritte nicht aufgetreten wäre. Beilage 11 zeigt das Protokoll vom 11. Januar 1931, in dem, außer drei inzwischen ausgeschiedenen Mitgliedern, Amersdorffer, Haslinde, Petersen, Frau Huch, Stucken, Loerke und ich anwesend waren. Auf Seite 2 dieses Protokolls ist meine politische Haltung eindeutig zu erkennen. Ebenso, daß ich gegen den Antrag Heinrich Mann und Frank war, die Schriftstücke der Ausgetretenen der Öffentlichkeit mitzuteilen.

Herr Kolbenheyer hat nach seinem Austritt, den ich nicht zur Kenntnis nahm, da ich nicht bei der Sitzung anwesend war, als ich davon hörte, machte ich den damals anwesenden Herren Vorwürfe, daß sie nicht nochmals an ihn geschrieben hätten, sondern daß Herr Loerke als Sekretär die Austritte einfach zur Kenntnis nahm, - ich war ja seit Monaten nicht mehr Vorsitzender - Herr Kolbenheyer hat nach seinem Austritt den Senat namentlich in der Presse angegriffen mit wirklich beleidigenden Unterstellungen infolge unrichtiger Informationen. Ich habe nie darauf erwidert. Heute aber wird Herr Kolbenheyer nach Kenntnisnahme dieser vorliegenden Originalprotokolle wohl selbst zugeben, daß er zu weit gegangen ist. Um der Sache willen habe ich am Freitag, den 5. d.M., clamit wir endlich zu geschlossener Arbeit kommen, für die Wiederwahl Kolbenheyer's, Schäfer's, Strauß' u.s.w. gestimmt. Ich meine, wenn mir die Sache und die Autorität des neuen Staates über allem Persönlichen steht, dann müßte das auch bei allen anderen Herren gleich sein. Und warum, frage ich 
schließlich, werde ich allein verfolgt, wenn die Amtssenatoren und die anwesenden Mitglieder Loerke und Stucken nicht verfolgt werden? Um so mehr muß ich diese Frage tun, als ich, wie aus Beilage 12 hervorgeht, ebenso aus Beilage 13, in der Hauptversammlung vom 27. Januar 1931 absichtlich nicht anwesend war, als Heinrich Mann (Seite 14 v. Beilage 13) einstimmig durch Akklamation gewählt wurde von den in der Akademie verbliebenen Mitgliedern Ponten, Halbe, Huch, Stucken, Loerke, Däubler.

Ich glaube, hochverehrter Herr Minister, nunmehr bewiesen zu haben, daß nicht der geringste Anlaß für Herrn Kolbenheyer und etwaige andere Herren vorliegt, anders zu mir zu stehen, als zu anderen Mitgliedern der ehemaligen Abteilung, die in der Akademie verblie\}sen sind. Ich habe über die Vorgänge in der Akademie bisher geschwiegen, nunmehr mußte ich aber doch die Originaldokumente vorlegen, und ich bitte, sich die Mühe zu machen, sie durchzusehen, weil daraus mein Handeln eindeutig ersichtlich ist.

Nicht ohne Humor darf ich wohl hier noch erwähnen, daß der Verlag Albert Langen, Georg Müller, dem Herr Kolbenheyer heute zugehört, ebenso wie Herr Schäfer und Herr Grimm, heute im Besitze von Ullstein wäre, hätte ich es seinerzeit nicht verhindert. Im Jahre 1923 machte mir Ullstein wieder einmal ein großes Verlagsangebot. Es lautete dahin, meine Gesamtausgabe herauszubringen. Und als ich daraufhin erklärte, ich sei an den Verlag Albert Langen gebunden, meinte der damalige Chef des Hauses Ullstein, Langen würde mir doch sicherlich kein Honorar bezahlt haben. Daraufhin sagte ich, daß ich wohl eine größere Summe dem Verlag, der seit Jahren in Schwierigkeiten war, stundete. Da wollte Ullstein, daß ich ihm meine Forderung an den Verlag Albert Langen übertrüge. Er sagte damals wörtlich: „Sie übertragen mir Ihre Forderung, und damit gehört der Verlag Albert Langen mir. Wir fahren dann morgen nach München und machen die Sache perfekt. Wenn Sie von dem Verlag Langen nicht wegwollen, dann kommen Sie auf diese Art zu uns. "Ich ging natürlich auf eine derartige Geschäftstüchtigkeit nicht ein, sondern unterrichtete Albert Langen und hielt bei ihm so lange aus, als es irgend möglich war. Die Schriftstücke liegen im Verlag Langen-Müller. Verzeihen Sie, hochverehrter Herr Minister, daß ich auch davon sprach, aber ich habe in den letzten sechs Tagen lernen müssen, daß es nötig ist. Ich lege einiges, das Sie vielleicht interessieren dürfte, über meinen seinerzeitigen Rücktritt ect. bei.

In aufrichtiger Verehrung ganz ergeben

Walter v. Molo

Preußische Akademie der Künste, Berlin W 8, Pariser Platz 4, Aktennotiz

Herr O[be]RR[egierungsrat] Dr. Zierold teilte mir heute telefonisch mit, daß gestern nachmittag mit einer Anzahl der neugewählten Dichter eine Besprechung bei dem Herrn Minister stattgefunden haJe. Einige Mitglieder hatten für die Annahme ihrer Berufung gewisse Vorbehalte gemacht, so Hans Grimm, dex erst die Versicherung wünschte, ob die Souveränität der Akademie genügend bewahrt bleibe. Alle diese Vorbehalte und sonst geäußerten Bedenken sind beseitigt und die Besprechung ist sehr gut verlanfen. Eines der neuen Mitglieder, Hans Carossa in München, hat die Berufung abgelehnt mit der Begründung, daß ex prinzipiell keiner Gemeinschaft beitrete. (Aus gleichem Grunde hat Carossa schon früher erklärt, daß er eine Wahl in die Akademie nicht annehmen würde.) Schriftliche Mitteilung über die Annahme der Berufungr durch die übrigen neuen Mitglieder wird die $\Lambda$ kademie in den nächsten Tagen erhalten.

Schon jetzt soll die konstituierende Sitzung der erneuerten Abteilung vorbereitet 
werden. Den in der Besprechung bei dem Herrn Minister anwesenden Mitgliedern wäre Mittwoch, der 7. Juni, der erwünschteste Termin für die Sitzung. An diesem Termin solle, wenn irgend möglich, festgehalten werden.

Dr. Zierold meinte, der alte Senat werde zurücktreten müssen. Ich erwiderte ihm darauf, daß dies wohl selbstverständlich sei, im übrigen sei der alte Senat durch die Austritte ohnehin so gut wie ganz verschwunden; er werde schon aus diesem Grunde im ganzen neu gewählt werden müssen.

Die Reise- und Aufenthaltskosten für die an der konstituierenden Sitzung teilnehmenden auswärtigen Mitglieder wird das Ministerium zur Verfügung stellen. Eine vorläufige Berechnung dieser Kosten erfolgt durch das Büro der Akademie und wird Dr. Zierold mitgeteilt.

Dr. Zierold teilte weiter mit, daß die Angelegenheit von Molo völlig bereinigt sei. Es sei weiter kein Widerspruch gegen ihn erfolgt, aber von Molo werde sich selbstverständlich äußerste Zurückhaltung auferlegen müssen, da noch große Gegensätze vorhanden seien. (Ich habe in diesem Sinne heute mittag mit Herrn von Molo gesprochen.)

Berlin, den 22. Mai 1933

Dr. Amersdorffer

61 Preußische Akademie der Künste, Berlin W 8, Pariser Platz 4, den 1. Juni 1933

Sehr verehrter Herr Dr. Binding,

die konstituierende Sitzung der „erneuerten Abteilung“ steht am 7. Juni bevor und wir freuen uns, Sie dann wieder in Berlin begrüßen zu können. Vorher noch ein paar informierende Worte für Sie, zu deren Absendung ich infolge der vielfachen Inanspruchnahme der letzten Wochen leider erst heute komme:

Die Abwicklung des Neuaufbaus der Abteilung hat sich nach der Besprechung bei dem Herrn Minister, an der Sie teilgenommen haben, verhältnismäßig rasch vollzogen. Die Liste der erwünschten neuen Mitglieder ist nach Anhörung der verschiedenen Instanzen (man sollte es kaum für möglich halten, wer hierbei heutzutage mitzusprechen hat!) zustande gekommen. Auch der Rumpfabteilung schien die Liste im allgemeinen durchaus annehmbar, und tatsächlich ist diese Liste einstimmig. angenommen worden. In unserem Bericht an den Minister konnte deshalb mit Recht betont werden, daß diese Mitglieder von der Abteilung einstimmig gewählt worden sind. Trotzdem wurde von diesem uns sehr günstig scheinenden Umstand kein Gebrauch gemacht, sondern die neuen Mitglieder wurden in der amtlichen Kundgebung: ausdrücklich als berufen bezeichnet, was wohl dem ausdrücklichen Wunsch einiger der neuen Herren entsprach. (Dies vertraulich!) Die Liste der Neuen kennen Sie ja aus den Zeitungsveröffentlichungen. Aus dieser publizierten Liste müssen Sie allerdings Hans Carossa streichen. Er hat die Berufung abgelehnt mit der Begründung, daß er prinzipiell keiner Gemeinschaft beitrete. Aus der Presse werden Sie ja auch ersehen haben, welche Mitglieder noch ausgeschieden sind. Die Schreiben, die wir an einige von ihnen richten mußten, waren für uns eine recht unerfreuliche Aufgabe; aber sie mußte leider erfüllt werden. Der Austritt von Frau Ricarda Huch ist in der amtlichen Veröffentlichung zunächst noch verschwiegen worden. Man glaubte wohl immer noch, eine gewisse Hoffnung hegen zu dürfen, daß sie ihren Entschluß zurücknimmt. Da wir aber bereits alles versucht haben, wird sich diese Hoffnung wohl leider nicht erfüllen. Da Paul Ernst gleich nach seiner Berufung verstorben ist, beträgt die Zahl der neuberufenen Mitglieder 12. Von den früheren Mitgliedern sind 16 verblieben, sodaß die Abteilung jetzt aus 28 Dichtern besteht.

Die konstituierende Sitzung am 7. Juni wird Herr von Schillings als Präsident mit Begrüßungsworten einleiten. Dann wird das älteste anwesende Mitglied (wahrschein- 
lich Stehr) die Versammlung leiten müssen bis der Vorsitzende gewählt ist. Die Frage, wer mit dieser Ehre betraut werden soll, ist natürlich von ganz besonderer Wichtigkeit. Auf wen die Wünsche der neuen Mitglieder hinzielen, darüber konnten wir noch nichts Endgültiges erfahren. Es scheint, daß die Herren sich selbst noch nicht ganz einig werden konnten. - Mir persönlich ist auch sehr daran gelegen, daß die Frage der Bestellung eines neuen Sekretärs bald gelöst wird. Unmaßgeblich würde ich dafür Herrn Dr. Benn für vorzüglich geeignet halten; ob alle neuen Mitglieder mit dieser Person einverstanden sein würden, das steht allerdings dahin.

Vorgestern hat der Herr Minister Herrn von Schillings gegenüber die bestimmte Absicht ausgesprochen, an der konstituierenden Sitzung teilzunehmen und in einer Ansprache Programmatisches auszuführen.

Nebenbei erwähne ich noch ganz vertraulich, daß einige der Neuen, besonders Herr E. G. K[olbenheyer] auch das Ausscheiden von W. v. M[olo] gefordert haben. Ich hatte die unangenehme Aufgabe, W. v. M. auf das Schlimmste vorzubereiten, worauf er sich mit gewaltigem Temperament zu wehren begann - und nicht ohne Erfolg. Es ist dem Herrn Minister, nachdem auch Herr von Schillings sich Herrn W. v. M. an die Seite gestellt hatte, gelungen, Herrn E. G. K. zu einer freundlicheren Haltung zu bringen. Hoffentlich bleibt der Frieden bestehen, wenn die beiden jetzt wieder in der Abteilung zusammensitzen! [. . . ]

Mit hochachtungsvoller Empfehlung

Ihr sehr ergebener Amersdorffer

\section{KONSTITUIERUNG DER NEUEN ABTEILUNG FÜR DICHTUNG}

Konstituierende Sitzung der erneuerten Abteilung für Dichtung am 7. Juni 1933, 62 vormittags $10 \frac{1}{2} \mathrm{Uhr}$

Anwesend: Herr Minister B. Rust, ORR Dr. Zierold; Präs. v. Schillings als Vors.; von Scholz, von Molo, Binding, Ponten, Stucken, Agnes Miegel, Benn, Halbe, Beumelburg, von Münchhausen, StrauB, Kolbenheyer, Schäfer, Johst, Loerke, Ina Seidel, Grimm, Blunck, Vesper, Stehr, Dörfler, Griese; zugezogen Dr. Amersdorffer.

Der Präsident eröffnet die Sitzung und begrüßt die Anwesenden, besonders den Herrn Minister. Er betont die in der Akademie vertretene Einheit der Künste, die alle aus einer gemeinsamen Wurzel ersprießen, und weist darauf hin, daß unsere Akademie ihrem Namen nach wohl eine preußische, ihrer Zusammensetzung, ihrem Wesen und ihrer Wirksamkeit nach aber eine deutsche Akademie ist. Alle bedeutenden Künstler, die die deutsche Sprache sprechen, können in unsere Akademie gewählt werden. Wir hoffen, daß bald im Laufe einer organischen Entwicklung anstelle des Wortes "preußische" das Wort "deutsche" gesetzt werden kann.

Der Präsident gedenkt dann des Hinscheidens des neuberufenen Mitgliedes Paul Ernst und verliest aus einem Brief seiner Witwe folgende Sätze: „Der Verstorbene hat in den Tagen seiner letzten Krankheit von den schweren Aufgaben der Akademie gesprochen. Seine Überzeugung war, da $ß$ sie ein geistiges Gewissen für das ganze deutsche Volk sein müsse. Dabei packte ihn eine ungeduldige Verzweiflung, daß ex gerade jetzt, durch sein Leiden gehemmt, den Anforderungen, die an ihn herantraten, nicht genügen konnte." Die Anwesenden erheben sich zu Ehren des Verstorbenen von ihren Sitzen.

Der Präsident betont, daß der Zweck der heutigen konstituierenden Sitzung der sei, die Grundlagen für die erneuerte Abteilung für Dichtung auszubauen. Er dankt Herrn Dr. Benn für die kommissarische Leitung der Abteilung während der letzten Monate und begründet die Anwesenheit von Professor Dr. Amersdorffer in der heu- 
tigen Sitzung mit dessen Zuständigkeit für die organisatorischen Fragen der Gesamtakademie. Der Präsident dankt dem Herrn Minister für sein bisher gezeigtes Streben, die Akademie wirklich zu einer Vertreterin aller Künste zu machen. Er spricht den Wunsch aus, daß wirklich ersprießliche Arbeit in dieser konstituierenden Sitzung geleistet werde, daß alle einst vorhandenen Gegensätze begraben und vergessen sein sollen und daß eine reine Harmonie in dieser Tagung vorwalten möge. - Er erteilt alsdann dem Kurator der Akademie, Herrn Staatsminister Rust, das Wort.

Herr Minister Rust knüpft an das Wort von Paul Ernst (in dem von dem Präsidenten verlesenen Brief seiner Witwe) an: die Dichterabteilung müsse ein geistiges Gewissen für das ganze deutsche Volk sein. Diese Auffassung gäbe der gegenwärtigen Tagung die Bedeutung einer feierlichen und ernsten Stunde. - Er habe zunächst den Wunsch, seine Neuberufung von Mitgliedern durch ein Wort zu rechtfertigen: Die von ihm vorgefundene Abteilung für Dichtung konnte von den Vertretern des geistigen Lebens nicht als eine Vertretung geistigen deutschen Lebens angesehen werden. Es mußte ein gemeinsamer Boden gefunden, eine Brücke geschlagen werden. - Der eine oder der andere sei vielleicht der Auffassung, hier solle etwas Vergangenes, Ehrwürdiges wieder in Ordnung gebracht werden. Dies sei nicht der leitende Gedanke. Wenn aus der Neuordnung ein lebendiges Leben erwachsen kann, so könne dies heute geschehen. Aber mehr noch solle geschehen: nicht ein Parnaß des deutschen Dichtertums solle erstehen, zu dem das Volk hinaufblickt, sondern es gelte: dem Volke den Weg zur Dichtkunst freizubrechen! Dessen bedürfen wir dringend. Dieses Ziel konnte nicht durch Statuten, nicht durch Richtlinien erreicht werden. Freiheit und Autonomie seien keine festen, konstanten Begriffe, ebensowenig wie der Begriff Revolution. Entscheidend sei, ob aus einer Handlung lebendiges Leben erwachsen könne. Die sei auch der entscheidende Maßstab für eine Revolution. - Wenn aus der gewaltigen Bewegung nicht ein Wachsen deutscher Kräfte entstehen würde, so würde sie umsonst gewesen sein. Deshalb habe er sich maßgebend eingesetzt für eine Neuordnung der Abteilung für Dichtung. Unter diesem Gesichtspunkt sei auch der Eingriff in die Abteilung zu verstehen. Es kam darauf an: einen Organismus wieder lebensfähig zu machen. -

Ex habe zwei Aufgaben vor sich gesehen: die eine rein vom Volke gesehen. Es war nicht möglich, eine Dichterakademie bestehen zu lassen, die das Volk als die seine nicht anerkannte. Es sei ihm nicht leicht geworden, die auf das Ausscheiden mancher Mitglieder abzielenden Wünsche trotz gewisser Sympathien für ihre Persönlichkeiten zu erfüllen. Diese Mitglieder waren aber für die Akademie weiterhin unmöglich in einer Zeit des völkischen Erwachens. Deshalb durfte man sich nicht durch einen Mangel an Entschlußkraft schwächen lassen. Das Volk habe eben seine Vorstellungen, seine Liebe und seinen $\mathrm{Ha}$. Andererseits könne nicht verschwiegen werden, daß es überhaupt schwer sei, mit einem Wertmesser an diese Persönlichkeitsfragen heranzugehen, denn wir sind alle Irrtümern unterworfen. Eines konnte bestimmt getan werden: Blutlosigkeit und Formlosigkeit mußten verschwinden. Die intuitive Erkenntnis unserer Zeit habe der Abteilung gefehlt.

Manche haben wohl gefürchtct, die völkische Revolution würde eine künstlerische Reaktion bringen, die zur Unfruchtbarkeit, zu einem hohlen patriotischen Pathos führen könnte; man könne vielleicht die als Führer ansehen, die sich durch lautes Gebaren besonders bemerkbar machten. Dies wäre erschütternd gewesen! Was geschehen mußte, war: es mußte dem deutschen Volke zunächst etwas Greifbares gezeigt werden. Vieles ist beiseite geworfen worden, vieles wird nicht mehr anerkannt. Ist eine Welt verschwunden und eine andere noch nicht da? Oder ist die andere im Dämmerzustande des Werdens? 
Diese andere neue Welt, fährt Herr Minister Rust fort, sind Sie für mich. Die ungeheure völkische Bewegung lebte ja schon im deutschen Dichter. Sie lebte bereits, es mußte nur gezeigt werden, daß sie schon da ist. Über alle persönlichen Schwierigkeiten hinweg mußte diese Körperschaft hergestellt werden. Dies wird vielleicht doch einmal als eine Tat anerkannt werden: da $\beta$ mit Fleisch und Blut erfüllt worden ist, was die Menschen in Deutschland erstreben und ersehnen. Ich danke Ihnen, daß auch Sie den Mut gehabt haben. Die völkische Bewegung wird sich nicht mit toten Dekorationen belasten. Etwas Lebendiges muß geschaffen, nicht etwas Totes fortgeschleppt werden. Das ist das Entscheidende. Die Aufgabe liegen vor. Ich möchte aber die Feststellung dieser Aufgaben nicht Ihnen selbst rorwegnehmen.

Der Eingriff in die Abteilung war notwendig, um dieses Lebendige zu schaffen. Dieser Eingriff soll der letzte sein. Die Akademie ist wieder autonom. Das weitere ist Ihre Angelegenheit. Man könnte vielleicht sagen: dies oder jenes ist unterlassen. Man soll aber zunächst nicht fragen, was kann man ändern, sondern, was mu $\beta$ man ändern.

Für die bevorstehende Arbeit der Abteilung bemerkt der Herr Minister: Ich bin nicht weit von Ihnen, ich stehe mit dem Apparat des Ministeriums, aber auch mit dem unserer Bewegung zur Verfügung. - Sie sollen zur Geltung kommen. Sie sollen das Edelste, das Wertrollste vermitteln. Ich denke nicht etwa an den Rundfunk. Es ist allerhöchste Zeit, daß unsere deutsche Presse, besonders in ihren Feuilletons, ein ganz anderes Gesicht erhält. Ich habe bereits Fühlung nach dieser Richtung genommen und absolute Bereitschaft gefunden. Die deutschen Dichter sollen im besten Sinne populär werden! - Der deutsche Buchhandel hat Pflichten zu erfüllen, hat vieles gutzumachen. Doch will ich mich auf diese wenigen Andeutungen beschränken.

Die Preußische Akademie soll nicht Gegenstand ständiger enger staatlicher Erziehungsarbeit sein. Auch hier soll dem groß-deutschen Gedanken Raum gegeben werden. Ich bin Niedersachse und habe immer vom Standpunkt der Heimat und des Stammes aus gesehen. Hitler hat eine große Verwirrung in unserem Staatsleben dadurch vermieden, daß ex überall Statthalter eingesetzt hat. Wir werden nicht dabei stehen bleiben; die biologische zwangsweise Entwicklung wird kommen! Preußens Aufgabe ist es, einem Groß-Deutschland den Weg zu bereiten. - Ein Staat mußte einmal die Brutalität haben, in der deutschen Tiefebene einen großen Staat zu schaffen. Wenn dies nicht geschehen wäre, würden wir das heutige Deutschland nicht besitzen. Das ist Preußens Leistung für das ewige Leben unseres ganzen Volkes. - Unter diesem Gesichtspunkt habe ich auch die Aufgabe der Preußischen Akademie gesehen: als große deutsche Dichterakademie der Zukunft. Die Autonomie der Akademie ist in diesem Augenblick wiederhergestellt. Diese Stunde ist die Stunde einer deutschen Dichterakademie mit der Aufgabe eines großen lebendigen Wirkens. Sie haben viel einzusetzen, Sie bringen Ihr Lebensschaffen, Ihre Namen mit. Aber auch die gegenwärtige Staatsleitung hat viel einzusetzen.

Der deutsche Dichter steht ewig auf seinem Volkstum! Der Staat kann sich nur als eine Selbstschutzorganisation des Volkes entwickeln. Stellen Sie sich immer vor Augen: vor uns steht ein deutsches Volk, das seine Existenz immer wieder zu verteidigen hat, von dem wir überzeugt sind, daß es das beste und edelste Material ist, aus dem Gott ein Volk formen kann. - Halten Sie sich dieses immer vor: draußen steht ein Volk, so erwartungsvoll, so aufnahmebereit, so gläubig! Dieses Volk glaubt an Sie, wird an Sie glauben, wenn von hier aus das Leben ihm wieder lebendig entgegentritt. Letzten Endes wird jede Bewegung beurteilt nach ihren Ergebnissen. Man darf heute nicht zu hart urteilen über das, was draußen geschieht. In derartigen unerhörten $A b-$ schnitten unserer Geschichte kann nicht gleich alles den höchsten Anforderungen gerecht werden. Es muß alles erst einmal reif werden. Tun auch Sie das Ihrige dazu! Diese Bewegung, deren Kraft anzuschüren zehn Jahre mittätig gewesen sind, 
wird nicht in eine Überorganisation abirren. Was weiter geschieht, ist jetzt in Ihre Hand gelegt. Wo die Künstler und der Staat zusammengegangen sind, ist immer etwas ganz Großes entstanden. Wenn zwischen Ihnen und dem Ministerium ein lebendiges Wollen bleibt, wenn Sie immer wieder das Volk sind, dann wird aus unserem Handeln etwas Großes entstehen. Ich glaube daran, und ich wünsche Ihrer Arbeit allen Segen! (Lebhafter Beifall)

Der Präsident erwidert: Der Beifall hat Ihnen, verehrter Herr Minister, gezeigt, wie tief Ihre Worte in die Seelen gefallen sind. Wir dürfen uns glücklich schätzen, daß in dieser Stunde ein Mann wie Herr Minister Rust vom Schicksal an diese Stelle gesetzt ist. Schon vom ersten Augenblick an hatte ich die Freude und die Ehre, die Kraft, Größe, Klugheit und das Schöpferische zu erkennen, das sich in Herrn Minister Rust, dem Kurator unserer Akademie, vereinigt. Sein Ernst, seine Gedanken und Hoffnungen sind würdig des Festes, das wir eben gefeiert haben. Möge er wirken als ein wahrer creator spiritus. Auch die Abteilung für Dichtung möge sich irgendwie eines Pfingstwunders freuen, in dem die Wünsche des Herrn Ministers in Erfüllung gehen. - Die nun wieder selbständige Abteilung möge ihre Arbeit jetzt beginnen.

Dr. Schäfer erbittet das Wort und führt aus: Es handelt sich um Dichter, Volk und Staat. Wir Dichter waren mit dem Volk immer in Ordnung, aber nicht das Verhältnis des Staates zum Dichter, und deshalb auch nicht das Verhältnis des Staates zum Volk. Der Staat konnte etwas für das Volk und für die Dichter tun. Aber was hätte er tun sollen? Der Staat hätte die Dichter rufen sollen, die Dichter als Volk, nicht um etwas zu geben, sondern damit die Dichter dem Volk etwas geben. (Beifall).

Der Herr Minister und Oberregierungsrat Dr. Zierold verlassen die Versammlung.

$11 \frac{1}{2}$ Uhr Beginn der Arbeitssitzung

Hermann Stehr übernimmt auf Bitte des Präsidenten als Alterspräsident der Abteilung den Vorsitz. Präsident von Schillings führt noch aus: Die Arbeit der Abteilung der Dichter wird vorbildlich sein für die Arbeit der anderen Abteilungen. Die Akademie wird sich nun auf der ihr gegebenen Grundlage mit neuer Kraft entwickeln. Sie soll eine wahre universitas artium werden. Die alten chinesischen Mauern zwischen den einzelnen Abteilungen müssen fallen, und es muß künftig mehr als bisher eine Aussprache zwischen den verschiedenen Abteilungen der Akademie stattfinden. Präsident von Schillings verläßt alsdann die Sitzung.

Max v. Schillings

Amersdorffer

Sodann wird die allgemeine Aussprache eröffnet. Schäfer bezeichnet als das Ziel der Arbeit die Schaffung der Deutschen Akademie, die natürlich aus den bestehenden Verhältnissen heraus zu entwickeln sei. Blunck bestätigt diese Ansicht von Schäfer.

Kolbenheyer erörtert die Frage, welches die Rechtsgrundlagen seien, aus denen heraus die neue Arbeit zu beginnen habe.

Amersdorffer bezeichnet die geistige Grundlage für wesentlicher als die Rechtsgrundlage. Man sei sich darüber einig, daß man sich an das bisherige Statut in der neuen Arbeit nicht zu kehren brauche. Natürlich sei die Abteilung für Dichtung nach wie vor der Preußischen Akademie der Künste angegliedert. Benn weist darauf hin, daß man mit Absicht keine formale Auflösung der alten Abteilung ausgesprochen habe. Die Lage sei so, daß sich die älteren schon vorhandenen Mitglieder mit den neuen Mitgliedern zur Neugründung der Abteilung zusammengeschlossen hätten. Es handle 
sich also um eine neue Versammlung mit konstituierenden Rechten. Die Erörterung über dieses Thema wird weiter fortgesetzt.

Ponten stellt die Frage, ob die Befugnisse der heutigen Versammlung sich darauf erstreckten: 1. die Akademie clurch neue Mitglieder zu erweitern; 2. die neue Abteilung gegenüber der Preußischen Akademie der Künste in ihren Rechten und Aufgaben abzugrenzen. Schäfer betont, daß wir rechtlich uns innerhalb der Preußischen Akademie befinden, daß wir dabei aber das Bewußtsein haben, eine Deutsche Akademie der Dichtung zu werden. Dieses Bewußtsein sei für ihn die Voraussetzung zur Mitarbeit. Stehr stellt fest, daß die Absicht zur Entwicklung der Deutschen Akademie einwandfrei und unbestritten sei. Früher sei die Entwicklung in Widerspruch zu dieser Absicht gegangen, und es sei dadurch zur Absentierung einer Reihe von Mitgliedern gekommen. Heute sei diese ursprüngliche Grundlage wieder hergestellt. Wir, die Anwesenden, seien die Grundlage, unserem Wesen nach seien wir bereits die Deutsche Akademie, wir hätten aber formale Rücksichten zu nehmen.

Blunck beantragt die folgende Entschließung: „Das Vorgehen des Herm Ministers bei Neuberufung der Mitglieder der Preußischen Akademie der Künste wird nachträglich genehmigt." Er weist darauf hin, daß eine solche Fassung auch im Sinne des Ministers liege und schlägt als zweite Entschließung die folgende vor: „Die am 7. 6. 33 in der Preußischen Akademie der Künste zur konstituierenden Sitzung der Abteilung für Dichtung anwesenden Dichter sind sich darüber einig, daß sie sich unter Anerkennung der jetzigen Rechtsgrundlage als den Beginn der Deutschen Akademie der Dichtung ansehen und den Herrn Minister bitten, mit den Ministerien der anderen Länder wegen dieser Umbildung Fühlung zu nehmen."

$V$ esper begründet diese Entschließung eingehender. Er weist darauf hin, daß die Frage der Alsademie eingeschlossen sei in die größere Frage eines Reichskultusministeriums. Wünschenswert sei, daß das Preußische Kultusministerium sich zu einem solchen entwickle. Darum liege es uns fern, uns von ihm zu lösen, und darum sei es wesentlich, daß wir unseren Wunsch in der beantragten Form aussprächen. Beide Entschließungen werden von der Versammlung durch Akklamation gebilligt.

Stehr bittet, ihn von der Leitung der Sitzung aus persönlichen Gründen zu entheben, und exörtert die Frage, ob man sofort zum zweiten Punkt der Tagesordnung: „Wahl des Vorsitzenden und seines Stellvertreters" schreiten solle. Ponten bittet, von der endgültigen Wahl des Vorsitzenden noch Abstand zu nehmen, denn man müsse sich doch erst über Satzung und Organisationsform klar sein. Er schlägt vor, für die laufende Sitzungszeit Schäfer zum Vorsitzenden zu wählen, da Stehr aus persönlichen Gründen zurücktreten wolle. Die Versammlung wählt mit Einstimmigkeit Schäfer zum Vorsitzenden bis zur Wahl des endgültigen Vorsitzenden.

Prof. v. Schillings, der vorübergehend noch einmal an der Sitzung teilnimmt, bittet die Versammelten, den Blickpunkt immer auf das Wesentliche gerichtet zu halten. Es sei unmöglich, sich in nutzlose Debatten zu verlieren, und es müsse praktische Arbeit geleistet werden, wobei man den Rahmen der Gesamtakademie nicht aus dem Auge lassen dürfe. Schäfer stimmt dieser Auffassung zu. Es sei nicht unsere Absicht, in großartiger Form abzuspringen und dabei den Boden zu verlieren. Es entspinnt sich eine kurze Debatte über die finanziellen Mittel, die der Akademie zur Verfügung stehen. Diese Frage soll baldigst geklärt werden. Darauf wird die allgemeine Aussprache fortgesetzt.

Kolbenheyer entwickelt in längeren Ausführungen einen von ihm ausgearbeiteten Plan für die Satzung einer Deutschen Akademie der Dichtung. Im Mittelpunkt dieses Plans steht die Festlegung der Stellung und der Befugnisse des Senats und die Schaffung eines Mittlertums für die deutsche Dichtung, das in irgendeiner organisatorischen Form der Akademie zu praktischer Arbeit und größerer Wirksamkeit ange- 
gliedert werden soll. Im Anschluß daran entwickelt sich eine erste Aussprache über die Gedanken Kolbenheyers, insbesondere über den Vorschlag des Mittlertums.

v. Münchhausen schlägt Vertagung der Sitzung auf morgen vor. Dagegen erhebt sich zahlreicher Widerspruch. $v$. Scholz bezeichnet die Wahl des Vorsitzenden als das Wichtigste und stellt den Antrag, diese Wahl unverzüglich vorzunehmen. Grimm schließt sich diesem Antrag an. Der Antrag wird mit 16 von 22 vorhandenen Stimmen angenommen. Prof. Amersdorffer weist darauf hin, daß gleichzeitig auch der Stellvertreter des Vorsitzenden gewählt werden müsse. Nach weiterer Erörterung schlägt Grimm vor, eine Mittagspause eintreten zu lassen und nach dieser Pause unmittellar zur Wahl des 1. Vorsitzenden, seines Stellvertreters und des Schriftführers zu schreiten. Im Anschluß daran werden von einzelnen Mitgliedern der Akademie bestimmte Mitglieder für die Stelle des 1. Vorsitzenden vorgeschlagen. Die Vorschläge betreffen Hanns Johst, Wilhelm Schäfer, Kolbenheyer und Hans Grimm. Hans Grimm lehnt für seine Person einen Vorsitz ab.

Blunck erörtert die Frage, daß ebenso wichtig wie die Wahl des Vorstandes die Bestimmung eines Arbeitsausschusses sei, der nach den Vorschlägen von Kolbenheyer und eventuellen anderen Vorschlägen die Satzung der Akademie zu formulieren habe. Halbe tritt ebenfalls für die Notwendigkeit ein, einen Ausschuß, ein kleineres Kollegium zu bilden, damit endlich fruchtbare Arbeit geleistet werde. Stehr ist ebenfalls für den Ausschuß. Grimm schlägt vor, daß dieser Ausschuß, der in der Nachmittagssitzung zu bestimmen sei, nach Möglichkeit so rasch arbeite, daß die Versammlungु noch im Laufe des morgigen Tages zu seinen Arbeiten Stellung nehmen könne. Blunck schlägt die folgende Entschließung vor: „1. Die Preußische Akademie der Künste, Abteilung für Dichtung, wählt einen Ausschuß zur Prüfung der Statuten. 2. Der Ausschuß wird den Vorschlag des Herrn Dr. Kolbenheyer und die im Verlauf der Debatte gegebenen weiteren Anregungen prüfen und wird beauftragt, dem Herrn Minister die formulierten Vorschläge vorzutragen. "Es wird in diesem Sinne beschlossen, worauf die Mittagspause eintritt.

Um 4.15 Uhr nachmittags wird die Sitzung wieder eröffnet.

Anwesend sind: v. Scholz, v. Molo, Binding, Ponten, Stucken, Niegel, Benn, Halbe, Beumelburg, v. Münchhausen, Strauß, Kolbenheyer, Schäfer, Johst, Loerke, Seidel, Grimm, Blunck, Vesper, Stehr, Dörfler, Griese; Amersdorffer.

Schäfer legt aus persönlichen Gründen den Vorsitz nieder. Nach Zustimmung der Versammlung übernimmt Binding den Vorsitz und schlägt vor, nach dem Beschluß der Vormittagssitzung die Wahl des Vorstandes vorzunehmen, wobei er bittet, auf die am Vormittag genannten Namen keine Rücksicht zu nehmen.

v. Münchhausen schlägt Blunck als 1 . Vorsitzenden vor. Binding möchte, daß einzelne Namen vor der Abstimmung nicht mehr genannt werden. Stehr schlägt vor, den 1. Vorsitzenden durch Zettel, den 2. auf Vorschlag des 1. Vorsitzenden durch Akklamation und den Schriftführer durch Akklamation zu bestimmen. Ponten bittet, die Wahl auszusetzen, bis die Frage geklärt sei, auf welche Zeit der Vorstand gewählt werde. Binding bezeichnet die Entscheidung dieser Frage als Aufgabe des nachher zu wählenden Satzungsausschusses. Schäfer sagt, er sei nach Berlin gekommen unter der Voraussetzung, daß hier die deutschen Dichter zusammengetreten seien, um die Aufgaben der Akademie festzulegen. Erst wenn das geschehen sei, könne man den Vorstand wählen. Binding lehnt diese Auffassung ab.

v. Scholz betont, daß, solange kein neues Statut angenommen sei, das alte Statut in Geltung bleibe. Nach diesem Statut regele sich also auch die Zeitdauer, für die der neue Vorstand gewählt werde. Binding stellt fest, daß auch für diesen Punkt der Minister der Akademie volle Autonomie zugesichert habe, und bezeichnet noch einmal die Wahl des Vorsitzenden als unbedingt dringend, weil sie der neubegründeten 
Akademie das Gesicht gäbe. Schäfer bestreitet die Auffassung von Scholz, nach welcher es angängig sei, den Vorsitzenden im Rahmen der bisherigen Statuten zu wählen. Binding tritt dann in die Wahl des 1 . Vorsitzenden ein, die durch Zettelabstimmung geschehen soll. v. Münchhausen und Stehr erklären, daß sie aus persönlichen körperlichen Gründen eine etwaige Wahl nicht annehmen können.

Anwesend sind 23 Stimmen. Im ersten Wahlgang erhalten: Johst 7 Stimmen, Blunck 4. Stimmen, Schäfer 4 Stimmen, Grimm 3 Stimmen, Gerhart Hauptmann 2 Stimmen, Kolbenheyer 1 Stimme, Binding 1 Stimme, 1 Zettel unbeschrieben.

Im zweiten Wahlgang ist also zu entscheiden zwischen Johst, Blunck und Schäfer. Das Ergebnis ist folgendes: Johst 14 Stimmen, Blunck 6 Stimmen, Schäfer 2 Stimmen, 1 Zettel unbeschrieben.

Binding stellt fest, daß damit Hanns Johst zum 1. Vorsitzenden gewählt ist. Johst schlägt vor, Blunck durch Akklamation zum 2. Vorsitzenden zu wählen und Vesper zum Schriftführer. Vesper lehnt für seine Person ab. Johst schlägt darauf Beumelburg zum Schriftführer vor. Blunck wird bei 2 Stimmenenthaltungen einstimmig durch Akklamation zum 2. Vorsitzenden gewählt. Beumelburg wird einstimmig durch Akklamation dem Minister als dem Kurator der Akademie zur Ernennung zum Schriftführer vorgeschlagen. Binding übergibt den Vorsitz an Johst.

Johst dankt für das ihm entgegengebrachte Vertrauen und nimmt die Wahl zum 1. Vorsitzenden an. Er betont, daß er seine Wahl als eine ganz unpersönliche Angelegenheit auffasse, als ein Bekenntnis der deutschen Dichter zu gewissen Prinzipien der nationalsozialistischen Idee, mit denen er verhaftet sei, und als einen starken Ausdruck dafür, daß niemand das Recht habe, die Nationalsozialisten als Barbaren zu bezeichnen. Persönlich bittet er, bei der Fortsetzung der Arbeiten sein Tempo und sein Temperament zu berücksichtigen. Praktische Arbeit sei etwas anderes als Diskussion. Darauf erteilt er dem neuen Schriftführer das Wort. Beumelburg dankt für seine Person ebenfalls für das Vertrauen, das man ihm entgegenbringe. Wenn er dieses Amt annehme, so geschehe das unter der Bedingung, daß von nun an und sofort praktische Arbeit geleistet werde. Er schlägt dann die Bildung von 7 Ausschüssen vor. 1. Ausschuß: zur Durchberatung und Formulierung der neuen Satzung aufgrund der Anregungen des Herrn Kolbenheyer.

2. Ausschuß: Buchhandel, Leihbücherei, Presse des Inlandes, Rundfunk, Film und Theater.

3. Ausschuß: Berufsständische Organisationsfragen, Pflege des dichterischen Nachwuchses, künstlerischer Arbeitsvertrag, Urheberrecht, Schaffung eines Katalogs über das deutsche Schrifttum, Verhältnis der Akademie zu anderen schriftstellerischen Organisationen.

4. Ausschuß: zur Behandlung aller Fragen, die die deutsche Sprache betreffen, worunter auch die Beziehungen der Akademie zum Sprachverein pp. zu betrachten seien.

S. Ausschuß: zur Behandlung aller Fragen, die sich aus den Beziehungen des deutschen Dichtertums zum Ausland ergeben, worunter auch die Auslandspresse zu verstehen sei.

6. Ausschuß: Fragen des Unterrichts, soweit sie Schulen und Hochschulen betreffen, und alle Fragen, die sich unter dem Begriff der Heranführung der deutschen Dichtung an die deutsche Jugend zusammenfassen lassen.

7. Ausschuß: zur Prüfung und Bearbeitung aller finanziellen Angelegenheiten und zur besonderen Erörterung der Frage einer Kulturabgabe.

Der 1. Vorsitzende Johst schlägt vor, daß man, bevor man die Frage der Ausschüsse zu einem Abschluß bringe, zunächst die Wahl des Senats der Akademie vornehme. Amersdorffer entwickelt die Aufgaben und die Befugnisse des Senats als einer be- 
ratenden Stelle des Ministers. v. Scholz schlägt vor, daß man in der Weise verfahre, $\mathrm{da} \beta$ der 1. Vorsitzende, sein Stellvertreter und der Schriftführer, die aus amtlicher Befugnis dem Senat angehören, die weiteren Senatoren zur Wahl vorschlügen. Johst macht eine Reihe von Herren namhaft, die er bittet, sich mit ihm zu einer internen Beratung über die Frage des Senats in ein besonderes Zimmer zu begeben. Es sind dies die Herren Johst, Grimm, Schäfer, Stehr, Kolbenheyer, v. Münchhausen, Strauß, Frau Miegel, Blunck und Beumelburg. Die Sitzung des Plenums wird für die Dauer dieser internen Beratung unterbrochen.

Nach ihrer Beendigung und nach Wiedereröffnung der Plenarsitzung trägt der Schriftführer den Beschluß dieser internen Beratung vor. Zur Wahl in den neuen Senat werden vorgeschlagen: Johst, Grimm, Schäfer, Stehr, Kolbenheyer, v. Münchhausen, Strauß, Frau Miegel, Blunck und Beumelburg. Dieser Vorschlag wird von der Versammlung durch Akklamation genehmigt. Sodann wird in die Beratung über die Frage der Arbeitsausschüsse eingetreten.

Der Vorsitzende schlägt zur Leitung der einzelnen Ausschüsse die folgenden Herren vor: 1. Ausschuß: Kolbenheyer; 2. Ausschuß: Vesper; 3. Ausschuß: Binding; 4. Ausschuß: v. Münchhausen; 5. Ausschuß: Grimm; 6. Ausschuß: Griese; 7. Ausschuß: Strauß. Es wird in diesem Sinne von der Versammlung beschlossen. Weiter wird beschlossen, daß jeder Leiter eines Ausschusses die Befugnis hat, nach eigenem Ermessen andere Mitglieder der Akademie zur Mitarbeit heranzuziehen. Von Amts wegen gehören der 1. Vorsitzende, sein Stellvertreter und der Schriftführer jedem einzelnen Ausschuß an. Die Zahl der Ausschußmitglieder soll möglichst eng gehalten werden.

Die Versammlung tritt sodann in eine grundsätzliche Erörterung der Vorschläge Kolbenheyers für die neue Satzung der Akademie ein. Kolbenheyer spricht in längeren Ausführungen über seinen Plan eines Mittlertums. Grimm befürchtet, daß man sich durch die Schaffung dieses Mittlertums und durch seine Angliederung an die Akademie im Sinne des Kolbenheyerschen Vorschlags von dem Grundgedanken der Akademie entferne. Binding stimmt Kolbenheyer im Grundsatz zu, möchte aber eine andere Form der Heranziehung des Mittlertums haben.

$V$ esper stellt zur Erörterung, ob es überhaupt die Absicht der Versammlung sei, die Akademie zu erweitern, wenn ja, ob es sich dann um eine Erweiterung ausschließ3lich durch neue Dichter handle, oder um eine Erweiterung auch durch Schriftsteller und Publizisten, oder schließlich um eine Erweiterung auch durch Männer aus praktischen Berufen, wie es der Vorschlag Kolbenheyers vorsehe. Johst stellt Vespers formulierten Vorschlag zur Abstimmung. Die Abstimmung ergibt, daß die Versammlung für eine prinzipielle Erweiterung durch Hinzuziehung anderer Dichter stimmt, daß sie aber gegen eine Erweiterung der Akademie durch Schriftsteller und Publizisten und gegen eine solche Erweiterung durch Männer des praktischen Lebens in irgendeiner Form ist. Blunck bezeichnet das Arbeitsgebiet der neuen Akademie als so ungeheuer groß, daß man im Grundsatz den Kolbenheyerschen Gedanken eines Mittlertums nur annehmen könne. Ebenso wichtig aber sei es, die Heiligkeit des Grundsatzes der Akademie zu wahren. Er halte es für den gangbarsten Weg, wenn die einzelnen Kommissionen von sich aus Sachverständige aus Kreisen des praktischen Lebens heranzögen und wenn man diese Herren als Sachverständige der Akademie auch offiziell bezeichne.

Kolbenheyer macht streng vertrauliche Ausführungen über die Ressortverteilung zwischen den Zentralbehörden in den Angelegenheiten des deutschen Dichtertums. Amersdorffer schlägt für die geplanten Sachverständigen den Titel „Beisitzer der Akademie" vor. Johst stellt noch einmal fest, daß diese Beisitzer von den Leitern der Arbeitsausschüsse vorgeschlagen und dann durch den Senat ernannt werden sollen. 
Kolbenheyer ist dafür, daß die Ernennung durch den Minister auf Vorschlag des Senats vorgenommen werden soll. Die Versammlung beschließt in diesem Sinne.

Sodann wird in die Erörterung der Zuwahlen zur Akademie eingetreten. Aus der Versammlung heraus werden im einzelnen folgende deutsche Dichter vorgeschlagen: Schaffner, Claudius, Ernst Jünger, Hans Franck, Magnus Wehner, Winkler, Kneip, Rudolf Huch, Isolde Kurz, Gustav Frenssen, Frau Handel-Mazzetti, Wilhelm Stapel, Watzlik, von Gagern, Stickelberger, Hohlbaum, Heinrich Wolfgang Seidel, Mechel, Schröder, Hermann Burte, Pudolf Paulsen, Friedrich Schnack, Meschendörfer, Wilhelm Wiegand, Johannes Schlaf, Heinrich Lersch, Lilienfein, Lulu von Strauss und Torney, Paula Grogger, Karl Röttger.

Johst stellt zur Erörterung, wie hoch man die Zahl der Akademiemitglieder äußerst beschränken will. Die Versammlung beschließt, die Zuwahl von 5 IMitgliedern vorzunehmen. Es entspinnt sich eine Erörterung darüber, ob man die Zuwahlen sofort oder später vornehmen solle. 16 von den vorhandenen Stimmen sind für sofortige Erledigung. Es wird zur Wahl geschritten. In einem einzigen Wahlgang nach dem Grundsatz der relativen Majorität werden folgende Stimmen abgegeben: Jakob Schaffner 13 Stimmen, Gustav Frenssen 9 Stimmen, Isolde Kurz 9 Stimmen, Magnus Wehner 8 Stimmen, Ernst Jünger 5 Stimmen. Die übrigen Stimmen sind zersplittert.

Johst weist darauf hin, daß diese Wahlen einstweilen eine vertrauliche Angelegenheit seien, da der Minister als Kurator das Recht habe, die Neugewählten zu berufen. Er setzt die nächste Vollversammlung für den kommenden Morgen 10 Uhr vormittags an. Die Sitzung wird darauf geschlossen.

\section{Vollversammlung vom 8. Juni 1933, vormittags $10 \mathrm{Uhr}$}

Anwesend sind: Johst, Beumelburg, Blunck, Vesper, Griese, Dörfler, Miegel, Seidel, v. Molo, v. Münchhausen, Ponten, Binding, Halbe, v. Scholz, Stehr, Kolbenheyer, Strauß, Grimm, Schäfer.

Der 1. Vorsitzende Johst exöffnet die Sitzung um 10.15 Uhr. Er weist darauf hin, daß für die kommenden Verhandlungen eine strengere Disziplin nötig sei. Vor allem habe jedes persönliche Moment auszuscheiden. Wenn einer gereizt sei, so möge er sich hier drinnen im Saale Luft machen, aber nicht nach draußen. Die Grundsätze der neuen Zeit verlangten, daß Geräusche nach außen vermieden würden, auch in der Presse. Man müsse sich darüber klar sein, daß eine Schweigepflicht für alle Mitglieder der Akademie insofern bestehe, daß niemand das Recht habe, über interne Vorgänge nach außen zu berichten, und daß die Kontrolle derartiger Veröffentlichungen in den Händen des Schriftführers oder des Vorsitzenden der 2. Kommission läge.

Die Versammlung beschließt sodann die Absendung dreier Telegramme an den Herrn Reichspräsidenten, den Herrn Reichskanzler und den Herrn Preußischen Minister für Wissenschaft, Kunst und Volksbildung.

$V$ esper trägt vor, daß er gewisse Bedenken gegen die gestrige Wahl neuer Mitglieder habe. Er bedauere, daß der eine oder der andere nicht hinzugewählt worden sei. Man müsse großzügig sein. Er schlägt die Wahl weiterer 5 Mitglieder vor, und zwar: Lersch, Johannes Schlaf, Frau Handel-Mazzetti, Stickelberger und Watzlik. Binding hat keine prinzipiellen Bedenken, wohl aber Bedenken gegen die Wahl von Stickelberger.

v. Münchhausen stimmt dem Grundsatz, eine weitere Zuwahl vorzunehmen, zu und hat ebenfalls Bedenken gegen den technischen Wahlgang vom gestrigen Tage. Ihm errege ebenso die stärkere Berücksichtigung der Jüngeren gewisse Bedenken, denn die Mitgliedschaft der Akademie sei eine Würde und eine Auszeichnung. Von diesem Gesichtspunkt gehörten in erster Linie Stefan George, Thomas Mann und Ricarda Huch zu uns. Ein gewisser Formalismus sei nötig, und es sei zu erwägen, ob man 
nicht die Mitgliedschaft der Akademie von einem bestimmten Lebensalter, etwa von 50 Jahren, abhängig machen solle. Johst meint, die Erörterung einer solchen Frage gehöre in die 1. Kommission. v. Münchhausen präzisiert seine Bedenken gegen Stickelberger und Watzlik, auch gegen Lersch. Entscheiden dürfe nur der Wert der künstlerischen Leistung. Er sei von den Genannten für Rudolf Huch und Frau HandelMazzetti.

Halbe stimmt Vesper im Grundsatz zu. Auch er hat Bedenken gegen die gestrige Wahl. Das Prinzip der relativen Majorität sei bei einem solchen Falle unmöglich anzuwenden. Er bittet, die gestrige Wahl zu revidieren und eine Nachwahl vorzunehmen. Er persönlich sei gegen Stickelberger und Watzlik, aber für Rudolf Huch, Handel-Mazzetti und Johannes Schlaf, dessen Fehlen in der Liste der Neuvorgeschlagenen er von Anfang an bedauert habe. Johst stellt fest, daß die gestrige Wahl jedenfalls bestehen bleibe.

Ponten erörtert ebenfalls seine Bedenken gegen den gestrigen Vorgang und ist gegen eine Erweiterung der Akademie auf 40 Mitglieder insgesamt. Persönlich stimmt er für die Zuwahl von Rudolf Huch, Johannes Schlaf und Frau Handel-Mazzetti. Kolbenheyer schlägt vor, die Abstimmung über die drei Genannten sofort vorzunehmen, die Höchstzahl der Mitglieder auf 40 festzusetzen und dann im Rahmen der noch vorhandenen Sitze über die übrigen Genannten einzeln Beschluß zu fassen. In den nachfolgenden Einzelwahlen werden sodann Johannes Schlaf, Frau Handel-Mazzetti und Rudolf Huch als neue Mitglieder in die Akademie gewählt.

Blunck bittet dringend, auch die jüngere Generation zu berücksichtigen. Er schlägt Lersch und Hermann Claudius vor. Von verschiedenen Seiten werden Bedenken gegen die Vornahme weiterer Zuwahlen geäußert. Kolbenheyer beantragt Schluß dieser Debatte und stellt Claudius zur Wahl. Ponten protestiert gegen dieses Verfahren. Schäfer hält Lersch für ebenso würdig wie Claudius und schlägt die Zuwahl beider vor. Johst stellt diesen Vorschlag zur Wahl, der durch Akklamation der Versammlung gebilligt wird. Ponten gibt seinen Protest gegen dieses Verfahren zu Protokoll. Durch die Wahl gelten als gewählt: Johannes Schlaf, Frau Handel-Mazetti, Rudolf Huch, Hermann Claudius und Heinrich Lersch. Die Frage der Neuwahlen wird damit abgeschlossen und die Erörterung über allgemeine Fragen wird fortgesetzt.

Ponten gibt zwei Anregungen. 1. Man müsse einmal im Jahre regelmäßig zusammenkommen, etwa in der dritten Oktoberwoche, aus praktischen Gründen. 2. erörtert er die Frage des Namens „Deutsche Akademie der Dichtung“. Binding erörtert die Frage der Autonomie. Kolbenheyer stellt fest, daß wir zunächst dem Preußischen Kultusminister als Kurator der Akademie unterstellt seien. Bei einer Erweiterung der Akademie über ganz Deutschland müßten natürlich die übrigen Kultusminister zugezogen werden, am zweckmäßigsten unter dem Vorsitz des Preußischen Ministers. Binding und Johst erklären sich mit dieser Auffassung einverstanden. Kolbenheyer schneidet noch einmal die Frage der Befugnisse der Arbeitsausschüsse an. Ponten stellt den Antrag auf offizielle Namensgebung und schlägt den Namen vor: „Deutsche Akademie der Dichtung". Die Versammlung nimmt diesen Vorschlag einstimmig an. Sodann ergibt sich eine Erörterung über eine gegen Deutschland gerichtete Publikation von Romain Rolland. Soll die Akademie als Ganzes antworten? Soll sie ein einzelnes Mitglied zu einer Antwort im Namen der Akademie autorisieren, oder soll sie es einzelnen Mitgliedern überlassen zu antworten? Auf Vorschlag des Vorsitzenden wird der Grundsatz angenommen, daß die Akademie als Gesamtheit nur dann antworten solle, wenn sie als solche angegriffen wird. Im vorliegenden Falle käme also nur der Grundsatz privater Erwiderung in Frage.

Kolbenheyer stellt noch einmal fest, daß es sich bei den Arbeiten der Ausschüsse um etwas Endgültiges handeln müsse. Wichtige Winke für diese Arbeiten müßten heute 
schon gegeben werden. Grimm hat gegen eine solche Auffassung Bedenken. Für ihn seien die Satzungen Glaubensartikel, zu denen er erst in dem Augenblick ihrer endgültigen Formulierung ja oder nein sagen könne. Johst stellt fest, daß es sich bei den Ausschußarbeiten um große und wichtige Dinge handle und daß wir zu den Herren, die diese Arbeiten durchführen sollen, unbedingtes Vertrauen haben müßten. Die Größe und Schwierigkeit würde erst dann einsetzen, wenn es sich darum handle, die Ergebnisse der Ausschußarbeiten zu verwirklichen. Wir müßten bereit sein, den Ausschüssen das Recht der Protestes zu geben. Mit diesem Grundsatz sei es vollkommen zu vereinigen, daß jeder für sich das Recht und die Pflicht zu schöpferischen Anregungen habe. Grimm hält gleichwohl seine Bedenken aufrecht. v. Münchhausen schließt sich diesen Bedenken an. Johst stellt fest, daß es keinem Mitglied der Akademie benommen sei, seine Bedenken zu äußern und seine Einwände vorzubringen.

Grimm fragt, wer das Recht der endgültigen Entscheidung über die Satzung habe. Kolbenheyer beansprucht dieses Recht für den Senat. $v$. Scholz widerspricht. Der Senat habe nur eine technische Funktion. Es sei nicht angängig, aus dem Gesamtkreis der Akademie heraus noch einmal eine besondere Elite zu bilden. Blunck präzisiert die Aufgaben des Senats als eines kleinen praktischen Arbeitsausschusses, der bei jeder dringenden Gelegenheit sofort zur Stelle sein könne.

Kolbenheyer beantragt, daß die Wahl der Senatoren auf Lebenszeit gelte. Strau $\beta$ ist der Meinung, daß sich die zeitliche Regelung ganz von selbst ergebe und daß es nicht nötig sei, eine zeitliche Beschränkung vorzunehmen. Johst stellt fest, daß man sein Vertrauen nicht für eine beschränkte Frist ausspräche, es sei ein falsches Verfahren, wenn wir den Senat der liberalistischen Weltanschauung ausliefern wollten. $v$. Scholz beantragt Abstimmung darüber, ob die Senatoren lebenslänglich oder für drei Jahre gewählt seien. Binding schlägt vor, daß der Senat mit dem gleichen Turnus wie der Vorsitzende wechsle. Blunck hält innerhalb der Gesamtakademie eine Einrichtung für notwendig, die von Zeitströmungen nicht abhängig sei. Kolbenheyer sagt, wenn man den Senat nicht als dauernde Einrichtung bestelle, so trete er aus ihm aus. Johst betont noch einmal, daß es sich hier um eine neue Form handle. Er stellt noch einmal fest, daß die Senatoren auf seine eigene Anregung und seine eigene Verantwortung hin gewählt worden seien, daß sie also in Funktion blieben, solange er es auch blieb. Kolbenheyer beantragt, den Senat für lebenslänglich zu erklären und zu bestimmen, daß der Vorsitzende immer aus den Reihen des Senats gewählt werde. Johst bittet, die Diskussion über dieses Thema heute abzuschließen. Senator sein bedeute lediglich eine größere Belastung, keine größere Ehrung. Es handle sich hier um ein Prinzip und ein Symbol, und er wehre sich dagegen, daß etwas, was gestern schweigend hingenommen worden sei, heute wieder zur Diskussion gestellt werde. Kolbenheyer betont, daß es ja innerhalb der eigenen Befugnis des Senats stehe, da $\beta$ er sich ändere. Johst schlägt vor, man müsse die lebendige Entwicklung der Dinge zunächst abwarten. Die Diskussion über diesen Punkt wird damit geschlossen.

Kolbenheyer bringt noch einmal das Thema des Mittlertums für die Akademie zur Sprache und schlägt für diesen Kreis den Titel „Ständige Kammer der Beiräte“ vor. Die Mitglieder dieser Kammer seien vom Senat zu bestätigen. Der Vorschlag Kolbenheyers wird in dieser Fassung von der Versammlung gebilligt.

Johst schließt darauf die Sitzung des Plenums. Er betont, daß es sich bei den Verhandlungen und bei der freimütigen Aussprache herausgestellt habe, daß im Grunde alle Mitglieder das Gleiche wollten und fordert die Herren auf, mit dieser Gesinnung ins Land hinauszugehen und für sie zu werben. Die Akademie stehe jetzt ganz anders im Volke als früher.

Die Sitzung wird darauf geschlossen.

Johst

Beumelburg 
63 Am 8. Juni 1933 wurden von der Akademie der Künste, Abteilung für Dichtung folgende Telegramme aufgegeben:

\section{An den Herrn Reichspräsidenten von Hindenburg.}

Die Deutsche Akademie der Dichtung grüßt am Tage ihrer Erneuerung den Herrn Reichspräsidenten im Namen des gesamten deutschen Schrifttums in herzlicher Verehrung und in Verbundenheit mit dem neuen, dem alten ewigen Deutschland.

Der Vorsitzende: Hanns Johst

\section{An den Herrn Reichskanzler Adolf Hitler}

Die Deutsche Akademie der Dichtung wünscht am Tag ihrer Exöffnung dem Herrn Reichskanzler als Führer des neuen Deutschland ihre Huldigung und den Ausdruck ihrer lebendigen Verbundenheit zum Ausdruck zu bringen.

Der Vorsitzende: Hanns Johst

\section{An den Herrn Kultusminister Rust}

Die Deutsche Akademie der Dichtung dankt am Tage ihrer Erneuerung dem Herrn Kultusminister als ihrem Kurator für allen vergangenen und zukünftigen Beistand bei der Vertretung der Interessen der Akadernie und des gesamten deutschen Schrifttums.

Der Vorsitzende: Hanns Johst

64 Amtlicher Preußischer Pressedienst -4- Berlin, den 9. Juni 1933: Tagung der Deutschen Akademie der Dichtung.

APP. Der Amtliche Preußische Pressedienst teilt mit: Am 7. und 8. Juni tagte in Berlin die exneuerte Abteilung für Dichtkunst in der Preußischen Akademie der Künste. Kultusminister Rust als Kurator und Max von Schillings als Präsident der Gesamtakademie eröffneten die Gründungsversammlung. In freimütiger EntschlieBung sicherte Kultusminister Rust der Abteilung für Dichtkunst bei ihrem weiteren Ausbau und Aufbau volle Selbständigkeit zu.

Die Mitglieder der Akademie beschlossen darauf einmütig, sofort die Durchführung jener Aufgabe in Angriff zu nehmen, die nach übereinstimmender Auffassung aller Mitglieder die wichtigste Vorbedingung einer wirkungsvollen Arbeitsleistung ist: den Ausbau der Abteilung für Dichtkunst zu einer allgemeinen deutschen Akademie der Dichtung.

Die Abteilung für Dichtkunst vereint in sich die deutschen Dichter aller Volksstämme. Aus dem betont außervölkischen Zustande ihrer früheren Zusammensetzung ist sie zu einem volksbewußten und artgerechten Lebenskörper umgebaut worden. Daher darf und will sie auch in ihrer Entwicklung der lebendigen Entwicklung des Reiches Ausdruck verleihen und erklärt sich, unter Wahrung der bisherigen Rechtsgrundlage, reichszuständig als die Deutsche Akademie der Dichtung. Die nächsten Arbeiten der Deutschen Akademie der Dichtung werden ihrer organisatorischen und rechtlichen Durchbildung gewidmet sein.

Die Deutsche Akademie der Dichtung hat zurzeit folgende Mitglieder: Hermann Bahr, Gottfried Benn, Rudolf G. Binding, Werner Beumelburg, Hans Friedrich Blunck, Theodor Däubler, Peter Dörfler, Friedrich Griese, Hans Grimm, Max Halbe, Gerhart Hauptmann, Hanns Johst, Erwin Guido Kolbenheyer, Oskar Loerke, Max Mell, Agnes Miegel, Waltex von Molo, Börries von Münchhausen, Josef Ponten, Wilhelm Schäfer, Wilhelm Schmidtbonn, Karl Schönherr, Wilhelm von Scholz, Ina Seidel, Hermann Stehr, Emil Strauß, Eduard Stucken, Will Vesper. Zur Berufung in die Akademie der Dichtung sind ferner gewählt worden: Hermann Claudius, 
Gustav Frenssen, Enrica von Handel-Mazzetti, Rudolf Huch, Ernst Jünger, Isolde Kurz, Heinrich Lersch, Johannes Schlaf, Josef Magnus Wehner. ${ }^{1}$

Ferner wurde die Berufung einer ständigen Kammer der Beiräte der Akademie für Dichtung beschlossen.

Zum ersten Vorsitzenden der Deutschen Akademie der Dichtung wurde gewählt Hanns Johst, zum zweiten Vorsitzenden Hans Friedrich Blunck, zum Schriftführer Werner Beumelburg. Zu Senatoren wurden bestimmt: Werner Beumelburg, Hans Friedrich Blunck, Hans Grimm, Hanns Johst, Erwin Guido Kolbenheyer, Agnes Miegel, Börries von Münchhausen, Wilhelm Schäfer, Hermann Stehr und Emil Strauß. Durch ihre innere und äußere Neugestaltung hofft die Akademie der deutschen Dichtung, ihrem Volke besser und wirksamer die Erlebniswerte zu wahren, zu steigern und zu vermitteln, die das deutsche Volk zu seinem Wiederaufbau aus den Werken der Meister seines Schrifttums schöpfen kann.

Preußische Akademie der Künste, Berlin W 8, Pariser Platz 4, den 10. Juni 1933

An die Pressestelle des Preußischen Staatsministeriums, Berlin W 8, Wilhelmstraße 63/64 - Vertraulich! -

Im Amtlichen Preußischen Pressedienst vom 9. d.Mts. findet sich eine längere Notiz „Tagung der Deutschen Akademie der Dichtung". Ich wäre dankbar für eine baldgefällige Auskunft darüber, auf welchem Wege und durch wen der Text dieser Notiz an die Pressestelle gelangt ist und bemerke, daß mir und dem zur Zeichnung berechtigten Ersten Ständigen Sekretär über die Absendung dieser Notiz nichts bekannt war. Ich habe erst aus den Zeitungen von ihr Kenntnis erhalten. Schon jetzt darf ich bemerken, daß zur Versendung von Pressenotizen, die die Alkademie oder deren Abteilungen betreffen, natürlich nur der Präsident als Leiter der Akademie oder der von ihm beauftragte Erste Ständige Sekretär befugt sind.

Der Präsident

Max von Schillings

Pressestelle des Preußischen Staatsministeriums, Berlin W 8, Wilhelmstraße 64, den 12. Juni 1933 - J.Nr.A. 592

An den Herrn Präsidenten der Preußischen Akademie der Künste, Herrn Professor Dr. Max von Schillings, Berlin W 8, Pariser Platz 4

Auf das Schreiben vom 10. d.Mts. betreffend die Notiz "Tagung der Deutschen Akademie der Dichtung" im Amtlichen Preußischen Pressedienst rom 9. d.Mts. wird ergebenst mitgeteilt, daß der Text der Notiz der Pressestelle des Preußischen Staatsministeriums vom Preußischen Ministerium für Wissenschaft, Kunst und Volksbildung zur Veröffentlichung übermittelt worden ist. Da die Notiz in der üblichen Form mit der persönlichen Unterschrift des Pressereferenten, Ministerialrat Sunkel, hier einging, konnte nicht angenommen werden, daß gegen ihre Veröffentlichung irgendwelche Bedenken bestehen konnten.

i. V. Dr. Kunckel

Regierungsrat

1 In diesex Presseerklärung ist der Name des ebenfalls gewählten Jakob Schaffner vergessen worden (vgl. Dok. Nr. 71). Im Unterschied zu den in der Sitzung vom 5. 5. 1933 gewählten 14. Mitgliedern ist für die in der Sitzung vom 7./8. 6. 1933 gewählten keine Berufung durch den Minister nachweisbar. Noch im Januar 1934 teilt der Vorstand mit, daß diese Berufung ausstehe (vgl. Dok. Nr. 90). Die 10 Gewählten werden aber in den Alkten als ordentliche Mitglieder der Abteilung für Dichtung geführt. 
67 Ernst Jünger, Berlin-Steglitz, Hohenzollernstraße 6 pt., den 16. 11. 33

An die Deutsche Akademie der Dichtung, Berlin

Ich beehre mich, Ihnen mitzuteilen, daß ich die Wahl in die Deutsche Akademie der Dichtung nicht annehmen kann. Die Eigenart meiner Arbeit liegt in ihrem wesentlich soldatischen Charakter, den ich durch akademische Bindungen nicht beeinträchtigen will. Im besonderen fühle ich mich verpflichtet, meine Anschauungen über das Verhältnis zwischen Rüstung und Kultur, die ich im 59. Kapitel meines Werkes über den Arbeiter niedergelegt habe, auch in meiner persönlichen Haltung zum Ausdruck zu bringen. Ich bitte Sie daher, meine Ablehnung als ein Opfer aufzufassen, das mir meine Teilnahme an der deutschen Mobilmachung auferlegt, in deren Dienst ich seit 1914 tätig bin.

Mit der Versicherung, daß ich bereits in der Tatsache, daß Sie an mich gedacht haben, eine hohe Auszeichnung erblicke,

Ihr sehr ergebener Ernst Jünger

67a Preußische Akademie der Künste, Berlin W 8, Pariser Platz 4, 18. November 1933 J.Nr. 1232

Sehr geehrter Herr Jünger, ich habe von Ihrem Schreiben vom 16. d. Mts. an die Akademie Kenntnis genommen. Eine Ablehnung Ihrer Berufung in die Deutsche Akademie der Dichtung wäre erst in Frage gekommen, sobald der Kurator der Akademie diese Berufung Ihnen amtlich mitgeteilt hätte. Ich werde dem Kurator eine entsprechende Mitteilung machen und bin Ihnen dankbar, daß Sie mich in die Lage versetzen, eine Ihnen unerwünschte Berufung zu verhindern.

Der Präsident der Deutschen Akademie der Dichtung

Im Auftrage Beumelburg

67b Ernst Jünger, Berlin-Steglitz, 18. 11. 1933

Sehr geehrter Herr Beumelburg,

Ihr Schreiben vom heutigen Tage erhielt ich mit bestem Dank und sehe dadurch die Lage zu meiner Zufriedenheit geklärt. Ich möchte nochmals betonen, daß ich dem Institut der Akademie mit der allergrößten Hochachtung gegenüberstehe und da $\beta$ der Hinweis auf mein Schrifttum in meinem vorigen Briefe lediglich in der Bedeutung eines für meine persönliche Lebensführung gültigen Grundsatzes aufzufassen ist. Zum Formalen möchte ich bemerken, daß ich mich zu meinem Briefe natürlich erst berechtigt fühlte, nachdem ich unter einem amtlichen Aufrufe der Akademie genannt worden war. Ich habe bei dieser Gelegenheit meinen Namen mit besonderer Freude zur Verfügung gestellt, - einmal des ausgezeichneten Anlasses wegen, dann aber auch, um zu betonen, da $\beta$ ich zur positiven Mitarbeit am neven Staate, ungeachtet mancher persönlichen Verärgerung, wie etwa der Haussuchung, die in meinen Räumen stattgefunden hat, durchaus entschlossen bin. Ich bin überzeugt, da $\beta$ dies auch auf meine eigene Weise möglich ist und schreibe Ihnen diese Zeilen frei von der Leber weg.

Mit kameradschaftlicher Hochachtung

als Ihr ergebener Ernst Jünger 
Preußische Akademie der Künste, Berlin W 8, Pariser Platz 4, den 10. Juni 1933

Dem rechts- und verwaltungskundigen Mitglied des Senats, Herrn Ministerialrat Dr. von Staa, ganz ergebenst vorgelegt.

Die beiliegende, vom Amtlichen Preußischen Pressedienst verbreitete Notiz ist mir gestern Abend durch die Zeitungen bekannt geworden. Auf welchem Wege und durch wen sie an den Staatlichen Pressedienst gelangt ist, konnte ich noch nicht ermitteln. Die Notiz wurde mir vor der Veröffentlichung nicht vorgelegt, obwohl in der Sitzung der erneuerten Abteilung für Dichtung der Erste Ständige Sekretär der Akademie, unterstützt von Herrn Dr. Benn, ausdrücklich darauf hingewiesen hat, daß eine etwaige die Dichtertagung behandelnde Pressenotiz durch meine Hand weiterzuleiten sein würde. Ich bin somit nicht in der Lage gewesen, als Präsident der Akademie in irgendeiner Form zu dem Inhalt der Notiz Stellung zu nehmen. Die Namen der neugewählten bzw. - wie es in der Notiz heißt - „bestimmten " Senatoren sind in dieser Notiz veröffentlicht, ohne die vorgeschriebene Bestätigung des Herrn Ministers abzuwarten.

Ich bitte Sie als den Justitiar der Akademie um gefällige gutachtliche Äußerung zu folgenden Fragen:

1. Wie ist die Tatsache rechtlich zu beurteilen, daß die erneuerte Abteilung für Dichtung, die am 7. und 8. d.Mts. zur Konstituierung in der Akademie versammelt war, sich selbst ohne Rücksicht auf die Autorität der Akademie und ihres Präsidenten und auf die Hoheitsrechte der staatlichen Instanzen als eine Deutsche Akademie der Dichtung "erklärt" hat? Welche rechtlichen Folgerungen sind aus diesem Vorgang zu ziehen?

2. Wie ist der Begriff „reichszuständig“, den sich die Abteilung für Dichtung selbst beigelegt hat, vom rechtlichen Standpunkt aus zu rechtfertigen und nach den maßgebenden Verfassungs- und sonstigen staatsrechtlichen Bestimmungen zu interpretieren?

Für eine gefällige möglichst umgehende Stellungnahme wäre ich Ihnen zu großem Dank verpflichtet, da ich erst auf der Grundlage Ihres begründeten Rechtsgutachtens in dieser Angelegenheit an den Herrn Minister herantreten möchte.

Der Präsident

Max von Schillings

Das rechts- und verwaltungskundige Mitglied des Senats der Akademie der Künste, Berlin W 8, Unter den Linden 4, den 15.6. 1933

Auf die mir mit Schreiben vom 10. d.Mts, zugeleiteten Fragen erlaube ich mir folgende gutachtliche Äußerung abzugeben:

Zu 1.: Die Tatsache, daß sich die Abteilung für Dichtkunst der Akademie durch Beschluß als eine „Deutsche Akademie der Dichtung“ erklärt hat, hat keine unmittelbare rechtliche Wirkung. Sie könnte nur bewertet werden als Antrag der Abteilung auf entsprechende verwaltungsmäßige Durchführung durch das vorgesetzte Ministerium.

Zu 2.: Der Begriff „reichszuständig“, welcher in der mir zugegangen Abschrift der fraglichen Pressenotiz angewandt ist, muß m.E. ausgelegt werden unter Heranziehung der vorhergehenden Worte: "unter Wahrung der bisherigen Rechtsgrundlage ". Das soll offenbar bedeuten, daß die organisatorische und finanzielle Zuständigkeit der Abteilung für Dichtkunst im Gefüge der Preußischen Akademie der Künste, 
also einer im preußischen Staatshaushalt behandelten Institution, unverändert bleiben soll. Ist dies so, dann kann der Ausdruck "reichszuständig“ nur den auch sonst in dem betreffenden Absatz zum Ausdruck kommenden Sinn haben, daß alle deutschen Volksstämme durch ihre Dichter Vertretung in der Abteilung für Dichtkunst finden sollen. Unter diesem Gesichtspunkt würde auch der vorgeschlagene Name „Deutsche Akademie der Dichtkunst“ mehr eine programmatische und publikatorische, als eine rechtliche Bedeutung besitzen.

Dr. von Staa

Ministerialrat

[Aktenvermerk]: Vertraulich. H[errn] Prof[essor] A[mersdorffer]. Auf diese Sache muß ich noch zurückkommen. Man kann doch nicht einfach dazu schweigen! Oder ist Schweigen Gold u. Reden wertloses Silber? S[chilling]s.

\section{Dr. Hans Friedrich Blunck, Hamburg 37, Parkallee 35, 24. 6. 33}

Lieber Herr Beumelburg!

Mir geht noch Ihre Bemerkung über die Sorgen mit der Akademie durch den Kopf. Liegt ein besonderer Anlaß vor? Ich vermute, daß die neuen Statuten den Widerspruch des Herrn von Schillings herausgefordert haben. Warum legen einige Herren so großes Gewicht darauf, den Verband mit den Malern, Bildhauern und Musikern zu lösen? Ich habe die alten Satzungen durchgesehen und geprüft und könnte mir vorstellen, daß man gut die Gedanken der Deutschen Akademie, wie auch die Änderungen Kolbenheyers hineinarbeiten kann. Es hat ja auch keinen Zweck, eine neue Satzung (die mir heute noch in keiner Weise genügt) aufzustellen und dann zu hören, daß keine Mittel da sind, wenn man sich von den Malern, Bildhauern und Musikern trenne. (So würde ich sagen, wenn ich der Kultusminister wäre.)

Jedenfalls ist es nicht angängig, daß die Protokolle heute nach vierzehn Tagen unabgeschrieben in den Räumen der Alrademie liegen. Ich habe zehnerlei Dinge im Kopf und möchte zumal die Beschlüsse die wir gefaßt haben, auf ihre Rechtswirkung nachprüfen und einen Vorschlag über Auffüllung und präzisere Abgrenzung der Kommissionen machen. Ohne die Unterlagen ist man aber einfach lahmgelegt. Selbst wenn das Protokoll mit dem Amtsschimmel um die Wette läuft, sollte es doch einmal ans Ziel kommen. Ich vermisse Schaffners Namen in den Veröffentlichungen. Hat der Herr Kultusminister ihn vielleicht gestrichen? Ich würde es bedauern im Hinblick auf die Deutsche Schweiz, in der sich der Zusammenhaltsgedanke heute ganz stark entwickelt. Wir blicken immer zu starr nach Österreich, - wir müssen aber auch die Wandlungen in Holland und in der Schweiz im Auge behalten. Für mich ist es etwas Erschütterndes, daß der Schweizer Schaffner die Marienburg als das gewaltigste germanische Kunstwerk besingt. Wenn er dabei seinen demokratischen Standpunkt betont, so ist das kein "Asphalt-Demokratismus", sondern jener alte Gemeinschaftswillen, der auch in Hitlers Worten von der germanischen Demokratie enthalten ist. Abschattungen tun da nichts zur Sache. Uns soll es darauf ankommen, die junge Schweiz neu zu gewinnen, - geracle uns aus dem Westen.

Ich schicke morgen einen Aufsatz über die neue Akademie, den ich für eine englische Zeitschrift geschrieben habe, an Johst und hoffe, daß er ihn mir umgehend zurückschickt. Die publizistische Behandlung der neuen Akademie ist bislang noch sehr dürftig. Aber es vergeht ja alles vor den Entscheidungen in der Politik.

Dies für heute in Eile. Bitte schreiben Sie mir, ob Sie mit dem 2. Juli einverstanden sind.

Mit herzlichen Grüßen

Ihr ergebener Hans Friedrich Blunck 
Lieber Herr Blunck!

Besten Dank für Thre beiden Briefe vom 24. 6. und vom 22. 6. Alles Gegenständliche möchte ich persönlicher Unterredung überlassen. Sobald ich von Ihnen Nachricht habe, daß Sie bestimmt am 2. Juli nach Berlin kommen, werde ich alles versuchen, um auch Zierold und Johst heranzuziehen. Wir setzen uns dann zusammen und sprechen den ganzen Fragenkomplex und unsere weiteren Handlungen gründlich durch.

Meine Bemerkung über die Sorgen, die mir die Akademie mache, ist nicht pessimistisch zu verstehen. Ich halte es aber für wichtig, daß wir zunächst mit dem Kultusminister bzw. mit Zierold völlig ins Klare kommen, ehe wir darangehen, die Arbeit der Ausschüsse zu aktivieren. Das Protokoll wird inzwischen hoffentlich bei Ihnen eingetroffen sein, sonst ist es unterwegs. Jakob Schaffner ist von Will Vesper in der Eile damals einfach vergessen worden. Sobald der Minister die Neuwahlen bestätigt hat, werden wir eine neue Liste, und diesmal eine vollständige, veröffentlichen und an die Presse geben.

In Eile und mit herzlichen Grüßen

Ihr ergebener Beumelburg

\section{REICHSGEDANKE UND PROJEKT EINER „GROSSEN AKADEMIE DER DEUTSCHEN KUNST", JULI 1933}

Lieber Herr Zierold!

6. Juli 1933

Aus einem Brief von Dr Vesper nachstehend ein kurzer Auszug, der sich auf die Haltung des sächsischen Kultusministeriums bezieht:

„... Ich glaube aber, daß wir von der Akademie aus doch ein wesentliches Gegengewicht schaffen müssen und können. Voraussetzung wäre, wie ich immer wieder betone, daß die Akademie der Dichtung vom ganzen Reich, also von sämtlichen Kultusministern als reichszuständig anerkannt wird, und daß dann die Behörden von den Kultusministern angewiesen werden, in allen Fragen, die das Schrifttum angehen, also auch in den Fragen der Schriftsteller-Organisationen, die Akademie zu hören!" [Forts.] s. weiter unten!

Mir scheint es doch wohl das Richtigste, wenn die Instanzen der Kultusministerien anderer Länder diese Vollmacht erteilen. Wir hätten dann die Ideallösung, die uns allen vorschwebt. Vielleicht aber wird noch früher eine solche Anregung vom Reichskultusministerium unter Threm von uns allen hochverehrten Chef verwirklicht? Dann macht uns das alles kein Kopfzerbrechen.

Ich komme eben von München zurück, das ich zuletzt kurz vor der Revolution sah und das ich damals in schwerer Sorge um die Reichseinheit verließ. Eine andere Welt heut! Ich habe mich bei diesem Besuch zum ersten Mal nicht in einem bayerischen, sondern in einem deutschen München befunden.

Mit vielen freundlichen Grüßen bin ich

Ihr Ihnen sehr ergebener Beumelburg

Fortsetzung: „... Die Voraussetzung aber für alles ist, daß unsere Reichszuständigkeit als oberster Rat in Fragen des Schrifttums von allen Kultusministerien anerkannt wird. Die Leitung der Akademie muß darauf dringen, da $\beta$ dies erreicht wird. Ich selber verhandelte, wie ich Dir schon schrieb, mit dem sächsischen Kultusminister, natürlich nur aufklärend und sondierend, und fand bei ihm volle Bereitschaft, die Akademie auch für Sachsen anzuerkennen, wenn er auf amtlichem Wege darum angegangen würde. -“" 
73 An die Mitglieder der Deutschen Akademie der Dichtung [12. 7. 1937]

1. Am 1. und 2. Juli fand in Berlin eine eingehende Besprechung innerhalb des Vorstandes der Akademie statt. Die Mitglieder des Vorstandes waren sich darüber einig, daß unabhängig von der noch ausstehenden endgültigen Regelung der Stellung und des Inhalts der Akademie dennoch unverzüglich in die praktische Arbeit eingetreten werden müsse. Die finanziellen Fragen werden in der nächsten Zeit eine befriedigende Regelung finden, sodaß von dieser Seite her keine Behinderung der praktischen Arbeit zu erwarten ist. Die Frage der neuen Satzung ist durch die Arbeit des 1. Ausschusses soweit gefördert, daß man damit rechnen kann, sie vor dem Oktober d.Js. zu einem positiven Abschluß zu bringen. Schon heute kann gesagt werden, daß der organisatorische Aufbau der Akademie in der Richtung liegen wird, in absehbarer Zeit die große Akademie der deutschen Kunst zu bilden, als deren wesentlicher Bestandteil die Deutsche Akademie der Dichtung bestehen wird.

2. Eingehend wurde die Frage einer großen Gesamttagung der Akademie, etwa Ende Oktober d.Js., besprochen. Wenn auch noch nicht endgültig festliegt, wo und in welchem Rahmen diese Tagung stattfinden wird, so muß doch heute schon gesagt werden, daß diese Versammlung eine Form haben wird, die der deutschen Öffentlichkeit einen eindrucksvollen Beweis von der neuen Aktivierung der Akademie geben wird. Schon heute ergeht an alle Mitglieder der Akademie das dringende Ersuchen, ihrerseits alle positiven Anregungen für diese Herbsttagung dem Vorstand mit tunlichster Eile zu übermitteln. Es muß gelingen, mit dieser Tagung den Beweis zu erbringen, daß die Akademie der Dichtung entschlossen ist, am Aufbau und Ausbau des neuen Staates mit aller Kraft und Geschlossenheit teilzunehmen. Es wird dafür Sorge getragen werden, daß die Öffentlichkeit auf den Wegen des Rundfunks und der Presse in ganz anderem Umfange als bisher sich dieser Tagung annehmen wird.

3. An die einzelnen Ausschüsse, die in der konstituierenden Sitzung Anfang Juni 1933 eingesetzt worden sind, ergeht hiermit die dringende Aufforderung, ihre Arbeit unverzüglich in Angriff zu nehmen. Es steht gemäß den damals gefaßten Beschlüssen nichts im Wege, daß diese Ausschüsse sich mit einzelnen Sachverständigen in Verbindung setzen. Es wird aber den Vorsitzenden der Ausschüsse empfohlen, sich vor der endgültigen Heranziehung bestimmter Persönlichkeiten mit dem Vorstand ins Benehmen zu setzen, der dann sofort seine Stellungnahme übermitteln wird. Die Bestätigung dieser Beiräte wird eine provisorische sein, solange die endgültige neue Satzung der Akademie vom Minister als dem Kurator der Akademie noch nicht verkündet ist. Dieser Umstand darf aber kein Hinderungsgrund sein, um die praktischen Arbeiten zu verzögern.

4. Die Arbeitsweise der Ausschüsse ist so gedacht, daß die Vorsitzenden im Benehmen mit den Mitgliedern der Ausschüsse und den heranzuziehenden Sachverständigen die Fragen ihres Arbeitsgebietes so weit klären, daß unmittelbar vor der noch zu bestimmenden Gesamttagung der Akademie im Herbst die einzelnen Ausschüsse zusammentreten können, um ihren Arbeiten die Form von Anträgen an die Akademie zu geben.

5. Wenn irgendwelche Zweifel darüber entstehen, welche Befugnisse in diesen oder jenen Ausschuß gehören, so wird gebeten, sich an den Vorstand zu wenden, der dann alsbald eine genauere Abgrenzung der Arbeitsgebiete vornehmen wird.

6. Nach den Beschlüssen der konstituierenden Sitzung Anfang Juni sind die Aufgabenkreise Rundfunk, Film und Theater dem 2. Ausschuß zugesprochen worden. Herr Will Vesper, der Vorsitzende dieses Ausschusses, hat darum gebeten, ihn von diesen Gebieten zu entlasten. Bevor der Vorstand diese Arbeitsgebiete einem anderen 
Mitgliede überträgt, bittet er diejenigen Mitglieder der Akademie, die für diese Gebiete ein besonderes Interesse haben, sich zu melden.

7. Mit der Deutschen Akademie in München sind Verhandlungen eingeleitet. Diese Verhandlungen können nicht ohne Rücksicht auf die politische Lage in Deutschland betrachtet werden. Es wird den Mitgliedern der Deutschen Akademie der Dichtung dringend geraten, einstweilen keine Einzelschritte zu tun, weil solche unter Umständen geeignet sein können, die Aufgaben des Ganzen zu stören. Die Mitglieder werden gebeten, zum Vorstand auch in diesen Punkten dasjenige Vertrauen zu haben, das unerläßlich ist, um heute bei der drängenden Entwicklung des politischen und kulturellen Geschehens die notwendigen raschen Entschlüsse fassen zu können. Es wird auch in diesem Zusammenhang noch einmal darauf hingewiesen, daß wir der festen Zuversicht sind, in absehbarer Zeit die große Akademie der deutschen Kunst in engster Zusammenarbeit mit den staatlichen Stellen ins Leben rufen zu können. Dies Ziel wird der Vorstand unter allen Umständen verfolgen.

8. Alle Mitglieder der Akademie werden gebeten, sehr viel aktiver als bisher für die grundsätzlichen Ziele des Aufbaus der Akademie einzutreten. Es hat sich herausgestellt, daß Presse und Zeitschriften eine gewisse Zurückhaltung an den Tag legen, teils aus Unsicherheit, teils aus mangelnder Kenntnis dessen, was wir mit dem Neuaufbau der Akademie erstreben. Es wäre sehr zu begrüßen, wenn alle Mitglieder sich verpflichtet fühlten, in Wort und Schrift und im Sinne eines freien Meinungsaustausches in positiver Richtung tätig zu sein und auch die ihnen nahestehenden Zeitungen und Zeitschriften zu solchem Verfahren zu ermuntern. Es wird ferner gebeten, Belege über solche Veröffentlichungen der Akademie zuzuleiten, damit dort ein Gesamtbild über das Geschehene entstehen kann.

9. Mit dem Kampfbund für deutsche Kultur sind Verbindungen aufgenommen, und es wurde auf beiden Seiten die Bereitwilligkeit zu engerer Zusammenarbeit festgestellt. Die Ausschüsse werden darum gebeten, den Kampfbund für deutsche Kultur in ihre Erwägungen miteinzubeziehen.

10. Schon heute erscheint es dringend notwendig, daß sich die Akademie bemüht, im Gegensatz zu den vorhandenen und noch zu erwartenden schwarzen Listen eine weiße Liste aufzustellen. Die Herstellung einer solchen Liste gehört in das Arbeitsgebiet des 2. Ausschusses unter Vorsitz von Herrn Will Vesper. Der Vorstand wird demnächst vor der gesamten deutschen Presse entweder in der Form eines Presseempfanges oder einer Erklärung sich zu den Zielen der Akademie äußern. Die Absicht dieser Äußerung wird darin liegen, Presse und Zeitschriften viel mehr als bisher in unserem Sinne zu aktivieren. Wenn einzelne Mitglieder der Akademie besondere Anregungen für diese Pressekundgebung haben, so werden sie gebeten, diese unmittelbar an den Schriftführer zu leiten.

11. Noch einmal muß hervorgehoben werden, daß die Aktivierung der Akademie und ihre bewußte Einschaltung in die Zeitentwicklung nur das Ergebnis der freimütigen und energischen Mitarbeit aller Mitglieder sein kann. In dieser Hinsicht steht der Vorstand allen Mitgliedern jederzeit zur Verfügung.

Der Vorstand

I. A. Beumelburg

(Deutsche Akademie der Dichtung), 14. Juli 1933

An die Mitglieder cles Senats der Deutschen Akademie der Dichtung1

Aus den Kreisen der Akademie ist der Vorschlag gemacht worden, die im Entwurf

1 Das Schreiben wurde an Beumelburg, Blunck, Grimm, Johst, Kolbenheyer, Miegel, v. Münchhausen, Schäfer, Stehr, Strauß gesandt. 
beigefügte Erklärung gelegentlich im Namen der Akademie abzugeben. Bevor dies geschieht, wird der Entwurf hiermit den Mitgliedern des Senats zugeleitet mit der Bitte, dazu kurz Stellung nehmen zu wollen.

Im Auftrage Beumelburg

\section{ENTWURF EINES BESCHLUSSES DER DEUTSCHEN AKADEMIE DER DICHTUNG}

Die deutschen Dichter, die in der Akademie der Künste vereinigt sind, kennen kein anderes Volkstum als jenes, das von Art und Sprache umgrenzt wird. Sie sehen nur dann die Möglichkeit, zu einem dauernden Frieden in Europa zu kommen, wenn die Völker dieses Erdteils frei sind, über sich selbst zu bestimmen und den herrschenden Staaten die Möglichkeit genommen wird, anderssprachige Volksgruppen innerhalb ihrer Grenzen zu unterdrücken oder fremde Volksteile in sich einzuverleiben.

Die deutschen Dichter kennen die furchtbare Geschichte ihres Volkes, das, von Glaubenskämpfen und von der Eifersucht der Dynastien zerrissen, durch die Jahrhunderte vergeblich um seine Einheit rang. Sie sehen es als ihre Aufgabe an, den Kampf neu aufzunehmen und werden sich mit aller Hingabe dafür einsetzen. Sie stoßen aus der deutschen Gemeinschaft aus, wer immer diesen Wunsch nach einem einigen Reich entgegentritt, wer deutsche Sprachgruppen verrät oder Teile des Volkstums außerhalb des kommenden Reichs zu stellen versucht. Sie sprechen aus, daß es nichts Hassenwerteres gibt, als jene Männer, die unter Billigung des Auslandes der ewigen Sehnsucht deutschen Geistes nach Einheit und Vereinigung, dem Zusammenschluß der Volksgruppen entgegenarbeiten.

Unauslöschlich ist zumal auch der Wunsch der Dichter nach einem engeren Zusammenschluß zwischen Reichsdeutschland und dem deutsch-österreichischen Volk. Sie fordern deshalb die Jugend auf, niemals von ihrem Ziel abzulassen und die Hoffnung zu pflegen auf den Tag, da sich ein Zelt über alles Volk deutscher Sprache spannt, da das Recht der Selbstbestimmung, wie es im alten Reich gegolten hat, von neuem über Europa die Herrschaft gewinnt, allen seinen Völkern zum Segen.

\section{Hans Grimm, Klosterhaus, Lippoldsberg, Weser, bei Bodenfelde, 15. 7. 33}

Lieber Herr Beumelburg,

ich empfing heute den Entwurf. Ich will ihn wohl zeichnen, obgleich ich eigentlich nicht recht einsehe, daß solche Verlautbarungen zu den Aufgaben der Akademie gehören.

Auf keinen Fall aber möchte ich meinen Namen unter die Fassung des mittleren Teiles gesetzt sehen. Von der Akademie aus kann nicht geschrieben werden: „Sie sehen es als ihre Aufgabe an, den Kampf neu aufzunehmen und werden sich mit aller Hingabe dafür einsetzen." Das ist Bürodeutsch. Erstens muß gesagt werden, welcher Kampf neu aufgenommen wird, da nehme ich wohl mit Recht an, daß es heißen soll „den Kampf um die Einheit“, aber das muß erst gesagt werden, und dann „werden wir diesen Kampf mit aller Hingabe führen oder werden wir ihn mit aller Hingabe führen", aber um Gottes willen nicht dafür einsetzen. Die Herren auf den Ministerien sitzen ein. Im übrigen ist dann auch der Bramarbaston unmöglich „sie stoßen aus der Gemeinschaft aus" und dann ist wieder sprachlich falsch „sie stoßen aus der Gemeinschaft aus, wer deutsche Sprachgruppen verrät“. Der Passus muß lauten „Sie sehen in dem ihren Feind oder einen deutschen Feind, der dem Wunsche nach einem einigen Reich entgegentritt, der deutsche Sprachgruppen verrät usw.". Wenn die Herren ausstoßen wollen, dann können sie nur den aus der deutschen Gemeinschaft 
ausstoßen, den sie nennen. Es muß dann also heißen „sie stoßen aus der Gemeinschaft aus jeden, der [durchgestrichen: immer] diesem Wunsche entgegentritt". Ich bin ganz überzeugt, daß Sie mit mir einig sind, daß wenigstens diese sprachliche Redaktion vorgenommen werden muß.

Bei dem anderen Entwurfe ist mir nicht ganz klar, was wir als Akademie mit dem Kampfbunde für deutsche Kultur zu tun haben sollen. Der Kampfbund für deutsche Kultur hat sich noch nicht bewiesen. Bewreist er sich, so kann er unserer Anteilnahme sicher sein. Die Akademie muß aber über diesen Dingen bleiben, sonst dient sie niemand.

Mit freundlichen Grüßen

Ihr Hans Grimm

Dr. Hans Fr. Blunck, Hamburg 37, Parkallee 35, 21. 7. 33

Lieber Beumelburg!

Anbei einige Abänderungen aufgrund des Briefes von Grimm. „Wer immer diesem Wunsch entgegentritt" ist ein Relativsatz im Akkusativ, das müßte Hans Grimm wissen. Wenn ich bei der zweiten Formulierung das Wort „immer" auslasse (wer deutsche Sprachgruppen verrät), so ist diese Auslassung sprachlich schöner als die Wiederholung.

„Sich für etwas einsetzen " ist eines von Goethes Lieblingsworten, wenn ich mich recht erinnere. Ich verstehe durchaus den Kampf gegen die Schablonenworte, es gibt aber manche, die man sich nicht versauern lassen soll, nur weil die Bürokratie sie gern führt. Immerhin habe ich in beiden Fällen nach Grimms Vorschlag Abänderungen getroffen, weil ich selbst oft einen recht eigenwilligen Sprachgebrauch habe.

Ob es richtig ist, daß man bramarbasiert (woher kommt das Wort eigentlich?), wenn man jemanden aus der Deutschen Volksgemeinschaft ausstößt? Ich gebe Dir gern Vollmacht, die Wendung zu mildern, meine aber, daß man beim Teufel nicht allzu lau mit den Verrätern am Reichsganzen verfahren soll. Denn, mein Lieber, die Zeit des Säuselns ist noch nicht gekommen, und was vor uns liegt, ist ernster, als wir denken.

Ich habe es nicht ungern, wenn man einmal am Stil krittelt. Man lernt immer wieder, deshalb Grimm schönen Dank und Dir herzliche Grüße von Deinem Hans Friedrich Blunck

Ich glaube übrigens, daß die Zeit für die Veröffentlichung reif ist.

Hermann Stehr, Ober-Schreiberhau, Faberhaus, den 19. Juli 33

Sehr geehrter Herr Beumelburg!

In Beantwortung Ihres Anschreibens vom 14. Juli mit den beiden Anlagen teile ich Ihnen mit, daß ich mit dem Entwurf dieses Beschlusses der Deutschen Akademie der Dichtung vollkommen inhaltlich einverstanden bin.

Mit kollegialem Gruß

Hermann Stehr

Dr. h.c. Wilhelm Schäfer, Sommerhalde, Post Ludwigshafen-Bodensee, den 20. Juli 33

An den Vorstand der Deutschen Akademie der Dichtung

Liebe Herren!

Zur Anfrage vom 14. d.M. meine herzliche Bitte, nichts zu übereilen, namentlich 
keine Proklamationen hinausgehen zu lassen, die nicht unumgänglich sind. Es war der Grundfehler der vergangenen Sektion, daß sie sich nicht genügend distanzierte; wir sind keine Schriftsteller-Kammer. M.E. wird sich als Resultat der Hauptversammlung eine derartige Erklärung, wie die vorgeschlagene, von selber ergeben. Vorläufig sind wir noch nicht unter dem Dach eines Statuts; dies zu erlangen und dann mit einem Programm vor das deutsche Volk zu treten, muß unsere vorläufige Aufgabe bleiben.

Zur Mitteilung vom 12. d.M., die ich als Lebenszeichen begrüße, im Einzelnen folgende Bemerkungen:

Zu I.) Ich hätte es gern gesehen, wenn die Vorst. Sitzg. vom 1. u. 2. d.M. schon mit einer Sitzung des Senats verbunden gewesen wäre, mit einer von uns aus endgültigen Verabschiedung des Statuts. Es sollte alles daran gesetzt werden, diese Sitzung sobald wie möglich zu erreichen.

Zu 2.) Das wichtigste an dieser Tagung ist ihr Programm; wir sollten darüber schon jetzt im Klaren sein. Dringend ist auch die Frage des Orts, damit dort der Gegenklang des Volkes vorbereitet werden kann, den wir unbedingt erreichen müssen. Es muß ein großer Tag der deutschen Dichtung werden, nicht nur eine Akademie-Tagung. Ich würde Nürnberg vorgeschlagen haben, wenn uns die Partei-Tagung dort nicht den Ort vorweg genommen hätte. Eine große Stadt muß es sein; also München, Frankfurt oder Leipzig (Dresden). In München hätten wir 7 Mitglieder, also Arbeitskräfte zur Vorbereitung.

$\mathrm{Zu}$ 7.) Wir dürfen nicht übersehen, daß die $\mathrm{D}$ [eutsche] $\mathrm{A}$ [kademie] dabei ist, ein Sprachamt zu schaffen, also in unser Gebiet einzugreifen. Die Herren müssen genötigt werden, sich mit uns abzufinden. Mein Vorschlag, daß der Senat dort als vollberechtigt mitzusprechen habe, bleibt bestehen.

$\mathrm{Zu}$ 8.) Solange wir nicht selber unsere Form gesichert haben, halte ich einen öffentlichen Meinungsaustausch nicht nur für unnütz sondern auch bedenklich.

Zu 9.) Die Verbindung mit dem Kampfbund ist unerläßlich, weil er für die Dichtung die Antwort des Volkes vorstellt. Wir dürfen aber kein Organ für ihn werden; er muß das unsere sein.

$\mathrm{Zu}$ 10.) Sowohl der Presseempfang wie eine schriftliche Erklärung, die die schwarzen und weißen Listen betreffend [sic!], scheint mir verfrüht. Wollen wir nicht damit bis zur Haupttagung warten, so doch bis zu dem Tag, da das Statut anerkannt, der Senat verpflichtet und die Akademie in der Lage ist, eine auf ihrer neuen Daseinsform gegründete Erklärung abzugeben. In dieser neuen Form ist der Senat das Entscheidende; er sollte dabei in Erscheinung treten. Der Schlüssel zu allem, was wir vorhaben, scheint mir der Plan Emil Straussens zu sein. Er sollte der Mittelpunkt unserer Erklärungen sein und mit dem Gewicht des Senats betont werden.

Mit freundlichen Grüßen

Wilhelm Schäfer

79 Dr. Kolbenheyer, München-Solln, 27. 7. 33

An den Vorstand der Deutschen Akademie der Dichtung, Berlin W 8

Sehr geehrte Herren!

Zu Ihrer Aufforderung vom 14. Juli 33:

$\mathrm{Zu}$ 1.: M.E. ist eine praktische Arbeit erst dann möglich, wenn über die Funktion, Rechtslage und Geldmittel der Akademie Gewißheit herrscht. Den Abschlußtermin der Statutredaktion habe ich in meinem Brief vom 25. unter Zusendung der II. Redaktion bekanntgegeben. Eine "große Akademie der deutschen Kunst" ist nur dann 
gesichert, wenn die Deutsche Akademie der Dichtkunst, wie beschlossen und zugesichert, ihren Organismus autonom gefestigt hat. Der Aufbau kann hier nicht durch eine Zentralorganisation aller Künste erfolgen, er muß durch Zusammenwuchs bewirkt werden.

Zu 2.: Mir scheint es nützlich, wenn die 1. Hauptversammlung der Akademie nach Bestätigung des Statuts vor allem den Beratungen der Ausschüsse über ihre Arbeiten zugewendet bleiben sollte; es scheint mir günstig für diese erste Tagung die allzugroße Öffentlichkeit noch zu meiden. Nach einer Jahresarbeit und etlichen Erfolgen wird eine Hauptversammlung eindrucksvoller werden. Ich stelle zur Erwägung, daß das deutsche Volk unter dem Begriffe der Dichterakademie noch nichts Begrüßenswertes verbinden kann, weil dieser Begriff durch die frühere Akademie recht belastet ist. Wir sollten ohne geleistete Arbeit nicht auftreten, wir sind noch im Werden, haben noch nicht einmal unser Statut. Presse, Rundfunk und sonstiger Aufwand scheint mir für dieses erste Mal noch nicht am Platze.

Eine erste öffentliche Erklärung müßte wohl eine besondere Form erhalten und auch einem besonderen Anlasse folgen.

$\mathrm{Zu}$ 4. und 5.: Widerspricht in gewissem Sinne bereits gefaßten Beschlüssen und muß diesen angepaßt bleiben.

$\mathrm{Zu} \mathrm{7.:} \mathrm{Die} \mathrm{Zusammenarbeit} \mathrm{der} \mathrm{Akademie} \mathrm{der} \mathrm{Dichtung} \mathrm{„mit} \mathrm{staatlichen} \mathrm{Stellen“}$ kann nur Gegenstand der Beratung des Senates sein. Es wäre gut wenn der Vorstand hierüber einen Plan vor dem Senate entwickeln könnte (Olktoberversammlung).

$\mathrm{Zu} \mathrm{8.:} \mathrm{Es} \mathrm{ist} \mathrm{empfehlenswert,} \mathrm{erst} \mathrm{nach} \mathrm{Bestätigung} \mathrm{des} \mathrm{Statuts} \mathrm{und} \mathrm{nachdem} \mathrm{die}$ Arbeiten der Ausschüsse ihre feste Form erhalten haben mit der Öffentlichkeit (Presse, Zeitschriften) in Verbindung zu treten. Die ersten Verlautbarungen sollten ihrem Inhalte nach gemeinsam beraten sein. Erfahrungsgemäß ist da große Vorsicht notwendig. Auch muß der letzte Punkt des Statuts, der gleichfalls Beschluß ist, mit dieser Aufforderung erst in Einklang gebracht sein; auch darüber wären während der Oktoberversammlung Aussprachen nötig.

Zu 9.: Auch das Verhältnis zum K[ampfbund] $f[\ddot{u r}] \mathrm{D}$ [eutsche] K[ultur] muß erst durchberaten sein, zumal schon eine Pressenachricht zu lesen war, in der einer der Leiter dieser Organisation von einer Einbeziehung der Dichterakademie spricht. Die Akademie kann keinesfalls das Organ einer Organisation werden. Ihr ist Autonomie und Unmittelbarkeit dem Kuratorium gegenüber fest zugesagt. Vorbesprechungen dieser Art scheinen m.E. äußerster Vorsicht zu unterliegen.

$\mathrm{Zu}$ 10.: Über diese Listen kann auch nur im Oktober gemeinsam beraten werden. Zu 11.: Erst klares Statut, klare Aufgabenstellung, clann folgt die Aktivität von selbst. Die Aktivität der Akademie kann m.E. nie eine sehr laute und augenfällige werden. Einschaltung in die Zeitentwicklung ist durch die Mitglieder gegeben, soweit sie einer Akademie entsprechen kann.

E. G. Kolbenheyer

\section{AUFNAHME DER SEKTIONSARBEIT}

Will Vesper, Herausgeber der „Neuen Literatur“ - Meißen, Badgasse 2, d. 22. 6.33

Lieber Herr Beumelburg!

Schönen Dank für Ihren Brief. Warten wir also noch etwas ab, aber nicht zu lange, damit es uns nicht geht, wie den Poeten schon einmal bei der Verteilung der Welt. Ich habe übrigens nun die Vorbereitung der Fragen, die Buchhandel und Büchereien angehen und auf Wunsch von Hans Grimm noch die Fragen der Inlandspresse übernommen, Hans Grimm die Auslandspresse. Theater, Rundfunk und Film muß schon 
jemand anders übernehmen. Filme sehe ich nie. Ins Theater gehe ich kaum noch und einen Rundfunkapparat besitze ich nicht. Dennoch gibt es auf all diesen Gebieten wichtige Fragen, die unbedingt unsere Aufmerksamkeit verdienen. Ich wäre durchaus dafür, daß wir in diesen Dingen Fühlung zum Kampfbund für deutsche Kultur suchen und ihn mit unserer Autorität unterstützen und ihn beraten.

Grimm schickt mir den beiliegenden Brief von Münchhausen, den ich Ihnen weitergebe. Ich bin sicher, daß auch sonst die Grammophonplattenindustrie einer Aufsicht bedarf. Auch hier können wir beratend wirken. Ich denke mir ja unsere Mitwirkung in allen solchen Dingen überhaupt im Wesentlichen so, daß wir solche Dinge nur zur endgültigen Regelung an das Kultusministerium weitergeben. Wir geben die Anregungen und Ratschläge. Natürlich müssen sie auch ernst genommen, beachtet und durchgeführt werden. Vielleicht können Sie herausbekommen, wie man solches Zeug packt und verschwinden macht*.

Mit herzlichen Grüßen

Ihr Will Vesper

* Das Ministerium müßte zunächst die Industrie selbst zur Säuberung auffordern und sie unter Druck setzen.

81 Enrica von Handel-Mazzetti

Linz, den 8. 9. 1933

Hochverehrte Herren,

verzeihen Sie, daß ich Thre vorletzte, sehr wichtige Sache noch nicht beantwortete. Ich wollte gleich mit einigen ausgearbeiteten Vorschlägen kommen und bin nun damit fertig geworden. Außerordentlich viel Arbeit liegt auf mir, und gerade in dieser Sache von höchster Wichtigkeit will ich nicht schlendern. Das ergreifende Wort Ihres gewaltigen Führers: „Die Meinung, daß in materiell dürftigen Zeiten kulturelle Fragen in den Hintergrund treten müssen, ist ebenso töricht wie gefährlich " gibt den Standpunkt, von dem aus die von Ihnen aufgerollten Fragen betrachtet werden müssen.

Ich legte mir zwei Weiße Listen an, die ich dieser Tage auszufüllen hoffe. Die eine für Volksbibliotheken; für diese möchte ich von dem ungemein vielen Guten, das unser deutsches Schrifttum Gott sei Dank besitzt, das anführen, was ich selbst gelesen habe, und was ich ganz genau kenne. - Die zweite Weiße Liste ist für Schulbibliotheken. Auch darauf ist größter Wert zu legen, was der werdende junge Mensch an geistiger Nahrung zu sich nimmt. Ferner habe ich, auf Anregung eines äußerst geschickten und zielbewußten kathol. Strafanstaltsseelsorgers in Nürnberg, noch eine dritte kleine Weiße Liste aufgestellt für Straf- und Besserungsanstalten. - Es ist gar nicht zu ermessen, wieviel Einfluß die Lektüre auf primitive und auch auf geistig fehlerhafte Menschen ausüben kann. In der Schule wirkt das gute Buch propagandistisch; auf die Gestrandeten kann es regenerierend wirken. - Ich bat meinen Gewährsmann in Nürnberg, mir eine Musterliste der Bücher, die er befürwortet, zu schicken. Aus ihr und aus einigem anderen guten Material will ich meine dritte Weiße Liste zusammenstellen.

Dadurch, daß Sie, unter der zielsicheren Führung eines Mannes, dem die Not des Volkes immer zu denken gibt, Kehraus mit Schmutz und Schund gemacht haben, ist viel, sehr viel geschehen, dies wird auch in meiner lieben Heimat rückhaltlos anerkannt, ja es ist niemand, der diese Großtat nicht lobt. Aber darin haben Sie sehr recht: zuerst roden[?], dann neue Kulturen anpflanzen. Die Versorgung des Volkes - jener, die schon im Leben stehen, jener, die erst zu Lebenskämpfern werden, und selbst jener, die im Kampf schon gestrandet und verwundet sind, - mit bester geistiger Nahrung ist mir die schönste Aufgabe, die das geistige Deutschland sich stellen kann. 
Lasterkunst bedeutet Siechtum und Untergang; reine kräftige Kunst Gesundes und Hochblüte eines Volksstammes.

Sie teilen in Ihrem bemerkenswerten neuen Rundschreiben mit, daß die Werke mehrerer Mitglieder unserer Akademie fehlen, und mit großer Freude werde ich Ihnen in allernächster Zeit meine Werke in Gesamtausgabe zugehen lassen.

Für die Zusendung des „Bücherwurm“ mit den wunderschönen und charakteristischen Bildnissen der Mitglieder der Deutschen Akademie der Dichtung danke ich verbindlichst. Dieses Heft ist ganz vorzüglich. Ich sandte das Exemplar, das Sie mir zugedacht haben, sogleich an Dr. Artur Dörrer in Innsbruck, den Staatsbibliothekar an der dortigen städtischen Bücherei, der mit den meisten österr. Bibliotheken ständig in Fühlung ist, und bat ihn um kurze Besprechung des schönen Heftes. Sie erhalten Belege von seinem Aufsatz. - Zum Wiener Katholikentag ist unsere größte Kulturrevue, die Schönere Zukunft, in festlicher Ausgabe erschienen. Ich habe mit dem mir befreundeten Redakteur Dr. Eberle Fühlung genommen, und er hat in der Festnummer, die in hoher Auflage gedruckt wird und weit herumkommt, auch eine hübsche Notiz über die Akademie gebracht. Ich lege Ihnen die Nummer in duplo bei. Sie sehen, daß darin alles Einigende betont wird, daß nicht ein Wort gegen unsere deutschen Brüder fällt und daß das Neue Reich verständnisvolle Würdigung findet. Auch von mir finden Sie eine kleine Studie, die keinen anderen Zweck hat als Brükken zu schlagen zwischen den beiden Bruderreichen, unseren beiden geliebten Heimaten, daß der allmächtige Gott bald vollsten Frieden und segensvolles Zusammenwirken gewähren möge.

Wenn Sie, verehrteste Herren, die Revue im Lesesaal auflegen wollen, so würde ich Herrn Dr. Eberle verständigen, daß er sie Ihnen regelmäßig kostenlos zugehen läßt. Auch die No. 51 ist noch als Festgabe zum Katholikentag gedacht und bringt u.a. den II. Teil meiner Studie "Die Heimat meiner Kunst“.

Darf ich Sie bitten, mir von dem prächtigen Bücherwurm-Heft 14 Exemplare zu senden?

Ich wurde schon von mehreren Seiten darum gebeten, ich will es unter anderem auch an meine Korrespondenten in Frankreich, in der Schweiz und in Amerika schicken.

Mit dem Ausdruck hoher Verehrung bin ich

Ihre aufrichtig ergebene Enrica v. Handel-Mazzetti

$V$ ertraulich! Verhandelt in der Preußischen Akademie der Künste, Sitzung des Senats, Abteilung für Dichtung (Deutsche Akademie der Dichtung), Berlin, den 26. Oktober 1933. Beginn der Sitzung: $101 / 4 \mathrm{Uhr}$

Anwesend unter dem Vorsitz des Herrn Johst: Beumelburg, Binding, Blunck, Grimm, Johst, Kolbenheyer, Miegel, v. Münchhausen, Schäfer, Stehr, Strauß, Vesper, entschuldigt: Griese

Blunck teilt mit, daß Hanns Johst erst im Laufe der Sitzung eintreffen wird, da er zu einer Besprechung zum Führer gerufen wurde. Als sein Vertreter eröffnet er die Sitzung und gibt einen kurzen Bericht über die im Sommer geleistete Arbeit. Viermal ist der Vorstand in Berlin zu Beratungen zusammengekommen. Die Fragen der Akademie können nur im Zusammenhang mit den großen politischen Fragen betrachtet werden. Unser Wunsch geht dahin, die Preußische Akademie der Künste in eine Akademie der Deutschen Kunst umzubilden und dadurch der gesamten Entwicklung Rechnung zu tragen. Diese besonderen Gründe haben den Vorstand veranlaßt, in diesem Herbst lediglich eine Sitzung der Senatoren gemeinsam mit den Vorsitzenden der Ausschüsse einzuberufen und von der Abhaltung einer Gesamttagung abzusehen, solange nicht die erstrebte organisatorische Gesamtlösung ge- 
funden ist. Über Einzelheiten wird der Schriftführer berichten. Der Vorstand hat beschlossen, folgende Tagesordnung zu empfehlen:

1. Bericht des Vorsitzenden

2. Verlesung der aus dem Kreise der Mitglieder gestellten Anträge

3. Berichte der Vorsitzenden der Arbeitsausschüsse, wobei die in das Gebiet des zweiten Ausschusses fallende Erörterung des Urheberrechtsgesetzes als besonderer Gegenstand ausgenommen werden soll.

4. Bericht des Schriftführers

5. Aussprache über die zu Punkt 2 gestellten Anträge

6. Grundsätzliche Aussprache über die Aufgaben der Akademie und über die Satzung

7. Besprechung des vom Reichsinnen- und Reichsjustizministerium aufgestellten Entwurfes eines Urheberrechtsgesetzes

\section{Punkt 2: Anträge}

Beumelburg gibt zu den Ausführungen von Blunck nähere Erläuterungen und verliest sodann die vorliegenden Anträge.

1. Der Antrag Binding über die Pflegschaft am Nachlaß bedeutender Künstler soll im Rahmen der Aussprache über das Urheberrechtsgesetz behandelt werden.

2. Grimm beantragt, daß über die Statuten gesprochen wird, ferner über die Haltung der Akademie gegenüber dem Kampfbund für deutsche Kultur, schließlich über die besondere Lage der Mitglieder Claudius und Frenssen. Die Aussprache über die Satzungen ist einem besonderen Punkt vorbehalten, die Aussprache über die Haltung zum Kampfbund soll mit der Aussprache über die Aufgaben der Akademie verbunden werden.

Münchhausen beantragt, daß die Akademie bei besonderen Anlässen Botschaften verkündet. Auf Vorschlag von Kolbenheyer wird Wilhelm Schäfer gebeten, eine Botschaft der Akademie zum 12. November 1933 zu verfassen und zu Beginn der morgigen Sitzung zur Beschlußfassung vorzulegen.

Binding beantragt, daß über die innere Not junger Menschen in der heutigen Zeit gesprochen wird.

Münchhausen beantragt, daß über den Reichsverband deutscher Schriftsteller gesprochen wird, insbesondere über den Ehrensenat, den der Reichsverband eingerichtet hat.

Kolbenheyer wiederholt seinen Antrag über eine Kundgebung der Akademie zum 12. November. Er hält es für gut, daß die Akademie im Gegensatz zu den Kundgebungen anderer Organisationen zum ersten $\mathrm{Mal}$ mit einer schönen und stilistisch gut gefaßten Veröffentlichung hervortritt.

Punkt 3: Ausschußberichte

1. Ausschuß: Für die Satzungen. Vorsitzender: Kolbenheyer. Über diese Frage soll im Verlaufe der Sitzung besonders gesprochen werden.

2. Ausschuß: Buchhandel, Leihbüchereien, Presse. Vorsitzender: Vesper.

Vesper: Die Arbeit des Ausschusses ist durch die Tatsache gehemmt, daß die endgültigen Statuten der Akademie noch nicht vorliegen. Zusammenarbeit mit der Reichsstelle für Schrifttum ist wesentlich. Die Akademie muß sich eine gewisse Kontrolle über deren Arbeit sichern. Einrichtung eines Zeitungsdienstes der Akademie ist nötig.

Beumelburg stellt fest, daß ursprünglich in das Arbeitsgebiet des zweiten Ausschusses auch die Behandlung von Rundfunk, Film und Theater fallen sollte. Diese Einteilung habe sich als unpraktisch erwiesen. Es wird darum die Einrichtung zweier neuer Ausschüsse, eines für die Fragen des Theaters und eines für Rundfunk und Film vorgeschlagen. Kolbenheyer erklärt sich bereit, den Vorsitz einer Kommission für das 
Theaterwesen zu übernehmen, sofern diese Kommission mit den erforderlichen Vollmachten ausgerüstet wird, um das heute herrschende Durcheinander in den Fragen des Theaters autoritativ zu klären. Beumelburg betont, daß es ihm vorerst darauf ankomme zu wissen, ob er sich in einem solchen Falle an Kolbenheyer wenden könne. Kolbenheyer sagt dies zu. Der Senat ist einverstanden.

Binding erklärt sich bereit, die Fragen des Rundfunks in den Arbeitsbereich seiner Kommission einzubeziehen. Die Behandlung der Filmfragen lehnt er ab mit der Begründung, daß es sich bei dem jetzigen Zustand des Films um keine Angelegenheit handle, die in den Bereich der Akademie falle. Der Senat ist einverstanden. Beumelburg betont, daß es ihm auch hier zunächst darauf ankomme, jemanden zu wissen, mit dem er sich in Verbindung setzen kann, sobald irgendwelche Fragen akut werden. Bisher habe er in solchen Fällen von sich aus gehandelt. Die eigentliche Arbeit auch dieses Ausschusses werde erst einsetzen, sobald das endgültige Statut der Akademie festliege.

3. Ausschuß: Berufsständische Organisationsfragen, Pflege des Nachwuchses, künstlerischer Arbeitsvertrag, Urheberrecht. Vorsitzender: Binding.

Binding führt aus, daß sein Arbeitsausschuß ein Gebiet umfasse, über dessen weite Bedeutung man sich erst nach und nach klar werde. Die Zeitentwicklung bringe es mit sich, daß man fast von Tag zu Tag vor neue Situationen gestellt werde. Um jederzeit eingreifen zu können, sei es von Bedeutung, daß er als Vorsitzender des Ausschusses sich häufiger in Berlin aufhalte. Er überlege, ob es nicht sogar nötig sei, daß er seinen Wohnsitz für den Winter aus diesem Grunde in die Hauptstadt verlege. Der Schriftführer habe im Benehmen mit ihm selbst bereits dafür Sorge getragen, daß die unwichtigen Aufgaben ron den wichtigen getrennt und abgeschoben würden. Es handle sich einmal um die allgemeinen Fragen wie Urheberrecht und Standesorganisation, zum zweiten um eine Fülle von persönlichen Fragen. Ihm liege besonders daran, das Thema zu besprechen, das er als „innere Not“ bezeichnet habe. Er habe Bedenken dagegen, daß die jungen Leute heute durch das körperliche Training zu stark beansprucht würden und daß der richtige Ausgleich zwischen Pflege des Körpers und Pflege des Geistes noch nicht gefunden sei. Es sei die Frage, ob man darüber eine öffentliche Stellungnahme der Akademie herbeiführen solle, oder ob es nicht zweckmäßiger sei, durch Fühlungnahme mit den betreffenden Amtsstellen das Richtige zu erreichen. Er wolle sich darauf beschränken, diese grundsätzlichen Ausführungen zu machen, ohne die Fülle der Einzelheiten zu berühren, die er im unmittelbaren Benehmen mit dem Schriftführer und dem Vorstand erledigt habe.

Johst teilt mit, daß er soeben von einer Besprechung mit dem Führer komme. Der Führer habe ihm zugesichert, daß er, sobald die außenpolitischen Dinge eine Beruhigung erfahren hätten, bereit sei, mit uns in einer ruhigen Stunde alle Dinge zu besprechen, die uns beunruhigten und beschäftigten. Die Bestimmung des Termins müßten wir dem Führer selbst überlassen. Schon heute könnte aber festgestellt werden, daß die Angelegenheiten der Kultur und des Theaters einer strengen Konzentration bedürften, die in der Schaffung einer Stelle zum Ausdruck kommen müsse, die dem Führer allein verantwortlich und unmittelbar unterstellt sei. Man müsse sich darüber klar sein, daß es nicht leicht sei, einer großen politischen Bewegung unsere besonderen Begriffe verständlich zu machen, dazu sei eine unentwegte und intensive Arbeit erforderlich. Es habe sich bisher um eine Massenbewegung gehandelt, und es sei eine alte Erfahrung, daß die Umschaltung der Masse nach gewonnenem Siege auf die Innerlichkeit viel Zeit und viel Arbeit erfordere. Diese Arbeit sei nur zu leisten, wenn das Präsidium des vollen Vertrauens des Senats sicher sei, so wie er verspreche, daß er niemals die großen Gesichtspunkte unserer kulturellen Arbeit aus dem Auge lassen werde. 
4. Ausschuß: Deutsche Sprache. Vorsitzender: v. Münchhausen.

Münchhausen weist darauf hin, daß es ganz von der Energie und dem Interesse des einzelnen Vorsitzenden abhänge, welche Arbeit einstweilen im Rahmen seines Ausschusses geleistet werde. Ihn beschäftige vor allen Dingen eine Neuregelung der deutschen Rechtschreibung. Er habe Verbindung zum Deutschen Sprachverein aufgenommen und ebenso zu der betreffenden Abteilung des Reichsinnenministeriums. Ihm sei dort versichert worden, daß in absehbarer Zeit ein Reichssprachamt gebildet werde, zu dessen Arbeit man ihn zuziehen wolle. Auch er empfinde das Nichtvorhandensein der endgültigen Satzung für seine Arbeit als hinderlich. Für besonders wichtig halte er den Kampf gegen den Gebrauch der Fremdwörter in den Verlautbarungen der Regierung.

Beumelburg weist darauf hin, daß die Tatsache, daß noch keine endgültige Satzung vorhanden sei, für die Arbeiten der Akademie und der Ausschüsse keineswegs eine Behinderung bedeute. Jeder Ausschußvorsitzende und jedes Mitglied könne sich mit jeder Anregung an den Vorstand wenden und dabei sicher sein, daß der Vorstand seinerseits sofort die richtigen Stellen ermittle, bei welchen er einzusetzen habe. Die bisherige Erfahrung habe bestätigt, daß die Stimme der Akademie im Gegensatz zu früher überall gehört werde und daß auch die Bereitschaft zum Handeln vorhanden sei.

Johst weist auf die besonderen Schwierigkeiten hin, die sich bei den Erlassen der Regierung und bei den Reden der Staatsmänner für den Gebrauch der Fremdwörter ergeben. Münchhausen betont, daß man darauf hinwirken müsse, daß alle Eingaben an die Behörden frei von Fremdwörtern seien und daß man ebenso auf die Schulen einwirken müsse.

Beumelburg: Über das Arbeitsgebiet des 5. Ausschusses (Beziehungen des deutschen Dichtertums zum Ausland und zur Auslandspresse, Vorsitzender Grimm) liegt ein besonderer Bericht nicht vor.

Über den 6. Ausschuß (Fragen des Unterrichts, Schulen und Hochschulen, Vorsitzender Griese) liegt ein schriftlicher Bericht des Vorsitzenden vor. Griese werde im späteren Verlauf der Sitzung erscheinen, um seinen Bericht vorzutragen.

7. Ausschuß: Finanzielle Angelegenheiten, Vorsitzender: Strauß.

Strau $\beta$ bringt einzelne Fragen seines Ausschußbereiches zur Sprache, die vom Schriftführer zur weiteren Behandlung zur Kenntnis genommen werden.

Im Anschluß an die Besprechung einer Reihe von Einzelfällen, die dem Bereich des 7. bzw. 3. Ausschusses angehören, ergibt sich eine grundsätzliche Aussprache über die Haltung der Akademie gegenüber den politischen und kulturellen Fragen der Gegenwart, die als vertraulich bezeichnet wird. Diese Aussprache berührt auch die Beziehungen der Akademie zu den einzelnen Ministerien und die Haltung, die von ihr gegenüber diesen Ministerien eingenommen werden soll. Besondere Beschlüsse werden dabei nicht gefaßt, jedoch wird der Vorstand die ihm gegebenen Anregungen bei seinem Verhalten beachten. Darauf tritt die Mittagspause ein.

Beginn der Nachmittagssitzung: 4 Uhr 15

\section{Punkt 4: Bericht des Schriftführers}

Beumelburg bespricht den Fall Hermann Bahr. Bahr wurde beschuldigt, an einer Emigrantenzeitschrift mitgearbeitet zu haben. Es stellte sich heraus, daß dies gegen seinen Willen unter Mißbrauch seines Namens geschehen war. Der Schriftführer hat alle Zcitungen und Zeitschriften, die diese Beschuldigung Bahrs abgedruckt hatten, zur Berichtigung aufgefordert und damit fast überall Erfolg gehabt. Der Fall ist als erledigt zu betrachten.

Das Verhältnis zwischen der Akademie und der Notgemeinschaft für das deutsche 
Schrifttum wird erörtert. Die Zusammenarbeit hat sich als reibungslos und zufriedenstellend ergeben. Sie ist besonders dadurch gewährleistet, daß sowohl der Vorsitzende der Akademie als auch der Schriftführer Mitglieder der Notgemeinschaft sind.

Das Verhältnis der Akademie zum Reichsverband deutscher Schriftsteller wird erörtert. Münchhausen wendet sich gegen den Ehrensenat, der vom Reichsverband eingerichtet wurde. Stehr ist dafür, daß hier der Staat mit einem Verbot eingreifen solle. Kolbenheyer ist dafür, daß man zwischen schon lange bestehenden Institutionen dieser Art und zwischen neugegründeten einen gewissen Unterschied machen müsse. Johst weist darauf hin, daß der Reichsverband unter der Schirmherrschaft des Reichsministeriums für Volksaufklärung und Propaganda stehe. Schäfer bespricht den Charakter des Reichsverbandes als einer Zwangsorganisation der Schriftsteller. Vesper macht dazu längere Ausführungen im Rahmen des ständischen Aufbaus. Er erklärt den Reichsverband als eine juristische Organisation, deren Funktion hauptsächlich in der Wahrung des Urheberrechts liege. Grimm bespricht verschiedene Fälle, in denen der Reichsverband sich nicht korrekt verhalten habe und in denen er sich des Eingriffs in ein schwebendes Gerichtsverfahren schuldig gemacht habe. Er berührt dabei besonders den Fall Bischoff, Breslau. Johst erklärt, daß solche Angelegenheiten erst dann befriedigend erledigt werden könnten, wenn die Akademie die Kontrolle über alle Vereinigungen dieser Art erlangt habe. Münchhausen betont, daß man im Falle Bischoff zunächst die schwebende Entscheidung des Reichsgerichts abwarten müsse. Nach längerer Erörterung wird beschlossen:

„Der Senat der Akademie hält es für nötig, daß die Politische Polizei bei Überprüfung der politischen und kulturpolitischen Haltung deutscher Schriftsteller den

Vorstand der Akademie anhört und nach seinem Gutachten entscheidet."

Beumelburg bringt den Fall Rudolf Huch zur Sprache. Von verschiedenen Seiten ist auf die Notlage Rudolf Huchs hingewiesen worden. Soll die Akademie ihm Unterstützung gewähren? Nach Aussprache wird in diesem Sinne beschlossen.

Grimm bringt den Fall Gustav Frenssen zur Sprache, der sich ebenfalls in einer gewissen Notlage befindet. Er behandelt dabei die Frage, ob die Akademie nicht von sich aus für ältere, um das Volk verdiente Dichter Ehrensolde aussetzen könne, damit diese nicht gezwungen seien, betteln zu gehen. Er halte dies für eine der wesentlichen Pflichten der Akademie. Es wird beschlossen:

„Der Senat sieht es als seine Pflicht an, aus den ihm zur Verfügung gestellten Mitteln verdienten älteren Dichtern der Nation Ehrensolde auszusetzen."

Beumelburg bespricht die Fälle Claudius und Griese. Bei beiden handle es sich darum zu erreichen, daß sie vom Staate von ihren Pflichten befristet entbunden würden bei Fortgewährung ihrer Bezüge zur Erledigung dichterischer Arbeiten. Der Senat beschließt in diesem Sinne.

Kolbenheyer bespricht in diesem Zusammenhang die Frage von Arbeitsunterstützungen für jüngere Autoren. Nach Erörterung wird beschlossen: „Der Senat beschließt, jüngeren Schriftstellern zur Erledigung dichterischer Arbeiten befristete Arbeitsunterstützungen zu gewähren."

Beumelburg bespricht die Kreismann-Stiftung. Bisher war Loerke Mitglied. Loerke hat seine Mitgliedschaft im Kuratorium niedergelegt. $\mathrm{Zu}$ seinem Nachfolger wird Binding bestimmt.

Es war dem Vorstand zur Kenntnis gekommen, daß eine gewisse Gefahr bestand, daß der diesjährige literarische Nobel-Preis einem der emigrierten deutschen Schriftsteller gewährt werden sollte. Der Vorstand hat sich mit dem Auswärtigen Amt ins Benehmen gesetzt. Es ist in Stockholm darauf hingewiesen worden, daß Deutschland eine solche Verleihung als einen unfreundlichen Akt betrachten würde. Diesem Schritt ist entsprochen worden. 
Johst bespricht die Lage der Kleist-Gesellschaft, der das Recht zusteht, den KleistPreis zu verleihen. Die Gesellschaft befinde sich in einer Umorganisation. Es findet eine Erörterung über den Kleist-Preis statt. Der Senat beschließt, sich nicht an der Kleist-Gesellschaft zu beteiligen, aber bestimmend bei der Verteilung des KleistPreises mitzuwirken. Die Einzelverhandlungen mit der Gesellschaft werden dem Vorstand überlassen.

Grimm bespricht das Verhalten des Kampfbundes für deutsche Kultur in Vortragsangelegenheiten. Er wendet sich dagegen, daß der Kampfbund von sich aus eine für die Vortragenden unbefriedigende Lösung der finanziellen Frage bestimmt habe. Schäfer und Binding schließen sich Grimms Ausführungen an.

Johst erörtert die Frage, ob die Akademie von sich aus finanzielle Richtlinien bestimmen solle. Münchhausen und Binding sind dagegen. Vesper regt an, mit dem Kampfbund in Verhandlungen zu treten, um dessen Richtlinien zu beseitigen. Schäfer weist darauf hin, daß es sich bei der Deutschen Gesellschaft für Volksbildung um einen gleichen Fall handle. Kolbenheyer erklärt sich bereit, mit der Reichsstelle für Schrifttum diese Fälle zu besprechen und sie einer befriedigenden Regelung zuzuführen.

Blunck erörtert in diesem Zusammenhang verschiedene Anregungen, die der Akademie von der Nordischen Gesellschaft in Lübeck zugeleitet worden sind. Es handle sich dabei um die Ermöglichung von Vorträgen deutscher Dichter im nordischen Ausland. Es wird beschlossen: „Der Senat gibt dem Vorstand Vollmacht, mit der Nordischen Gesellschaft in Lübeck über den Inhalt ihrer beiden Denkschriften zu verhandeln mit der Einschränkung, daß keine ausschließlichen Bindungen für die einzelnen Mitglieder der Akademie daraus entstehen dürfen."

Johst schließt die Sitzung um 1/27 Uhr.

Fortsetzung der Sitzung des Senats am 27. Oktober 1933. Beginn 10 Uhr 15

Johst eröffnet die neue Sitzung.

Schäfer verliest den Wortlaut der von ihm verfaßten Kundgebung zum 12 . November: „Wir Mitglieder der Deutschen Akademie der Dichtung stimmen dem Entschluß der Reichsregierung bei, einen unerträglichen Zustand durch den Austritt aus dem Völkerbund zu beenden. Wir begrüßen, daß der Aufruf ins deutsche Volk gegangen ist, seine Einigkeit in dieser Ehrenfrage vor der Welt zu bekunden. Wir erwarten, daß jeder Deutsche am 12. November durch sein Ja die gerade Politik des Volkskanzlers Adolf Hitler stärken wird." Der Senat ist mit diesem Wortlaut einverstanden und beauftragt den Schriftführer, das weitere zu veranlassen.

Beumelburg gibt davon Kenntnis, daß sich Staatssekretär a. D. Lewald als Vorsitzender des olympischen Komitees an die Akademie gewandt habe, um eine Beteiligung der Akademie am Preisgericht für eine olympische Hymne zu erreichen. Nach kurzer Aussprache wird Münchhausen für diese Aufgabe in Vorschlag gebracht; er nimmt den Auftrag an.

Beumelburg gibt davon Kenntnis, daß rom 26. 11. bis 6.12.1933 in Berlin unter dem Protektorat des Propagandaministeriums, veranstaltet von der Fichte-Gesellschaft, eine deutsche Büchermesse stattfindet. Die Fichte-Gesellschaft ist an die Akademie herangetreten, um die Frage einer Beteiligung der Akademie an dieser Messe zu klären. Es wird beschlossen, daß Münchhausen im Verlauf der Buchwoche einen Vortrag über das deutsche Buch hält. Johst bringt die prinzipiellen Bedenken der Akademie gegen den weiteren Vorschlag der Fichte-Gesellschaft, der sich auf Autogramme bezieht, zum Ausdruck. Der Schriftführer wird beauftragt, die Auffassung der Akademie der Fichte-Gesellschaft zu übermitteln.

Beumelburg bittet um die Meinung der Anwesenden über die Stellungnahme der Akademie gegenüber der im Entstehen begriffenen Reichsschrifttumskammer. Nach 
kurzer Aussprache übernimmt es Kolbenheyer, die Angelegenheit im Propagandaministerium zur Sprache zu bringen, um zu klären, was mit der Reichsschrifttumskammer von dort aus bezweckt ist. Er wird über das Ergebnis dem Vorstand berichten. Beumelburg bringt das Verhältris der Akademie zur Deutschen Akademie in München zur Sprache und hält es für erwünscht, daß mit dieser ein besonderes Abkommen getroffen wird. Schäfer stellt fest, daß in einer der letzten Sitzungen der Deutschen Akademie in München Grimm und Kolbenheyer in den Senat dieser Akademie gewählt worden sind. Er hält dadurch eine ausreichende Fühlungnahme für gewährleistet. Vesper betont, daß aus dem Gleichklang der beiden Namen eine gewisse Verwirrung entstehen könne. $\mathrm{Er}$ würde es begrüßen, wenn die Münchener Akademie veranlaßt werden könnte, ihren Namen zu ändern. Grimm weist darauf hin, daß die Münchener Akademie die ältere ist. Johst betont, daß es sich bei München um eine private Akademie handle, bei uns um eine staatliche. Die Frage müsse vom Staat bei Gelegenheit autoritativ geklärt werden.

Beumelburg bringt auf Wunsch von Binding den Fall Ernst Hardt zur Sprache. Nach kurzer vertraulicher Aussprache stellt sich der Senat auf den Standpunkt, daß die Angelegenheit Hardt nicht die Akademie berühre.

Beumelburg bringt einen weiteren Antrag Bindings zur Sprache, der den Wunsch äußert, in jedem Jahre möge ein Mitglied der Akademie einmal in Berlin einen Vortrag halten. Er bittet, dabei grundsätzlich die Vortragsfrage zu berühren. Schäfer weist darauf hin, daß in früheren Zeiten in ähnlicher Weise verfahren worden sei. Man habe jedoch dabei schlechte Erfahrungen gemacht. Zu begrüßen sei, wenn bei den geplanten großen Herbsttagungen der Akademie, die nach unsern Wünschen in einer deutschen Stadt außerhalb Berlins stattfinden sollten, jedesmal ein Mitglied der Akademie eine bedeutsame Rede halten würde.

Beumelburg bringt einen Antrag Münchhausens zur Sprache, der sich mit Botschaften der Akademie zu besonderen wichtigen Anlässen beschäftigt. Münchhausen begründet seinen Antrag und weist darauf hin, daß durch die zu Beginn der Sitzung beschlossene Kundgebung der Senat in der Praxis diesem Antrag zum ersten Mal entsprochen habe. Er betont, daß diese Botschaften nur bei besonderen Anlässen und nur selten erfolgen dürften.

Beumelburg bittet, die 'Tagesordnung derart urnzustellen, daß man jetzt zunächst die Frage des Urheberrechts besprechen möge und in der Nachmittagssitzung die Frage der Satzungen und der Aufgaben der Akademie. Der Vorschlag wird genehmigt.

\section{Punkt 6: Urheberrecht}

Strauß verliest seinen ausführlichen Vorschlag zur Änderung des Urheberrechtsgesetzes und über die Pflege des Nachlasses bedeutender Künstler. Der Vorschlag gipfelt darin, daß nach Ablauf der 30jährigen Schutzfrist bis zum 50. Jahre die Akademie durch eine besondere Kommission die Pflege dieses Nachlasses übernimmt und bei vollkommener Wahrung cler Erbrechte der Nachkommen das Recht besitzt, von den Verlegern einen geringfügigen Prozentsatz als Kulturabgabe zu erheben und zu verwalten. $[\ldots]$

\section{Punkt 7: Statuten und allgemeine Aufgaben der Akademie}

Kolbenheyer berichtet über die Entstehung des Entwurfs der Statuten, der dem Minister mit der Bitte um Genehmigung zugeleitet ist. Beumelburg stellt fest, daß der Vorstand genau den Beschlüssen des 1. Ausschusses entsprechend verfahren habe. Das Statut liege beim Minister, sei aber noch nicht verkündet. Grundsätzliche Bedenken dagegen seien ihm nicht bekannt geworden. Allerdings spiele hier die Gesamtlage eine gewisse Rolle. Solange die kulturellen Kompetenzen der einzelnen Mini- 
sterien noch nicht endgültig abgegrenzt seien, solange werde wohl auch die endgültige Verkündung des Statuts der Akademie noch ausstehen. Es sei zu hoffen, daß eine endgültige Lösung in allernächster Zeit erreicht werde. Soviel sei wohl heute schon festzustellen, daß der Minister an dem Gedanken der Gesamtakademie festhalten werde. Die Abteilung für Dichtung habe von sich aus den Schritt von Preußen zum Reich bereits getan. Logische Fortsetzung dieser Aktion werde sein, daß man die Akademie der deutschen Kunst bilde, zusammengesetzt aus den drei Akademien für die bildenden Künste, für Musik und für Dichtung. Kolbenheyer stellt fest, daß man gegen den Gedanken der Gesamtakademie keine grundsätzlichen Einwendungen erhebe. Er habe es aber für richtiger gehalten, daß sich zunächst die Abteilung für Dichtung konsolidiere und daß man von dort aus zur Gesamtlösung gelange.

Grimm erörtert die Frage der Autonomie. Er hegt Bedenken gegen die Fassung der $\$ \$ 2,4$ und 6 des Satzungsentwurfs. Kolbenheyer macht zu diesen Einwendungen nähere Ausführungen. Nach kurzer Aussprache erklärt Kolbenheyer sich damit einverstanden, daß im $\ 6$, wo es lautet "gewählt und ernannt", die Worte „und ernannt" gestrichen werden. Darauf tritt die Mittagspause ein.

Beginn der Nachmittagssitzung: 4 Uhr 15

Anwesend: alle Mitglieder außer Steh.

Johst stellt die Frage, ob vor der Besprechung der allgemeinen Aufgaben der Akademie noch einer der Herren irgendwelche Angelegenheiten von. Bedeutung zur Sprache zu bringen habe.

Vesper schlägt vor, daß die Akademie als solche Mitglied der Paul-Ernst-Gesellschaft werde. Kolbenheyer ist dagegen. Strauß ebenfalls. Nach kurzer Aussprache zieht Vesper seinen Antrag zurück.

Beumelburg gibt Kenntnis davon, daß der Staatliche Ehrensold, der bisher Paul Ernst gewährt wurde, zu neuer Verfügung frei geworden sei. Er bittet um Vorschläge. Schäfer schlägt Lersch vor, Vesper schlägt Rudolf Huch vor. Binding schlägt Gustav Frenssen vor. Johst schlägt Agnes Miegel vor. Es wird beschlossen, für die Verleihung des staatlichen Ehrensoldes Agnes Miegel dem Minister vorzuschlagen.

Grimm bringt eine Reihe von Einzelfällen zur Sprache, die er nicht für bedeutend genug hält, um die Akademie als solche damit zu befassen, die ihm aber als Kennzeichen der besonderen gegenwärtigen kulturellen Lage erscheinen.

Beumelburg fragt, ob der Senat mit folgendem technischen Verfahren einverstanden sei. Die zu Beginn der Sitzung beschlossene Kundgebung zum 12. November 1933 sei an den Kanzler zu leiten und gleichzeitig zur Veröffentlichung in der Presse freizugeben. Über die gestrige und heutige Sitzung des Senats und der Ausschußvorsitzenden sei ein Protokoll niederzulegen, das allen Teilnehmern der Sitzung zugestellt werde. Außerdem sei ein Bericht zu verfassen, der allen Mitgliedern der Akademie zugehe. Schließlich übernehme Vesper die Aufgabe, eine kurze Verlautbarung für die Presse zu formulieren, sobald er im Besitz des Protokolls sei. Der Senat ist damit einverstanden.

Binding spricht über den Begriff der inneren Not und formuliert ihn folgendermaßen: „Über die innere Not wertvoller Teile unseres Volkes, insbesondere unserer Jugend, hat die Deutsche Akademie der Dichtung als von einer sie tief berührenden oder bewegenden Frage gesprochen und hat sich entschlossen, unter Darstellung dieser inneren Not und ihrer Gründe über das Ministerium deren Milderung bei dem Führer zu erbitten." Johst lehnt eine solche Formulierung ab. Binding betont, daß es nicht seine Absicht sei, in der Öffentlichkeit vorzugehen, sondern auf dem Wege über das Ministerium bzw. die maßgeblichen Stellen. Johst stellt fest, daß es die Absicht des Führers sei, nach der Wahl und nach dem Abklingen der politischen Ereignisse von 
sich aus in solchem Sinne zu handeln. Wir könnten unsere Bedenken und Wünsche in die Form ron Anregungen bringen. Er halte aber das Wort „innere Not" für bedenklich. Binding wird um eine entsprechende Formulierung seines Antrags gebeten.

Schäfer bringt die Frage der neuesten Literaturgeschichte zur Sprache und wendet sich scharf gegen das Verhalten gewisser Professoren. Es gehe nicht an, daß in literaturhistorischen Werken neuesten Ursprungs davon gesprochen werde, es gebe keine Volksdichter, sondern es gebe in Deutschland nur Dichter von provinzieller Bedeutung. Hier werde von unberufenen Händen der Versuch unternommen, das zu zerstören, was in langen Jahren aufgebaut worden sei. Johst weist darauf hin, daß solche Dinge nur möglich seien, weil die deutschen Dichter sich scheuten, den Weg in die Öffentlichkeit zu gehen. Man dürfe sich auch vor dem Wort Propaganda nicht fürchten. Andererseits sei es Sache des Staates, für die Publizität der Dichter zu sorgen. Münchhausen bespricht ähnliche Fälle.

Johst stellt zur Erörterung, wie die Akademie gegen solche Dinge mit Erfolg einschreiten könne. Vesper führt aus, man dürfe sich nicht schenen, für oder gegen einzelne Bücher eindeutig Stellung zu nehmen. Bei den Büchern der Dichter sei eine solche Stellungnahme heikel und schwierig, aber bei literarhistorischen Werken sei sie durchaus angebracht und möglich. Er empfiehlt Zusammenarbeit mit dem zukünftigen Reichsant für das Schrifttum.

Er bespricht weiter die Notwendigkeit eines Zeitungsdienstes für die Akadernie und einer Kartei über das neue deutsche Schrifttum, die man zur Pflege des Nachwuchses unbedingt nötig habe. Auf Grund einer solchen Kartei werde man in der Lage sein, dem Auswärtigen Amt geeignete Vorschläge zur Förderung deutscher Dichtung im Auslande zu machen. Es wird beschlossen, Vesper mit der Herstellung und der laufenden Ergänzıng einer Kartei über das gegenwärtige deutsche Schrifttum zu beauftragen. Alle Mitglieder der Akademie sind gehalten und verpflichtet, geeignete Beobachtungen an Vesper mitzuteilen. Vesper wird jeweils vor den Tagungen der Akademie an den Vorstand über seine Arbeit berichten.

Mürchhausen macht einen Vorschlag für die in jedem Jahre geplante Herbsttagung der Akademie. Er wünscht, daß am ersten und zweiten Tag die Sitzung des Senats stattfinde, der dritte Tag soll sitzungsfrei sein, am 4. und 5. Tag sollen Plenarsitzungen stattfinden. Der sitzungsfreie Tag sei dazu bestimmt, jungen Dichtern der Nation Gelegenheit zu geben, vor der Gesamtheit der Akademie und einem besonderen, geladenen Publikum aus ihren Werken rorzulesen. Dies sei ein ungeheuer wirksames Mittel, um junge Talente zu fördern. Er denke sich das Verfahren so, daß auf Vorschlag einzelner Mitglieder der Alrademie etwa 4 oder 5 junge Dichter ausgewählt würden, ron rlenen jeder etwa 20 Minuten lesen solle.

Schäfer fragt, ob schon heute ein fester Plan über die zukünftige Hauptsitzung der Akademie vorliege. Beumelburg äußert dazu, daß man im Augenblick noch nicht endgültig entscheiden könne, ob die nächste Hauptversammlung im kommenden Frühjahr oder erst im Herbst stattfinden werde. Diese Entscheidung hänge aufs engste mit der gesamten Lage zusammen. Der Vorstand habe den Wunsch, eine Entscheidung möglichst bald herbeizuführen, sei aber einstweilen noch durch Dinge gehemmt, über die bereits genugsam vertraulich gesprochen sei.

Johst weist darauf hin, daß aller Wahrscheinlichkeit nach in absehbarer Zeit der Senat noch einmal berufen werden müsse, um, wie er bereits gestern ausgeführt habe, mit dem Führer zu einer vertraulichen Besprechung zusammenzukommen.

Münchhausen fragt, ob sein Vorschlag über die Gesamttagung der Akademie und insbesondere über die Vorträge junger Dichter vom Senat gebilligt werde. Der Senat beschließt in diesem Sinne. 
Johst stellt fest, daß weitere Wortmeldungen nicht vorliegen. Er dankt für die außerordentlich rege und wertvolle Mitarbeit aller Anwesenden und versichert, daß der Vorstand alles daran setzen werde, diese Anregungen zu verwirklichen.

Binding drückt seinen besonderen Dank aus, daß man die Vorsitzenden der Arbeitsausschüsse zur Sitzung des Senats zugezogen habe. Er hält dieses Verfahren für praktisch, außerordentlich wertvoll und hofft, daß man auch in Zukunft daran festhalten werde.

Agnes Miegel bringt in ihrem eigenen und im Namen aller Anwesenden zum Ausdruck, daß Hanns Johst wie bisher so auch in Zukunft ihr und der anderen volles Vertrauen genieße. [ Es ist mein erstes Wort, daß ich zu Ihnen sprechen darf. Ich werde das Vertrauen haben, solange ich unter Ihnen sein darf, und ich glaube, wir alle sind der gleichen Auffassung. "] Der Senat stimmt diesen Ausführungen zu.

Die Sitzung wird geschlossen.

Werner Beumelburg

\section{Kundgebung der Deutschen Akademie der Dichtung [30.10.1933]}

Wir Mitglieder der Deutschen Akademie der Dichtung stimmen dem Entschlu 3 der Reichsregierung bei, einen unerträglichen Zustand durch den Austritt aus dem Völkerbund zu beenden.

Wir begrüßen, daß der Aufruf ins deutsche Volk gegangen ist, seine Einigkeit in dieser Ehrenfrage vor der Welt zu bekunden.

Wir erwarten, daß jeder Deutsche am 12. November durch sein Ja die gerade Politik des Volkskanzlers Adolf Hitler stärken wird. ${ }^{2}$

84 Deutsche Akademie der Dichtung, 13. 11. 1933

Herrn Dr. Haupt, Fichte-Gesellschaft e. V., Berlin W 35, Am Karlsbad 8

Sehr geehrter Herr Dr. Haupt,

in der Anlage übersende ich Ihnen einige Sätze zur Buchmesse, deren Verwendung ich Ihnen als Äußerung der Dichterakademie anheimstelle.

Mit deutschem Gruß

Ihr ergebener Beumelburg

Aufruf!

Alle große Kunst ist Rechtfertigung eines Volkes vor Gott; sie ist auch Erfüllung des Überkommenen und Auftrag an die Nachfahren.

Aber es ist nicht das allein. Wie der Leib des Brotes bedarf, so will die Seele das Ge-

\footnotetext{
1 Später gestrichen

2 Diese Kundgebung ist von Wilhelm Schäfer im Auftrag des Senats der Abteilung formuliert worden (vgl. Dok. Nr. 82). Sie erschien im Völkischen Beobachter v. 7.11. 1933 mit folgenden Unterschriften: Der Präsident Hanns Johst, Benn, Beumelburg, Binding, Blunck, Claudius, Däubler, Dörfler, Frenssen, Griese, Grimm, Halbe, Hauptmann, Rud. Huch, Mell, Miegel, v. Molo, v. Münchhausen, Ponten, Schäfer, Schlaf, Schmidtbonn, Scholz, Seidel, Stehr, Strauß, E. Stucken, Vesper, Joseph Magnus Wehner. Auf gleicher Seite erschien (ohne Unterschriften) eine „Kundgebung der Abteilungen Bildende Künste und Musik“, in der die Mitglieder dem Reichskanzler Hitler „ihre treue Ergebenheit und Gefolgschaft" versichern. Diese Kundgebungen sollten die Volksabstimmung am 12.11. 1933 unterstützen, in der nachträglich der Austritt Deutschlands aus dem Völlkerbund plebiszitär bestätigt wurde. Gleichzeitig wurden bei dieser Volksabstimmung die Abgeordneten für einen neuen Reichstag (Einheitsliste) gewählt.
} 
heimnis vorahnen, das zwischen Gott und Mensch steht, will sie die Schauer von Lied und Dichtung empfinden und auch das Glück kosten, das aus der schwingenden Sprache ihres Volkes aufsteigt, einer Gemeinschaft, mit der sie schon auf Erden gewinnt, siegt und weiterlebt.

Arm ist, wer nicht darum weiß. Erst die Feier des Sonntags bestimmt die Kraft im Werk des Alltags; wer sich den stillen Stunden der Besinnlichkeit, wer sich dem Glück eines guten Buches, wer sich der Sammlung am Tage der Einkehr entzieht, hat in der Woche einen engen Blick oder auch freudlosen, mißmutigen Gewinn.

Echte Kunst macht stark; sie ist die Erfüllung deiner selbst; sie erst ist aber auch die höchste Kraft deines Volkes, das gleich dem einzelnen der Schöpfung Antwort zu stehen hat auf die Frage nach Weg, Wert und Ziel. ${ }^{1}$

\section{KOMPETENZÜBERSCHNEIDUNGEN UND ZUNEHMENDE FUNKTIONSLOSIGKEIT}

Hanns Johst, Oberallmannshausen, Starnberger See [o.D.]

Mein lieber Werner Beumelburg,

ich höre durch Blunck, daß ihr zwei unsere Akademie bei M. v. Schillings vertreten habt.

Ich lege einen Zeitungsausschnitt bei ${ }^{2}$, der mich nervös macht. Was ist gegen diesen Typus des Gewerkschaftsgedankens (unter Regie Goebbels) zu tun? Eines Tages schluckt wohlmöglich von der Flanke her die Propaganda die Kultur, wenn wir nicht auf der Hut.

Laß dir doch einmal Wulf Bley (Kampfbund für deutsche Kultur) kommen. Ihr zwei habt von mir her plainpouvoir [pleins pouvoirs] gegen diesen Kram. Vielleicht warten wir aber auch September (also meine Rückkehr) ab? Nur - wenn es brennt, löscht schnell!! Ich sprach hier mit Hinkel eben drüber, der meinte, die Akademie müsse sich diesen Kram unterordnen. Wäre vielleicht Will Vesper und sein Arbeitsgebiet dafür fällig?

Im übrigen scheint die Sonne, und ich spüre die Pflicht gegenüber meinem Kadaver, ihn bescheinen zu lassen.

Ich grüße Dich auf das Lebendigste und bin und bleibe Dein getreuer Hanns Johst

Hans Grimm, Klosterhaus Lippoldsberg, Weser, bei Bodenfelde, 17. 11. 33

Lieber Beumelburg,

ich muß Sie wieder behelligen. Ich bekomme vom Reichsverband die einliegenden

1 Dieser Aufruf wurde von Vesper entworfen und von Bluncl überarbeitet. Er erschien u.a. im Völkischen Beobachter vom 22./23. 11. 1933.

2 Zwangskartell im deutschen Schrifttum. Bei der Gründungsversammlung der ersten Fachschaft im Reichsverband deutscher Schriftsteller, der Fachschaft der Erzähler, führte Hans Richter, der Stellvertreter des Präsidenten Götz Otto Stoffregen, aus, daß der Verband als einzige von dem Propagandaministerium anerkannte Organisation des freien Schrifttums zu einem Zwangsverband ausgebaut werden soll. Damit ist verknüpft, daß zukünftig in Deutschland nur ein Buch erscheinen kann, dessen Verfasser Mitglied des Reichsverbandes ist. Der Schutzverband Deutscher Schriftsteller, der Verband Deutscher Erzähler und der Deutsche Schriftsteller-Verband werden in dem Reichsverband aufgehen. Im ganzen werden zehn Fachschaften gebildet. In den Ehrensenat sind u. a. berufen worden: Walter Bloem, Atz vom Rhyn, Fedor von Zobeltitz, Rudolf Presber, Agnes Miegel, Hermann Stehr und Ina Seidel. 
Papiere, die ich zurück erbitte. Ich habe damals auf die ersten Papiere nicht geantwortet, weil ich die Fragen für ganz würdelos halte. Ich bin mit meinen sämtlichen Vorfahren und meine Frau mit ihren sämtlichen Vorfahren selbstverständlich arisch. Ich bin Kriegsteilnehmer. Ich bin Nationalist Zeit meines Lebens gewesen. Es ist unmöglich, daß ein Senator der Akademie auf diese Schmockfragen antwortet. Ich bitte einen generellen Beschluß für die Akademie herbeizuführen. Dem Verband deutscher Erzähler gehöre ich seit vielen Jahren an. Ich meinte die Umwandlung erfolge automatisch. So geht die Sache nicbt. Darf ich um sofortige Antwort bitten. Ich kann mich natürlich als Schriftsteller auch keinen Anordnungen des Reichsführers des $R$ [eichsverbandes] $D$ [entscher] $S$ [schriftsteller] fügen. Die Anordnungen kommen von Gott. Wo der Staat meint, daß sie ihn stören, hat er seine Zensur.

Ich freute mich, daß ich Sie neulich abends sehen konnte.

Mit freundlichen Grüßen

Ihr Hans Grimm

87 [Emil Strauß] Freiburg i. B., Sandstraße 46, 5. 12. 1933

Dem Vorstand zur gefl. Kenntnisnahme. E. St.

Lieber Börries v. Münchhausen, gegen die beabsichtigte Veranstaltung von Vorträgen muß ich - für den Augenblick Einsprache erheben.

Wir sind als Akademie zusammenberufen, als die nach Verdienst und Geltung höchste Vertretung des deutschen Schrifttums, ,autonom “, „souverän “. Im Oktober merkten wir, daß wir noch in der Luft schwebten, in der Glücksschaukel schaukelten: nun aber ist die Schaukel oben ausgehängt worden, und wir befinden uns auf einer Luftfahrt in unbekannte Tiefen. Es ist eine Reichsschrifttumskammer gegründet, die Akademie, die höchste Vertretung des Schrifttums ist als solche nicht zugezogen, nicht befragt, sie ist nicht gebeten worden, einen Akademiker an die Kammer abzuordnen: der zweite Vorstand der Akademie ist unversehens - als ob sie schon nicht mehr wäre - Präsident der Schrifttumskammer, und die "Stellung der Akademie" ist, wie der Vorstand gelegentlich mitteilt, noch nicht „endgiltig festgelegt".

Ehe die Akademie feststeht und als solche etwas ist, können wir keine Vorträge veranstalten, als Vortragsverein dürfen wir nicht in Erscheinung treten, - wenn wir überhaupt noch in Erscheinung treten.

Übrigens hat die Akademie, falls sie daseinsberechtigt ist, von vorn herein von der Fürsorge der Schrifttumskammer ausgenommen - juryfrei - zu sein!

Mit den besten Grüßen

Ihr E. Strauß

\section{8 [Hans Grimm] Lippoldsberg, Klosterhaus, 6. 12. 33}

Meine verehrten Mitsenatoren, als ich gestern von Elbing zurückkam, fand ich Münchhausens Vorschlag hier liegen, ich erhielt heute das Schreiben von Emil Strauß, mit dem er Münchhausens Vorschlag beantwortet. Auch ohne diese beiden Vorgänge hätte ich heute ein Rundschreiben an Sie gerichtet.

Mir ist bei meiner neuntägigen Fahrt und bei verschiedenen Gesprächen das noch deutlicher geworden, was meinen sorgenden Brief an Münchhausen veranlaßte. Ich meine immer deutlicher zu sehen, daß die Akademie in großer Gefahr steht, in Bedeutungslosigkeit zu versinken, weil sie sich nicht zu sich selbst macht sondern zu- 
wartet in einer brausenden Zeit, wo jeder eben so viel bedeutet, als er aus sich zu machen versteht. Ich glaube, wir sind gleich im Anfang einen falschen Weg gegangen, als wir uns von Aufgaben erzählten, zu deren Erfüllung wir die Macht nicht hatten, und als wir uns um die Beglaubigung von Statuten bemühten. Denn, lieber Emil Strauß, unsere Bedeutung liegt wirklich in unserer "Autonomie“ und „Suveränität" und nicht in einem ministeriellen Kuratorium. Wir sind eine Gemeinschaft, in der jeder Einzelne von Gottes Gnade her Geltung hat, wir können nicht dadurch etwas für unser Volk und unseren Staat exfüllen und bedeuten, daß uns irgendjemand bestätigt oder ernennt, sondern nur dadurch, daß durch unsere gewollte freie Gemeinschaft ein Mehrfaches an Gnade und Dienst und Geltung sichtbar wird. Durch unsere gewollte Gerneinschaft besteht die Akademie zuerst, nicht durch einen Staatsakt. Von dieser Erkenntnis aus muß die Akademie ihre Aufgaben sich stellen. Das ist zum Teil endlich geschehen, als wir uns im Oktober als Senat trafen, aber es ist für die wartende Öffentlichkeit noch nirgends geschehen. Bei uns selbst ist aber eine ganze Klärung auch noch nicht erfolgt. Das zeigt mir Straußens Brief und seine Erwähnung der Reichsschrifttumskammer. Diese Kammer hat ausschließlich Aufgaben vom Staate her, sie dient dem ständischen Aufbau des Schrifttums. Sie sucht ihre Wirkung nicht von Gott und Gnade her. Was hat Rechtsschutz, Ehrengericht, Altersversorgung, Vertrag, Buchhandel, Verlagsgeschäft mit Gott und Gnade zu tun? Die Kammer könnte von ein paar sauberen, lebensklugen Männern ebenso gut gemacht werden. Daß die Kammer dennoch Anregungen der Akademie zu hören bereit sein soll, wird immerhin dadurch deutlich, daß die drei berufenen ersten Mitglieder des Präsidialrates der Schrifttumskammer Senatoren der Akademie sind, die - wenn ich nach mir gehe - wahrscheinlich sehr zögernd zustimmten und gerade auch, um die Verbindung dahin herzustellen, wo die Geltung eben von Gott kommt.

Aber jetzt ist es höchste Zeit, daß sich die Akademie vor der Nation zu sich selbst macht, daß sie den Mut hat zu der Würde ihrer Gemeinsamkeit und daß sie diese Würde dartut vor der Nation. Es kommt auf den ersten Schritt an. Ich bin ein Hasser jeder Geschäftigkeit und jedes Theaters und jeder Kostümierung, dennoch müssen Kronen einmal gesehen werden.

Ich erinnerte deshalb Münchhausen an seinen Vorschlag. Ich sehe den Hergang freilich etwas anders als er und allerdings ganz anders als Strauß, dessen Wort von „Vortragsverein" erst recht ganz an der Sache vorbeigeht.

Ich will, daß wir als Gemeinsamkeit vor die Nation treten in feierlicher Form. Ich glaube, daß das augenblicklich nur dadurch geschehen kann, daß wir bei gemeinsamem, ganz feierlichem Aufzuge und gemeinsamer Verantwortung etwa in der Aula der Universität zu Berlin oder dem Festsaal des Harnack Hauses alljährlich fünf unbekannte oder wenig bekannte Dichter vor die Öffentlichkeit bringen. Es ist dazu notwendig, daß wir den Schützlingen vorausschreiten wie etwa der Lehrkörper einer Universität bei einer großen Feier der Universität, und hierbei ist der alte Talarvorschlag von Münchhausen richtig; es ist nötig, daß wir alle teilnehmen und hinter unseren Schützlingen vor der Festversammlung alle während der Veranstaltung sichtbar sitzen und daß große Musik und große Ausstattung die einmal jährlich stattfindende Feier umrahmen und etwa eine kurze Rede Kolbenheyers die große Feier einleitet und jeder Schützling von einem Paten aus dem Senate der Akademie aufgerufen und genannt wird. Gibt der Staat die Mittel nicht, müssen wir selbst dafür aufkommen, ich bin bereit, wenn das nötig ist, natürlich ohne Namennennung einen sehr erheblichen Betrag zu zeichnen. Art und Kleid der Feier werden Münchhausen und Kolbenheyer am besten entwerfen können. Ich denke, daß der Kanzler mit der Reichsregierung der Feier, die den Kommenden gelten soll, als Gast gern beiwohnen wird. Ihr müßt einmal gesehen werden. Ihr müßt zeigen, daß Ihr etwas zu vergeben 
habt, was niemand sonst hergeben kann. Tut nachher bescheiden schöne stille Arbeit, aber seid einmal endlich da für die suchenden Augen und den ungeduldigen Willen der Jugend. Denn, wenn unsere Gemeinsamkeit einmal verlacht ist, dann ist es zu allem zu spät. Wir nähern uns diesem "Zu spät", das fürchte ich.

Lieber Münchhausen, wir müssen über die fünf jungen Dichter als Senat in gemeinsamer Sitzung beraten. Wir müssen alle dem zugestimmt haben, was jene vorschlagen, vorzutragen. Die Dichter sollen, meine ich, keineswegs "ungedruckt" sein müssen, sie sollen nur der Akademie noch nicht angehören. Ich möchte sogar einen wenig bekannten Mann wie etwa von Mechow aufrufen dürfen, wenn es nach mir ginge. Der Hinweis auf Gnade, die wir erkennen, soll alles sein, das durch uns geschieht. Zu den Namen, die Sie nennen, schlage ich Dimar Möring vor, der Mann selbst ist mir fremd. Ich finde, daß erst, wenn dex ganze Plan gut ausgearbeitet ist, die Erwählten befragt werden sollen. Es muß sich um sie für eine ganz große Ehrung handeln. Ist der Plan ausgearbeitet, soll er der Presse bekanntgegeben werden noch ohne Nennung der Namen der Erwählten. Sie werden am Abend genannt. Mir scheint, der Abend biete größere Möglichkeit als der Nachmittag. Ich schlage vor, daß ein ganz bestimmter Tag alljährlich oder auch alle drei Jahre der Feier dient.

Wir müssen uns die Krone der Akademie vom Altar nehmen oder nach Hause gehen. Unser heutiges Aschenputtel-Wesen wird ja unwürdig und zwecklos.

Die Zugehörigkeit der Akademiker zum Reichsverband für Deutsches Schrifttum scheint mir am besten durch Hans Bluncks Vorschlag erledigt, der mir schreibt, er habe sich mit dem Vexband dahin geeinigt, daß die Mitglieder der Akademie keine besondere Erklärung abzugeben brauchen, sondern ipso jure in den Listen geführt werden, ohne mit besonderen Erklärungen behelligt zu werden. Diese Fassung lautet freilich etwas anders als das weniger befriedigende Rundschreiben Beumelburgs.

Mit guten Grüßen an die Senatoren

Ihr Hans Grimm

89 Hans Grimm, Klosterhaus, Lippoldsberg, Weser, bei Bodenfelde, 7. 12. 1933

Lieber Beumelburg,

ich muß meinem Brief von gestern noch eine Anfrage nachsenden. Johst schickte ein Rundschreiben, in dem er sich erkundigt, wer den Wunsch habe, durch die deutsche Kunstgesellschaft zu Vorträgen ins Ausland zu gehen. Ich möchte wissen, wer die Deutsche Kunstgesellschaft ist, und auch, wer die Gesellschaft für Deutsche Kultur ist.

Ich habe vor, im Frühjahr, es sei denn, der Anfang einer größeren Arbeit glücke mir, etwa vom 1. 2. an auf zwei bis drei Monate nach England zu gehen. Ich fahre hin für meine Arbeit und zur Neuausbildung in englischen Dingen. Denn da, wie Sie wissen, mein Lieblingsthema ist, daß es nur zwei Herrenvölker gibt, nämlich das deutsche und englische, so sind [sie!] eine immer neue Kenntnis von beiden Seiten für unsere Zukunft notwendig.

Ich will in England gern lesen und sprechen und gehöre ja wohl zu den Schriftstellern, die am ehesten dazu berufen sind. Ich möchte also die Vorschläge der Deutschen Kunstgesellschaft wohl hören, was England angeht.

Mit freundlichen Grüßen

Ihr Hans Grimm 
Deutsche Akademie der Dichtung, Berlin W 8, Pariser Platz 4, den 2. 1. 1934 - 90 J. Nr. 43

An die Mitglieder der Deutschen Akademie der Dichtung - Vertraulich!

\section{Reichsschrifttumskammer und Deutsche Akademie der Dichtung}

Die Gründung der Reichsschrifttumskammer, die Besetzung ihres Präsidiums und ihre Kundgebungen haben zu einigen Mißverständnissen Anlaß gegeben. Es wird darum folgendes festgestellt:

a) Die Reichsschrifttumskammer ist ohne Zutun und ohne Befragen der Akademie gegründet worden.

b) Die Reichsschrifttumskammer beruht auf dem bekannten Reichsgesetz. Dieses Gesetz erfordert die Mitgliedschaft aller am deutschen Schrifttum Tätigen, also auch der Mitglieder der Deutschen Akademie der Dichtung. Im Benehmen mit der Kammer ist die Regelung getroffen worden, daß in gewisser Abänderung des Rundschreibens vom 1. Dezember 1933 - J. Nr. 1314 - die Mitgliedschaft bei der Akademie automatisch die Mitgliedschaft bei der Kammer bzw. beim Reichsverband deutscher Schriftsteller herbeiführt. Hierdurch entfallen alle weiteren Formalitäten.

c) Das Reichspropagandaministerium hat die Herren Blunck, Johst und Grimm aufgefordert, das Präsidium der Kammer zu übernehmen. Die drei Herren haben diesen Ruf aus eigenem Entschluß angenommen. Für die Übernahme der Präsidentenstelle durch Herrn Blunck war eine Fühlungnahme innerhalb des Vorstandes maßgebend, die Übereinstimmung in der Auffassung ergab, daß die Besetzung des Kammerpräsidiums durch ein Mitglied der Akademie am ehesten geeignet sei, die Wirksamkeit beider Einrichtungen aufeinander abzustimmen. Die bisherige Praxis hat diesen Standpunkt gerechtfertigt.

d) Die Funktionen der Akademie werden durch die Kammer nicht nur nicht beeinträchtigt, sondern es ist der Akademie durch die Schaffung der Kammer die Möglichkeit gegeben, eine große Zahl praktischer, das Schrifttum betreffender Dinge rasch, wirksam und in ihrem Sinne zu erledigen. Die Person des Präsidenten der Kammer bietet die volle Gewähr für einen weiteren zweckmäßigen Ausbau dieser Zusammenarbeit.

e) Die Kammer ist die Zusammenfassung der am Schrifttum Tätigen im Rahmen des ständischen Aufbaus des Reichs. Die Deutsche Akademie der Dichtung ist die Zusammenfassung einer engen Gemeinschaft deutscher Dichter, die in Ehrung und Anerkennung ihrer besonderen Leistungen vom Staate berufen ist, das künstlerische Gewissen der Nation zu billen und ihre Stimme in den entscheidenden Fragen deutscher Dichtung zur Geltung zu bringen. Dies kann auch auf dem Wege über die Kammer geschehen, genauso wie auf dem Wege über das Preußische Kultusministerium oder auf dem öffentlichen Wege. In keinem einzigen Punkt werden die Funktionen der Akademie durch die Funktion der Kammer eingeschränkt ${ }^{1}$.

f) Für die Auffassung der Reichsschrifttumskammer gelten nur die Kundgebungen des Präsidenten oder des zuständigen Reichsministers. Es hat sich leider gezeigt, daß einzelne Mitglieder der Akademie sogar Kundmachungen zum Opfer gefallen sind, die von Stellen ergingen, die mit der Reichsschrifttumskammer nicht das geringste zu tun haben. Bei Zweifelsfällen genügt eine Anfrage an den Schriftführer der Akademie. Es wird empfohlen, von dieser Möglichkeit regen Gebrauch zu machen, damit künftigen Mißverständnissen vorgebeugt wird.

1 Dieser letzte Satz wurde gestrichen. 


\section{Satzungen.}

In der Frage der Verfassung der Deutschen Akademie der Dichtung kann vertraulich mitgeteilt werden, daß der Preußische Minister für Wissenschaft, Kunst und Volksbildung dem Grundsatz einer „Akademie der deutschen Kunst“, zusammengesetzt aus der Akademie für die bildenden Künste, der Akademie für Mlusik und der Akademie der Dichtung zugestimmt hat. Die weitere Frage, ob die Verfassung der Akademie der deutschen Kunst im Zuge der bevorstehenden Reichsreform erledigt, oder ob sie vorgwegenommen werden soll, ist im Sinne der letzteren Lösung entschieden worden. Die amtliche Stellungnahme des Ministers zu dem Satzungsentwurf der Akademie der Dichtung steht noch aus. Dem Vernehmen nach ist bald mit ihr zu rechnen. Die Arbeiten der Akademie werden durch die Frage der Satzung nicht gehemmt. Die Akademie nimmt den Standpunkt ein, daß sie sich bis zur Verkündung der Satzung so verhält, als ob diese Satzung bereits vorhanden sei.

3. Der Präsident der Deutschen Akademie der Dichtung nimmt die Gelegenheit, darauf hinzuweisen, daß es der Sache der Akademie nicht zuträglich sein kann, wenn einzelne Mitglieder einer Stimmung Ausdruck verleihen, als ob die Akademie „in der Luft schwebe“, oder als ob es fraglich sei, "ob die Akademie überhaupt noch bestehe" usw. Die Akademie ist entweder imstande, ihrer Auffassung und ihrer Haltung geschlossenen und nachhaltigen Ausdruck zu verleihen, oder sie ist bedeutungslos. Wenn in der Vergangenheit innere Gegensätze und Spannungen die Akademie oftmals an positiver Arbeit gehindert haben, so wird kein Zweifel darüber gelassen, daß in Zukunft Gegensätze, die sich aus solchen Resten der Vergangenheit ableiten, nicht mehr anerkannt werden. Der Präsident, sein Stellvertreter und der Schriftführer, auf deren Schultern der Hauptteil der Arbeit und die Verantwortung für zahlreiche Entscheidungen liegen, fordern von allen Mitgliedern die regste Mitarbeit beim Aufbau der Akademie, wobei sie sich weder zu übereilten Entscheidungen drängen, noch zux Zielscheibe sachlich nicht gerechtfertigter Vorwürfe machen lassen werden.

4. Die Berufung der im vergangenen Jahre von der Versammlung neugewählten Mitglieder, die dex Kurator ursprünglich mit der enclgültigen Inkraftsetzung der neuen Verfassung verbinden wollte, soll nach neuer Vereinbarung gesondert vorgenommen werden.

S. Gesamttagung der Akademie.

Es kann schon heute als feststehend betrachtet werden, daß die nächste Gesamttagung im Herbst d.Js. stattfinden wird.

6. Pflege des dichterischen Nachwuchses.

a) In der Oktobersitzung des Senats wurde beschlossen, bei den großen Herbsttagungen der Akademie eine beschränkte Zahl junger Dichter unter der Autorität und der Verantwortung der Akademie öffentlich aus ihren Werken vortragen zu lassen. Die Organisierung dieser Vorträge hat Börries Freiherr von Münchhausen übernommen. Herr von Münchhausen wird gebeten, auf der Grundlage seines Schreibens an die Mitglieder des Senats vom 1. Dezember 1933 einen Vorschlag auszuarbeiten und dem Präsidenten einzureichen. Anregungen irgendwelcher Art sind unmittelbar an Börries Freiherr von Münchhausen, Schloß Windischleuba bei Altenburg zu leiten.

b) In der gleichen Senatssitzung war beschlossen worden, daß Herr Will Vesper, Meißen, Badgasse 2, eine Kartei über das junge deutsche Schrifttum anlegen möge. Herr Vesper bittet, ihm nicht nur irgendwelche Namen zu melden, sondern neben den Namen und der genauen Anschrift derjenigen jungen Dichter, für die ein Mitglied der Akademie die moralische und künstlerische Verantwortung über- 
nehmen zu können glaubt, auch eine kurze Charakteristik der Person und des Werkes ihm einzusenden.

7. Werkhilfen und Unterstützungsangelegenheiten.

Mit der Bearbeitung dieses Gebietes ist durch Beschluß der Akademie Herr Rudolf G. Binding, Buchschlag in Hessen, beauftragt. Bei verschiedenen Gelegenheiten, bei denen besondere Mittel zur Verfügung standen, hat sich herausgestellt, daß die Mitarbeit der Mitglieder der Akademie nur sehr unvollständig ist. Es wird nochmals dringend gebeten, fortlaufend alle persönlichen Beobachtungen über die Notwendigkeit und Zweckmäßigkeit von Werkbeihilfen innerhalb und außerhalb der Akademie vertraulich unmittelbar an Herrn Binding zu leiten, der das gesammelte Material dem Schriftführer zur weiteren Bearbeitung übergeben wird.

8. Rundfrage der Deutschen Buchgemeinschaft wegen Herausgabe eines Sammelbandes der Akademiemitglieder.

Der Senat ist der Notwendigkeit, die Ablehnung dieser an alle Mitglieder gerichteten Aufforderung der Deutschen Buchgemeinschaft dringend zu empfehlen, durch die Tatsache enthoben worden, daß die Buchgemeinschaft von sich aus ihren Plan hat fallenlassen. Es herrscht Übereinstimmung darüber, daß ein solcher Sammelband nur unter der ausschließlichen Autorität und Verantwortung der Akademie selbst erscheinen kann. Herr Will Vesper wird gebeten, einen Plan für einen solchen Band auszuarbeiten und einzureichen.

9. Es wird empfohlen, daß die Mitglieder der Akademie,wenn sie untereinander über Angelegenheiten der Akademie korrespondieren, dem Schriftführer einen Durchschlag ihres Briefes zuleiten. Von den meisten Herren wird diese Praxis, die den Geschäftsgang sehr erleichtert, auch heute schon angewandt.

10. Der Schriftführer war durch eine Erkrankung mehrere Wochen lang nicht in der Lage, die Korrespondenz zu erledigen, und bittet die davon betroffenen Herren um Entschuldigung für die Verzögerung ihrer Angelegenheiten.

Im Auftrage:

Dr. Wilhelm Schäfer, Hanns Johst, Dr. Kolbenheyer, Werner Beumelburg

[Binding, Grimm u.a.]

München, den 29. März 1934، 91

An den Herrn Minister für Wissenschaft, Kunst und Volksbildung, Berlin 8, Unter den Linden 4

Die Unterzeichneten sind von dringlicher Sorge um die Zukunft, ja, um die Möglichkeit der Deutschen Akademie der Dichtung erfüllt:

Der Senat der Akademie, der durch die Satzung für den Bestand und die Arbeit der Akademie verantwortlich ist, findet die Akademie heute ohne satzungsgemäßen Vorstand.

Der Vorsitzende befindet sich auf ein halbes Jahr im Ausland. Der Vorstandsstellvertreter hat sein Amt niedergelegt. Der Stellvertreter des Schriftführers hat noch nicht ernannt werden können. Alle Geschäfte bleiben dem Ersten Schriftführer aufgebürdet.

Eine verantwortliche und der Würde einer Akademie vor Volk und Ausland entsprechende Arbeit konnte seit ihrer Neugründung weder vom Senat noch durch die Gesamtakademie geleistet werden. Eine beantragte Senatssitzung konnte nach Auskunft des Schriftführers nicht einberufen werden. 
In dieser Lage erinnern die Unterzeichneten daran, daß in der konstituierenden Versammlung am 7. VI. 1933 ihr Kurator, Herr Staatsminister Dr. Rust der Akademie volle Autonomie zugesagt hat (Sitzungsbericht der konstituierenden Sitzung Seite 6, Abs. 3, Seite 7 letzter Absatz, Seite 8 letzter Absatz). Auf Grund dieser Autonomie hat die Akademie eine Satzung beschlossen und sie dem Herrn Kurator ordnungsgemäß als Beschluß vorgelegt.

Nach der Satzung übernimmt der Senat die Verpflichtung, den Vorstand der Akademie zu bestellen, dessen Vorsitzender die Akademie „in allen ihren Angelegenheiten im Auftrage des Senates zu leiten hat".

Ohne die gewährleistete und in der beschlossenen Satzung festgelegte Autonomie erklären sich die Unterzeichneten außer Stande, Würde, Haltung und Stellung einer Deutschen Akademie, die der neue Staat ihr zugedacht hat, aufrecht zu erhalten, und ihre Arbeit für die Volksgemeinschaft zu leisten.

Rudolf G. Binding, Hans Grimm, E. G. Kolbenheyer, Münchhausen, Wilhelm Schäfer, E. Strauß

Verhandelt in der Preußischen Akademie der Künste, Sitzung des Senats der Deutschen Akademie der Dichtung, Berlin, den 4. 6. 1935 - Beginn der Sitzung: 10 Uhr 15

Anwesend unter dem Vorsitz des Herrn Hanns Johst: Beumelburg, Binding, Blunck, Grimm, Johst, Schäfer, Stehr, Strauß; entschuldigt: Miegel, v. Münchhausen

Die Sitzung wird um 10 Uhr 30 durch den Vorsitzenden Hanns Johst eröffnet. Johst stellt zunächst fest, daß die Einladung des Senats ohne seine Befragung erfolgt sei. Er stellt weiter fest, daß eine Einladung an Kolbenheyer ergangen sei, obwohl Kolbenheyer seinen Sitz im Senat niedergelegt habe. Er stellt weiter fest, daß im Gegensatz zu dem bisherigen Verfahren Vesper als Vorsitzender eines Ausschusses nicht eingeladen worden ist. Er stellt schließlich fest, daß ihm Kenntnis geworden sei von einem Schreiben, das Herr Binding in der Angelegenheit des 60. Geburtstages von Thomas Mann an den Reichsinnenminister gerichtet hat. Er ersucht, solche Handlungen in Zukunft nicht mehr ohne sein Wissen vorzunehmen, da er als Vorsitzender der Akademie für die Folgerungen einstehen müsse. Er erteilt sodann das Wort an Binding.

Binding erklärt, daß ex Kolbenheyer in einem besonderen Schreiben eingeladen habe und mit dem Hinweis, daß Kolbenheyers Teilnahme an der Sitzung nur in Frage komme, wenn er den ihm offengehaltenen Senatssitz formell wieder einnehme. Dieses sei nicht geschehen. Er erklärt weiter, daß es nicht seine Absicht gewesen sei, in der Angelegenheit Thomas Mann den Senat zu übergehen. Herr Vesper sei von ihm zunächst eingeladen gewesen, es seien dann aber aus dem Senat heraus Bedenken geäußert worden, denen er stattgegeben habe.

Er spricht dann zu dem ersten Punkt der Tagesordnung: „Die Akademie und die Organisationen der künstlerischen Berufe“. Man müsse bei allen Vorschlägen und Anregungen beachten, daß es sich auch um die anderen Abteilungen der Preußischen Akademie der Künste handle. Es betreffe also unsere Besprechung die Frage der Gesamtakademie. Er führt aus, daß uns gegenwärtig zwei Dinge beunruhigten, einmal das Dunkel des Wohin und dann die Tatsache des Vorhandenseins der Kulturkammer. Wohin immer wir kommen würden, so würden doch die inneren Erfordernisse der Akademie die gleichen sein. Es sei aber notwendig, sie sichtbar zu machen. Er habe eine Reihe von Punkten aufgestellt, in denen diese Erfordernisse zusammengefaßt seien. Er teilt dem Senat diese Ausarbeitung mit, in der gesprochen wird vom Sinn und Willen einer Akademie, von ihrer Unterstellung, von den Satzungen, von 
der Zusammensetzung, von ihrer Aufgabe als Wahrerin, Pflegerin und Schützerin der deutschen Kunst und von ihrer Abgrenzung gegen die berufsständischen Organisationen.

Er erklärt, daß er sich den weiteren Verlauf so denke, daß der Senat diese Punkte dem Vorsitzenden üJsergebe mit dem Auftrag, den zuständigen Minister darüber zu verständigen. Er betont ausdrücklich, daß er diesen Vorschlag ohne vorausgegangene Besprechung mit irgendjemand zum Zwecke einer unbeeinflußten Stellungnahme des Senats mache. Er berührt das Verhältnis der Akademie zur Reichsschrifttumskammer und betont, daß Hans Friedrich Blunck unsere Auffassung und Stellung, soweit sie die ständische Berufsorgranisation betreffe, dort so gut vertrete, wie wir es nur wünschen könnten. Es fehle aber die klare Abgrenzung zwischen beiden Einrichtungen. Es dürfe nicht dahin kommen, daß die Kammer sich gewissermaßen eine Akademie halte, sondern die Akademie habe ihre selbständigen Aufgaben, die in der Substanz des künstlerischen Schaffens liegen.

In der grundsätzlichen Aussprache über die Ausführungen Bindings und seinen Vorschlag über die „Erfordernisse einer Akademie“ ergreift zunächst Grimm das Wort. Grimm findet, daß Bindings Erklärung alles enthalte, was notwendig sei. Bedenklich findet er die Überschrift, und es sei besser, das Schriftstück eine „Erklärung des Senats an den Kurator" zu nennen. Man möge auch die Frage der Satzungen in dieser Erklärung nicht berühren. Durchaus dagegen aber sei er, daß in diesem Schriftstück die Frage einer Dotierung berührt werde. Es sei jetzt nicht die Zeit, materielle Forderungen zu stellen.

Blunck weist darauf hin, daß es sich bei den Kammern um gesetzlich begründete Einrichtungen handele, indessen die Frage der Akademie noch schwebend sei. Er sei verpflichtet, das Gesetz zu erfüllen. Im Rahmen dieses Gesetzes sei er immer bemüht, die Stellung der Akademie zu wahren und zu sichern. Er glaube, daß die Frage der Zuständigkeit, der gegenwärtigen und der zukünftigen, uns nur mittelbar berühre, und $d a ß$ es sich hier um eine Entscheidung handele, auf die wir wenig Einfluß hätten. Er weist darauf hin, daß die Stimmung der Akademie gegenüber zunächst sehr kritisch und ablehnend gewesen sei, daß starke Strömungen die Akademie als eine antiquierte und individualistische Einrichtung betrachteten und die Lösung der Fragen des künstlerischen Schaffens auf ständischem Gebiete suchten. Er glaube aber sagen zu können, daß im Gegensatz zu diesen Strömungen der Gedanke einer geschlossenen Akademie der deutschen Kunst als die Vertretung der künstlerischen Substanz sich durchgesetzt habe, während die Kammern sich auf das ständische Gebiet beschränken würden.

Johst macht zu diesem Punkt vertrauliche Ausführungen und warnt vor jeglicher Handlung, die uns falsch ausgelegt werden könnte. Auch er anerkenne Bindings Formulierung und sei bereit, anhand eines solchen Vorschlags zur richtigen Stunde mit der maßgebenden Stelle zu sprechen.

Grimm fragt, ob diese Erklärung an den Kurator gehen werde, oder ob es sich gewissermaßen um eine akademische Verpflichtung unter uns handele. Binding glaubt, die Erklärung sei so zu verstehen, daß der Vorsitzende ermächtigt werde, auf ihrer Grundlage zu verhandeln.

Schäfer erinnert an die ersten Besprechungen mit Minister Rust. Wir seien aufgerufen worden zu helfen, damit die Gefahr der „Organisiererei“ gebannt werde. Er sei der Auffassung, die Bindingsche Erklärung möge sich auf ihren ersten grundsätzlichen Punkt beschränken. In der ständischen Organisation sei die Realität des Volkes aufgerufen, wir aber seien Vertreter der Idealität. Unser Standpunkt sei der, daß wir das, was geschehen sei, billigten, aber daß wir gleichzeitig auf das aufmerksam machten, was nicht geschehe. Wir müßten unsere Berufung und deren Notwendig- 
keit ganz klar darstellen. Wir müßten begründen, warum schöpferische Menschen an der Spitze stehen müßten. Wir müßten klarmachen, daß man uns braucht.

Grimm betont, er habe sich die Sitzung so gedacht, daß wir zu einer Art Bekenntnis zusammenkämen, zu einer confessio, die dem Kurator zu übergeben sei. Entweder hätten wir den Glauben an unsere Berufung, oder wir hätten ihn nicht. Wenn wir ihn hätten, so müßten wir damit stehen und fallen. Zu diesem Bekenntnis sei er nach Berlin gekommen, nicht aber zu taktischen Erörterungen.

Strauß meint, Bindings Erklärung sei keine confessio, sondern ein taktischer Vorschlag. Mit einer confessio sei auch er einverstanden, er sei aber dagegen, daß in dieser Erklärung die Fragen der Taktik enthalten seien. Blunck warnt davor, ein Bekenntnis abzugeben, das falsche Ausdeutungen zulasse. Wir dürften heute nichts zerbrechen, was uns später von selbst zuwachse. Binding ist der Meinung, daß ein „Bekenntnis“ seine Ergänzung durch reale Vorschläge verlange. Grimm schlägt eine eigene kurze Formulierung vor. Strau $\beta$ ist der Auffassung, da $\beta$ auch diese Formulierung schon gewisse satzungsmäßige Dinge berühre. Unser Bekenntnis müsse sich auf Aufgabe, Berufung und Selbständigkeit der Akademie beschränken.

Grimm sagt, eine confessio in seinem Sinne müsse zwei Dinge enthalten, einmal, daß der Vorsitzende im Auftrage des Senats handele, zum zweiten, daß sich die Akademie ihre Satzung selbst gebe, wobei natürlich eine Verhandlung mit dem Kurator erforderlich sei. Er möchte im voraus diese Punkte feststellen, um später nicht als ein Frondeur zu erscheinen. Blunck ist mit der von Grimm vorgeschlagenen Erklärung nicht einverstanden, weil er befürchtet, daß durch sie der praktische Weg zur Gestaltung der Akademie verschüttet werden könnte. Eine allgemeine Erklärung würde ausreichen. Die Aufnahme von Einzelheiten bringe die Gefahır einer Zerstörung des Akademiegedankens mit sich.

Stehr äußert, unsere Aufgabe sei einmal, Wesen und Sinn der Akademie nach außen klar darzustellen. Darüberhinaus hätten wir für uns selbst die sich daraus ergebenden Richtlinien festzulegen. Binding stimmt dem zu. Wir müßten neben unserem grundsätzlichen Bekenntnis vorbereitet sein für den Fall, daß wir gefragt werden, was wir uns im einzelnen unter der Akademie vorstellen.

Johst formuliert den Zweck eines Bekenntnisses so, daß der Vorsitzende wissen müsse, was der Senat im Grundsätzlichen will. Es handele sich darum, eine Richtung festzustellen, an die wir gebunden seien. Blunck schlägt vor, als dieses „Bekenntnis" den ersten Satz der Bindingschen Formulierung hinzustellen, der folgenden Wortlaut hat:

„Eine Akademie der deutschen Kunst - oder wie immer künftig die Akademie heißen mag, - soll und will ihr Volk durch die Vereinigung der besten und vornehmsten Kräfte dieses Volkes auf dem Gebiete der Kunst vertreten. Ihre Zusammensetzung erfolgt auf dem Grundsatz von Leistungen für das Volk."

Er schlägt zu diesem Satz folgenden Zusatz vor:

„Die Akademie bedarf zur Erfüllung ihrer Aufgaben der Selbständigkeit in Führung und Wahl."

Er bittet, diesen Vorschlag als Antrag anzunehmen. Es handele sich hier gewissermaßen um ein "Grundgesetz" oder besser noch "Zielgesetz". Es könnten Notwendigkeiten eintreten, die Abweichungen von einem solchen Zielgesetz erforderlich machten, die aber getragen werden müßten, ohne daß einer deswegen die gemeinsame Front verlasse. Es dürfe niemandem der Vorwurf des Wortbruchs gemacht werden, wenn nicht gleich alles erreicht würde, was dieses Grundgesetz enthalte. Wir seien verpflichtet, mit allen unseren Mitteln im Sinne dieses Gesetzes zu handeln, aber es müsse Spielraum bleiben, und ein jeglicher sei für die Auslegung des Gesetzes seinem eigenen Gewissen unterworfen. Mit der restlosen Erfüllung des von uns anzunehmenden Gesetzes sei dann das Ziel erreicht. Grimm sagt, daß er bei solcher Auslegung 
diesem Gesetz nicht zustimmen könne. Johst tritt dem entgegen und schließt sich der Auffassung Bluncks an.

Strau $\beta$ weist darauf hin, daß wir seinerzeit unter Voraussetzungen in die Akademie eingetreten seien, die heute noch nicht erfüllt sind. Aber das dürfe kein Anlaß sein, das Streben nach der Erfüllung aufzugeben. Es sei darum richtig, diese Erklärung, wie Blunck es tue, als ein Zielgesetz zu bezeichnen, um zu vermeiden, daß Gewissenskonflikte entstünden. Grimm betont ajermals, daß er einem solchen Grundgesetz oder Zielgesetz nur dann zustimmen könne, wenn es unbedingt gelte, aber nicht, wenn eine Auslegung möglich sei. Schäfer und Binding bitten Grimm, von dieser Haltung abzustehen.

Johst führt aus, daß der Vorsitzende, oder wer in seinem Auftrage mit den zuständigen Stellen zu verhandeln habe, an die von uns zu beschließende Erklärung gebunden sei. Er könne darum die Bedenken Grimms nicht teilen. Wenn sich ein Zustand ergäbe, der die Auffassung zulasse, als sei von dem Grundgesetz abgewichen worden, so werde dem Senat Gelegenheit gegeben, dazu Stellung zu nehmen. Nach weiterer kurzer Erörterung stimmt der Senat der vorgeschlagenen Erklärung, die er als sein Grundgesetz ansieht, einstimmig zu.

Schluß der Vormittagssitzung: $1.20 \mathrm{Uhr}$

$[\ldots]$

Der Vorsitzende

Hanns Johst

Der Schriftführer

Werner Beumelburg

[Rudolf G. Binding] den 21. November 1935

Lieber Grimm,

den sachlichen Bemerkungen dieses Briefes möchte ich einigre wenige persönliche vorausschicken. Ich mußte Ihnen vorgestern von Hamburg aus die Untunlichkeit ja fast Unmöglichkeit ankündigen Sie gestern zu besuchen wie ich es vorhatte. Ich war durch zwei entsetzlich überfüllte Vorträge in Hamburg an zwei aufeinanderfolgenden Abenden - und es folgten auch noch Stunden der Nacht in ähnlicher Umdrängung - wirklich so erschöpft, daß die lange Reise nach Lippoldsberg und von dort die nicht kürzere nach Berlin meine Kräfte überschritten hätte. Sie sehen also daß auch der Feldsoldat manchmal schlapp macht, und ich schäme mich, daß es gerade auf dem Weg zu Ihnen war.

Nun traf mich aber zu meinem Glück und meiner Erleichterung inzwischen Ihr Brief, den Sie nach Starnberg geschickt hatten und ich kann also hoffen Sie zum mindesten im Dezember dort zu sehen, wenn es mir nicht gelingt noch vorher (Anfang Dezember) den Besuch nachzuholen, den ich jetzt versäumt habe. Dazu wäre auf einer Vortragsreise Anfang Dezember nach meiner Ansicht Raum. Doch warnt mich eben gerade die Starnberger Helferin insoweit zuviel zu versprechen oder zuviel zu hoffen.

Ich teile daher, vorsorglich und mit der Bitte, jedenfalls diese Möglichkeit für uns beide nie außer Auge zu lassen, mit daß ich zu der von Ihnen angegebenen Zeitspanne im Dezember in Starnberg anwesend bin und bestimmt damit rechne Sie zu sehen (ab 7. 12. bin ich von meinen Vorträgen zurück).

In den Dingen die wir verhandeln müssen Kolbenheyer zuzuziehen, ist mir durchaus recht, obwohl er sich mir neulich in etwas merkwürdiger Weise entzog als ich ihn bat unserm Mitglied Max Halbe zu seinem 70. Geburtstag mit mir gemeinsam persönlich Glückwünsche zu bringen. Bedenklich bei Kolbenheyer ist immer, daß er sich nicht vorstellt wie anders die Vorstellungen von einer Akademie sind, die heute 
an treibenden Stellen bestehen, als die seinen; und überdies wie unmöglich es ist, andere Vorstellungen bei den treibenden Stellen zu erwarten.

Denn es gibt treibende Stellen und untätige Stellen, zu welch letzteren ich auch die zu Untätigkeit verurteilten rechne. Welche Stellen zu Untätigkeit verurteilt sind und in welchem Maße sie zu Untätigkeit verurteilt sind, vermag ich nicht zu erkennen. Ich vermag nur untätige Stellen zu erkennen. Bei einer erheblichen Anzahl solcher Stellen, die eigentlich für die Akademie tätig sein müßten und sollten, scheint eine große Unlust eingetreten überhaupt noch etwas zu tun. Dies drückt sich dadurch aus daß auch an die Akademie kaum noch etwas von Belang herankommt, herangebracht wird oder ihr, selbst von dem zuständigen Ministerium, an Arbeit zugemutet wird.

Ich überzeuge mich gerade davon: es liegt nichts vor was nicht ebenso gut Beumelburg mit einem Federstrich hätte erledigen können und was jetzt mit einem Federstrich von mir erledigt wird.

Eben hatte ich eine kurze und mir sehr willkommene, auch persönlich erfreulich offene, Unterredung mit Johst, der mir sagt daß er als Präsident der Reichsschrifttumskammer jeden Monat eine Woche hier in Berlin sei. Seine subjektive Meinung über die Zukunft der Akademie - er betonte ausdrücklich daß diese Meinung subjektiv sei - geht dahin, daß man wohl nichts gerade gegen sie habe, daß man sie aber als für das öffentliche Dasein, wie man es sich vorstellt, als unwichtig und jedenfalls kaum verwertbar ansieht. Diese Ansicht ist auch ganz richtig: von einer Leidenschaft, von einem Aktivismus, von einem Kämpfertum in der Form wie man es allseitig preist und predigt - und man kann dies verstehen - ist allerdings bei der Akademie in keiner ihrer Abteilungen etwas Einheitliches zu erblicken.

Daß eine Akademie durch ihr Dasein, durch ihre Körperlichkeit - auch wenn diese regungslos wäre - sagen wir durch ihren Geist und ihre Substanz wirkt, und zwar mächtiger als man denkt, ist vielleicht nicht bekannt oder vielleicht (was wahrscheinlicher ist) nicht anerkannt. Wir können nicht einmal erwarten daß es anerkannt wird. Und es ist nicht einmal ganz nach meinem Sinne, daß es anerkannt wird. Es ist deswegen nicht ganz nach meinem Sinne, sozusagen blind anerkannt zu werden, weil ich der Ansicht bin, daß unsere sogenannte Leistungen, also sagen wir unser Beitrag zu dem deutschen Schrifttum, zur deutschen Dichtung, zu den Fragen unseres Daseins, wie sich all dies in unseren Büchern auftut, nicht für die Akademie und für uns als Akademie genügen. Wir müssen uns auch als Akademie in unser Recht setzen. Es ist möglich, daß uns unser Ministerium oder unser Minister insoweit nicht allzusehr zu unterstützen vermag. Es ist aber möglich daß wir dieses Recht für uns suchen und auch ihm damit ein höheres Recht an uns verschaffen.

Das was ich mit Ihnen besprechen möchte und mit Ihnen ausführen möchte, ist das Herausstellen von zwei Vorträgen (etwa im Februar/März, damit alles genügend vorbereitet sei), von denen einer von Ihnen und einer von mir zu halten wäre. Beide müssen aber im Zusammenhang stehen. Der erste (meiner) hat zum Gegenstand und wird sprechen "Vom Recht der Dichtung“ und muß alles Tatsächliche aber auch Grundsätzliche und Substantielle enthalten, was eine Akademie rechtfertigt. Dies muß erst einmal aufgezeigt werden, und ich bin erbötig, es zu tun. - Der zweite (Ihrer) muß handeln "Vom nordischen Wesen und der nordischen Berufung" im Sinne Ihrer amerikanischen Rede und muß 3 also das deutsche Schrifttum in seiner Bedeutung für die Welt und damit auch die Welt in ihrer Bedeutung für uns als geistiges Widerspiel dartun. (Ich skizziere hier nur mit diesen Überschriften die beiden Vorträge.) Diese beiden Vorträge werden zusammen angekündigt, sind nur durch einen Tag voneinander getrennt und sollten etwa in einem Raum, wie die Singakademie es ist, stattfinden. Man muß es richtig aufziehen und jedenfalls sind 
die Räume der Akademie zu klein. Ich möchte hoffen, daß wir g'emeinsam etwas derartiges als Notwendigkeit empfinden, es nunmehr gemeinsam wünschen und gemeinsam unter uns beiden und durch uns beide bei Johst (den ich keinesfalls dabei auslassen möchte) und nötigenfalls bei unserem Ministerium betreiben. Übrigens ist es, wie ich eben erkenne, unnötig das Ministerium überhaupt dafür in Bewegung zu setzen, außer mit der Einladung zu den Vorträgen. (d.h. indem wir es einladen).

Nun bitte ich Sie vorerst, ehe wir uns gesprochen haben, diesen Plan in einem verschlossenen Herzen zu tragen und zu bedenken. Er entspringt nicht dem heutigen Tage und der heutigen Stunde noch einer beim Schopf gefaßten Gelegenheit, sondern es war der Plan, den ich Ihnen bei meinem für gestern angekündigten Besuch mitzubringen gedachte. Ich halte ihn für gut weil er ausführbar ist. Ich halte ihn auch für richtig, weil ich das Vertrauen habe, daß wir beide, Sie und ich, in Dingen der Verantwortung gleich denken und auch eine solche zu tragen die Schultern haben.

Womit ich Sie herzlich grüße als

Ihr Binding

P.S. Anfang Dezember werde ich nun im Starnberger Haus soweit auf festem Boden sein, daß ich Sie und die Münchener Freunde des Lippoldsberger Treffens gastlich aufnehmen kann. Bitte verfügen Sie insoweit über mich und das Haus. Die sehr bequemen elektrischen Vorortzüge bringen Sie in 30 Minuten zu mir hinaus und wenn ich mich sozusagen nicht lohne, tut es die Landschaft: hinter dem See stehen die Berge mit ausgebreiteten Armen und den schönsten Farben angetan. Es ist sehr köstlich! Bitte entschuldigen Sie mich bei Luise Siebel für den vergeblich hergestellten Fahrplan und ihre darauf verwandte Mühe. 